This manuscript is a peer-reviewed preprint submitted to EarthArXiv that will appear in the United States Geological Survey (USGS) volume Volcanic and Seismic Hazards of Northern Harrat Rahat, Saudi Arabia. The final published version of this manuscript will be available via the 'Peer-reviewed Publication DOI' link on the manuscript's webpage. Please feel free to contact any of the authors, we appreciate all feedback!

\title{
Thickness of the Saudi Arabian Crust
}

\author{
Alexander R. Blanchette ${ }^{\mathrm{a}, \mathrm{b}, *}$, Simon L. Klemperera , Walter D. Mooney, ${ }^{\mathrm{a}, \mathrm{b}}$, Hani M. Zahran ${ }^{\mathrm{c}}$
}

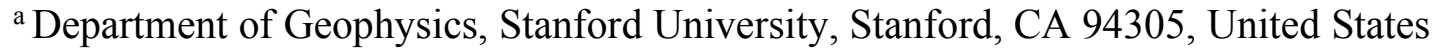

${ }^{\mathrm{b}}$ United States Geological Survey, Earthquake Science Center, Menlo Park, CA 94025, United States

${ }^{\mathrm{c}}$ Saudi Geological Survey, Jeddah 21514, Saudi Arabia

${ }^{*}$ Corresponding author email address: ablanch@stanford.edu

\begin{abstract}
We analyzed P-wave receiver functions from seismic stations covering most of Saudi Arabia to map the thickness of the crust across the Arabian plate. We present an update of crustal-thickness estimates and fill in data gaps for the western shield and the rifted margin at the Red Sea, as well as the eastern Arabian platform. Our application of a conventional H-k stacking algorithm included careful attention to stacking weights, two forms of sedimentary corrections for stations located on the Arabian platform, and additional processing for noisy stations. Average crustal thickness (i.e. depth to Moho below surface) beneath the Red Sea coastal plain (the rift margin) is $29 \mathrm{~km}$, beneath the volcanic harrats is $35 \mathrm{~km}$, the shield (excluding harrats) is $37 \mathrm{~km}$, and the platform is $38 \mathrm{~km}$. Crustal thinning appears not to extend east of the rift escarpment, suggesting uniform extension, that is no broader at depth than at the surface. In contrast to some previous claims that the platform crust is thicker than the shield, we find no statistically significant difference between whole crustal thickness of the Arabian shield and platform. However, the average sub-sedimentary crustal thickness (i.e., the crystalline crust) of stations on the platform is $34 \mathrm{~km}, 3 \mathrm{~km}$ thinner that the crust of the shield. Individual station $\mathrm{V}_{\mathrm{p}} / \mathrm{V}_{\mathrm{s}}$ wavespeed ratios are highly variable for the Arabian plate, ranging from 1.60 to 1.97 and averaging 1.75 , with a standard deviation of 0.07 . There are no statistically significant differences between $V_{p} / V_{s}$ ratios of the different geologic regions of Arabia. Similar $\mathrm{V}_{\mathrm{p}} / \mathrm{V}_{\mathrm{s}}$ ratios, coupled with similar crustal thicknesses for harrats and shield, imply that Cenozoic magmatism has contributed negligibly to crustal growth.
\end{abstract}

\section{Introduction}

The present-day thickness and composition of the Earth's crust and its lateral variability are the product of its evolution from initial formation and evolution through multiple tectonic episodes. To infer the thickness of the present-day crust with minimal assumptions, we computed P-wave receiver functions (PRFs) and measured the travel-time differences between seismic P-waves and the converted phases (Ps, 3p1s, 2p2s) they generated at the boundary between the crust and mantle (i.e. the Moho). Compared to previous PRF studies of crustal thickness of Saudi Arabia (Sandvol and others, 1998; Julià and others, 2003; Al-Damegh and others, 2005; Tkalčić and others, 2006; Tang and others, 2016, 2019), we: (1) use more stations that were active for a longer recording period than in previous studies; (2) more thoroughly explore the methodological parameter space to obtain estimates of uncertainties; (3) correct for sedimentary cover where known; and (4) make statistical comparisons between different geologic regions. 
The Arabian shield constitutes the eastern portion of the Arabian-Nubian shield (ANS) and is separated from the Nubian shield by the Red Sea rift, a divergent plate boundary that merges into the Dead Sea Transform boundary at its northern end (fig. 1). The ANS was formed by the accretion of multiple terranes, primarily in the period $\sim 800-550 \mathrm{Ma}$ (Stern and Johnson, 2010). The Arabian craton began to subside at $725 \mathrm{Ma}$ and gradually accumulated up to $15 \mathrm{~km}$ of sediments (Stern and Johnson, 2010). The arrival of the Afar Plume at $\sim 30$ Ma triggered extension in East Africa, the Gulf of Aden, and the Red Sea region (Stern and Johnson, 2010). Voluminous flood basalts in Ethiopia and Yemen were succeeded in Arabia by modest alkali-basalt fields, locally known as harrats (Stern and Johnson, 2010). Recent magmatism was recorded in the 2009 intrusion at Harrat Lunayyir and eruptions in Mohammedan times of Harrats Rahat and Khaybar, which lie along the Makkah-Medina-Nafud (MMN) line (fig. 1a) (Camp and Roobol, 1992; Pallister et al., 2009).

In this paper we introduce the newly expanded seismic data set, then discuss the calculation of our receiver functions including data quality control. We describe the standard H-k stacking approach and our four key improvements over previous work in Saudi Arabia: (1) careful analysis of the effects of the chosen stacking weights; (2) use of a resonance removal filter (Yu and others, 2015), followed by a sedimentary H-k stack on stations whose data are difficult to analyze due to sedimentary reverberations; (3) application of phase-weighted stacking (PWS) (Crotwell, 2007) to noisy data; and most importantly, (4) application of an additional sedimentary correction based upon the well-mapped sedimentary thicknesses of the Arabian Platform (Stern and Johnson, 2010). We discuss our statistical approach in determining if apparent differences between subsets of the data are real, and then provide a geographic tour of our results.

\section{Data and Methods}

\section{Preprocessing and Quality Control}

We examined data from 165 broadband seismic stations of the Saudi Geological Survey (SGS) National Seismic Network (Endo and others, 2007) that are now deployed in all of Saudi Arabia except for the Rub' al Khali (Empty Quarter) (fig. 1a). In addition to the SGS data, we have also incorporated nine seismic stations from a 1995-1997 IRIS/PASSCAL array (Vernon, 1995). The recorders used by both SGS and IRIS are Trillium T40, T120, and Streckeisen STS2 seismometers (Blanchette and others, 2021). We obtained useful results at 154 stations (fig. 1b) from 898 teleseismic events (fig. 1c) over a two-year period from 1995-1997 and a six-year period from 2008-2014. Each three-component recording was used to construct a P-wave receiver function (PRF) (Langston, 1979). The PRF method is a well-established technique to image seismic boundaries within the lithosphere, including the Moho and the base of sedimentary rocks that overlay the crystalline crust.

We rotated event recordings from their North-East-Vertical (NEZ) coordinate system to the RadialTransverse-Vertical (RTZ) coordinate system, based on the theoretical back-azimuth of each recorded teleseismic earthquake, in order to isolate the first arrival (P-wave) on the vertical component and the converted $\mathrm{S}$-wave on the radial component. We picked arrival times for every station-event pair using a short-term average (STA) over long-term average (LTA) algorithm (Earle and Shearer, 1994), and manually refined these arrival times to correct for slight errors in the picking algorithm by visually inspecting the data.

We band-pass filtered the raw data from 0.2 to $1.5 \mathrm{~Hz}$ and trimmed the filtered traces such that each trace begins 20 seconds before the first P-wave arrival and extends to 80 seconds after. PRFs were calculated by deconvolving the vertical $(Z)$ signal from the radial $(\mathrm{R})$ signal using an iterative-time domain approach (Ligorria and Ammon, 1999). Some previous workers simply visually inspected the calculated PRFs for quality (Sandvol and others, 1998; Thurner and others 2015; Miller and others, 2018; etc.); Tang and others (2016) used a minimum-fit criterion; and we quantitatively used both a minimum-fit criterion and a cross-correlation filter. 


\section{Figure 1}

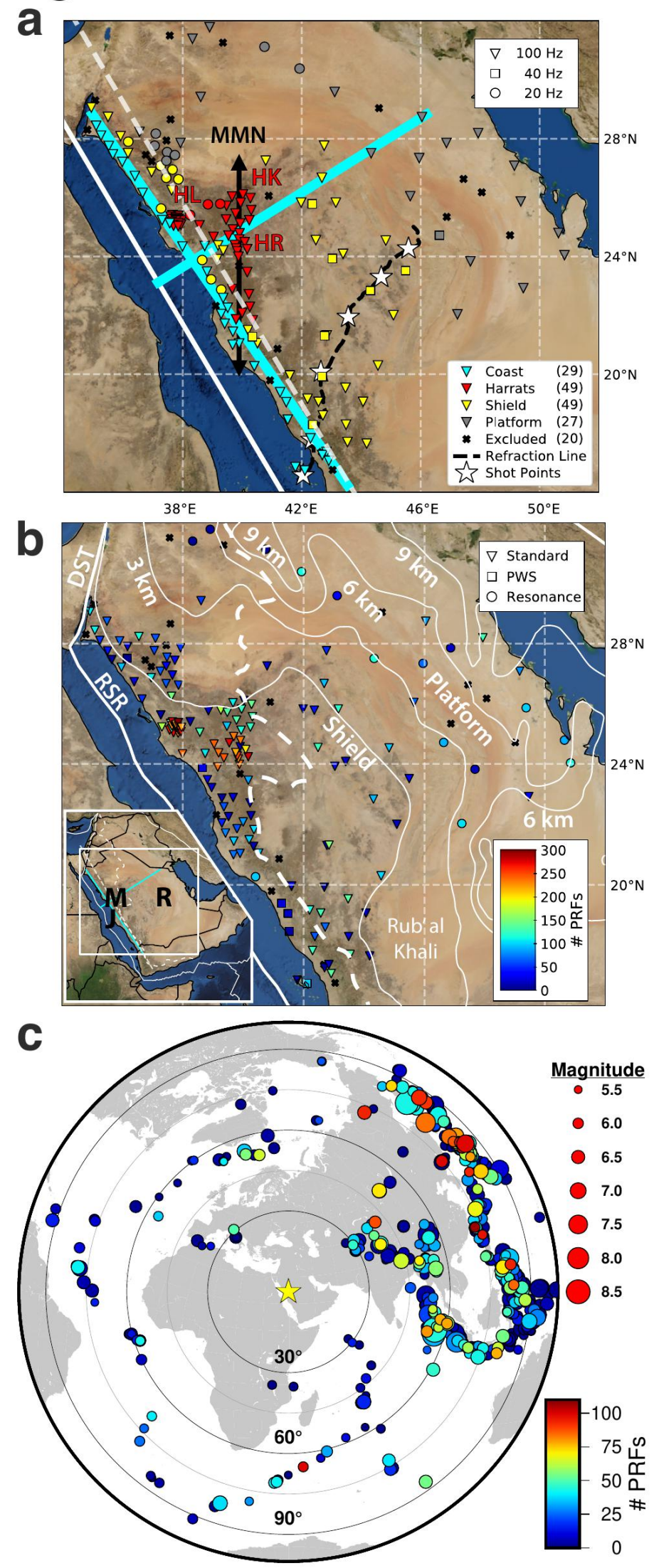

Figure 1. a) True-color image of Saudi Arabia (Stöckli and others, 2005) with locations of Saudi Geological Survey (SGS) and PASSCAL/IRIS seismometers, which are color-coded by geologic region and shape-coded by the sampling rate of available data. The number of stations in each group is shown in the legend. Harrats are named following Camp and others (1991): HL: Harrat Lunayyir; HK: Harrat Khaybar; HR: Harrat Rahat; MMN: Makkah-Medina-Nafud Line (black line). Red Sea "parallel" and "orthogonal" Common Conversion Point (CCP) lines (aqua, drawn to be $50-\mathrm{km}$ wide, the region stacked in CCP images) locate CCP sections in Figure 8 are chosen to traverse the maximum station density, as opposed to being truly parallel/orthogonal to our straightline proxy for the Red Sea rift (RSR) axis (white line). Transparent dashed white line is $250 \mathrm{~km}$ from RSR axis. The refraction line (black dashes) and shot points (white stars) are from Healy and others (1983). b) One hundred and fifty-four stations (triangles, circles, and squares) for which we report crustal thickness, color-coded by the number of useful PRFs and shape-coded by the applied H-k methodology. White lines are $0,3,6$, and 9-km contours of basement depth below surface (modified from Stern and Johnson, 2010) but are not available along the Red Sea margin. DST: Dead Sea Transform, RSR: Red Sea rift axis. Dashed white line: drainage divide between Red Sea and Persian Gulf, corresponding to Great Escarpment south of Jeddah, and in that region close to the dash line in (a), 250-km from RSR. Inset locator map shows shows Jeddah (J), Medina (M) and Riyadh (R), national boundaries (black lines), plate boundaries (white lines) and drainage divide (dash line). c) Polar plot of earthquakes used in our analysis, scaled in size to earthquake magnitude and color-coded by the number of useful PRFs generated. 
We band-pass filtered the raw data from 0.2 to $1.5 \mathrm{~Hz}$ and trimmed the filtered traces such that each trace begins 20 seconds before the first P-wave arrival and extends to 80 seconds after. PRFs were calculated by deconvolving the vertical $(Z)$ signal from the radial $(\mathrm{R})$ signal using an iterative-time domain approach (Ligorria and Ammon, 1999). Some previous workers simply visually inspected the calculated PRFs for quality (Sandvol and others, 1998; Thurner and others 2015; Miller and others, 2018; etc.); Tang and others (2016) used a minimum-fit criterion; and we quantitatively used both a minimum-fit criterion and a cross-correlation filter.

Our minimum-fit criterion requires that we are able to reproduce the radial and transverse components of motion with a fit that is equal to or better than $70 \%$ when we convolve the respective components of the PRF with the vertical component. The $70 \%$ minimum-fit criterion is chosen to enforce a decent match between the original signal and the PRF while not discarding an excessive amount of data. The initial dataset comprised 22,716 receiver functions, and $18,242(\sim 80 \%)$ of the receiver functions met our $70 \%$ fit requirement. Our crosscorrelation filter constructs a template PRF by stacking all PRFs for a given station and calculates the maximum cross-correlation coefficient of each event with the template. To minimize assumptions about the structure beneath each station, no moveout correction was applied to the PRFs, and we required a low minimumthreshold cross-correlation coefficient of 0.6 on the radial component of the PRFs only. Of the 18,242 receiver functions that passed the minimum-fit criteria, 15,519 ( $\sim 68 \%$ of the raw dataset) passed the cross-correlation filter requirement. The final number of receiver functions is far lower on the platform $(\sim 11 \%$ of the final usable PRFs) than on the shield $(\sim 24 \%)$ or in the harrats $(\sim 51 \%$; fig. $1 b)$. A very high proportion of the useable receiver functions was generated by $\mathrm{M}_{\mathrm{w}} 6+$ subduction zone earthquakes northeast of the recording array (fig. 1c) in comparison to the less numerous and smaller mid-ocean ridge events at most other back-azimuths.

\section{Standard H-k Stacking}

PRFs utilize teleseismic P-wave energy from earthquakes that are 30-90 distant from the receiver. Some of the P-wave energy is converted to transmitted S-wave motion at first-order (abrupt) impedance boundaries in the lithosphere. This S-wave is denoted Ps (capital letters denote waves that are initially downgoing and lowercase letters indicate purely up-going waves). Three other arrivals ('multiples') are also commonly observed on the better-quality P-wave receiver functions: the PpPs (or 3p1s) arrival and two phases that arrive together (for a 1D Earth model) with the same sense of motion (PsPs and PpSs, collectively referred to as 2 p2s) (fig. 2). The piercing point at the Moho varies between phases and with the earthquake distance, but is farthest away from the seismic station (about $50 \mathrm{~km}$, fig. 2c) for the $3 \mathrm{p} 1 \mathrm{~s}$ multiple at the shortest teleseismic offset used, here $30^{\circ}$. For clarity, we denote the depth of the interface at which the waves are refracting and converting with a subscript (e.g. $\mathrm{P}_{35 \mathrm{~S}}$ is a P-to-S conversion at $35 \mathrm{~km}$ depth). The travel-times ( $\mathrm{t}$ [s]) of each phase as a function of crustal thickness $(\mathrm{H}[\mathrm{km}])$, $\mathrm{P}$-wave velocity $\left(\mathrm{V}_{\mathrm{p}}\left[\mathrm{km} \cdot \mathrm{s}^{-1}\right]\right), \mathrm{V}_{\mathrm{p}} / \mathrm{V}_{\mathrm{s}}$ ratio $(\mathrm{k})$, and rayparameter $\left(p\left[\mathrm{~s} \cdot \mathrm{km}^{-1}\right]\right)$ are given by equations (1)-(3):

$$
\begin{gathered}
t_{P s}\left(H, k, V_{p}, p\right)=H\left[\sqrt{\frac{k^{2}}{V_{p}^{2}}-p^{2}}-\sqrt{\frac{1}{V_{p}^{2}}-p^{2}}\right] \\
t_{3 p 1 s}\left(H, k, V_{p}, p\right)=H\left[\sqrt{\frac{k^{2}}{V_{p}^{2}}-p^{2}}+\sqrt{\frac{1}{V_{p}^{2}}-p^{2}}\right] \\
t_{2 p 2 s}\left(H, k, V_{p}, p\right)=2 H \sqrt{\frac{k^{2}}{V_{p}^{2}}-p^{2}}
\end{gathered}
$$

H-k stacking (Zhu and Kanamori, 2000) is a standard approach used to analyze PRFs for H and k beneath a given seismic station, normally assuming a homogenous isotropic layer over a half-space beneath the seismic station. Standard H-k stacking employs a grid-search over H-k space for the stacking amplitude:

$$
s(H, k)=\frac{1}{N} \sum_{n=1}^{N}\left[w_{1} r_{n}\left(t_{P s}\right)+w_{2} r_{n}\left(t_{3 p 1 s}\right)-w_{3} r_{n}\left(t_{2 p 2 s}\right)\right]
$$


Figure 2
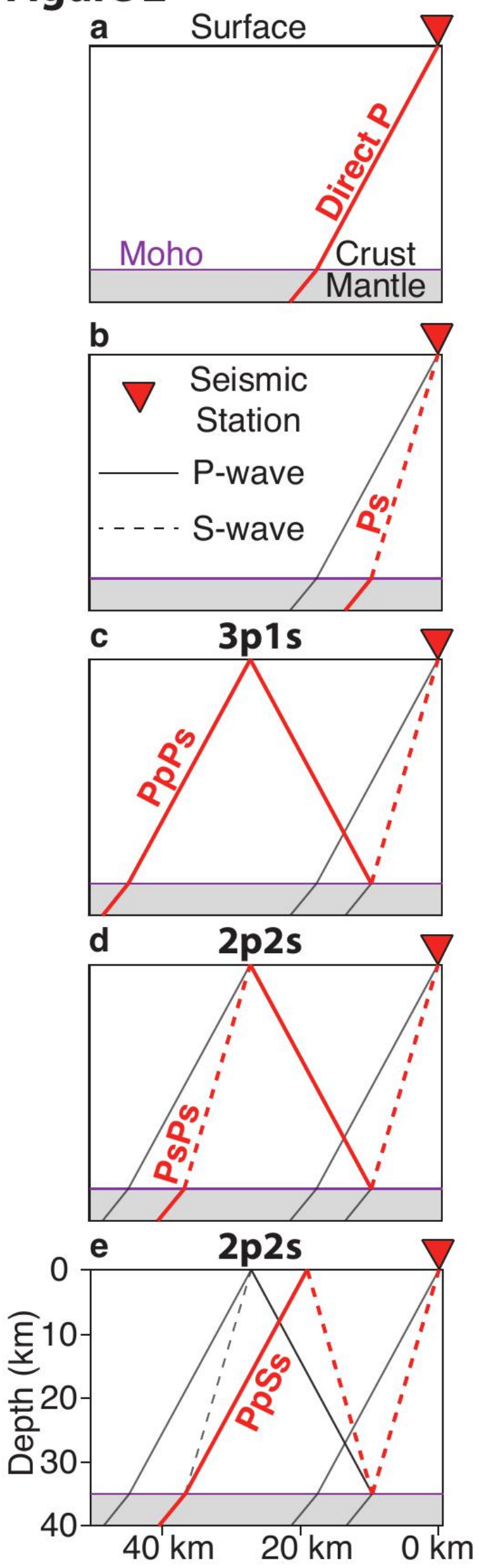

Figure 3
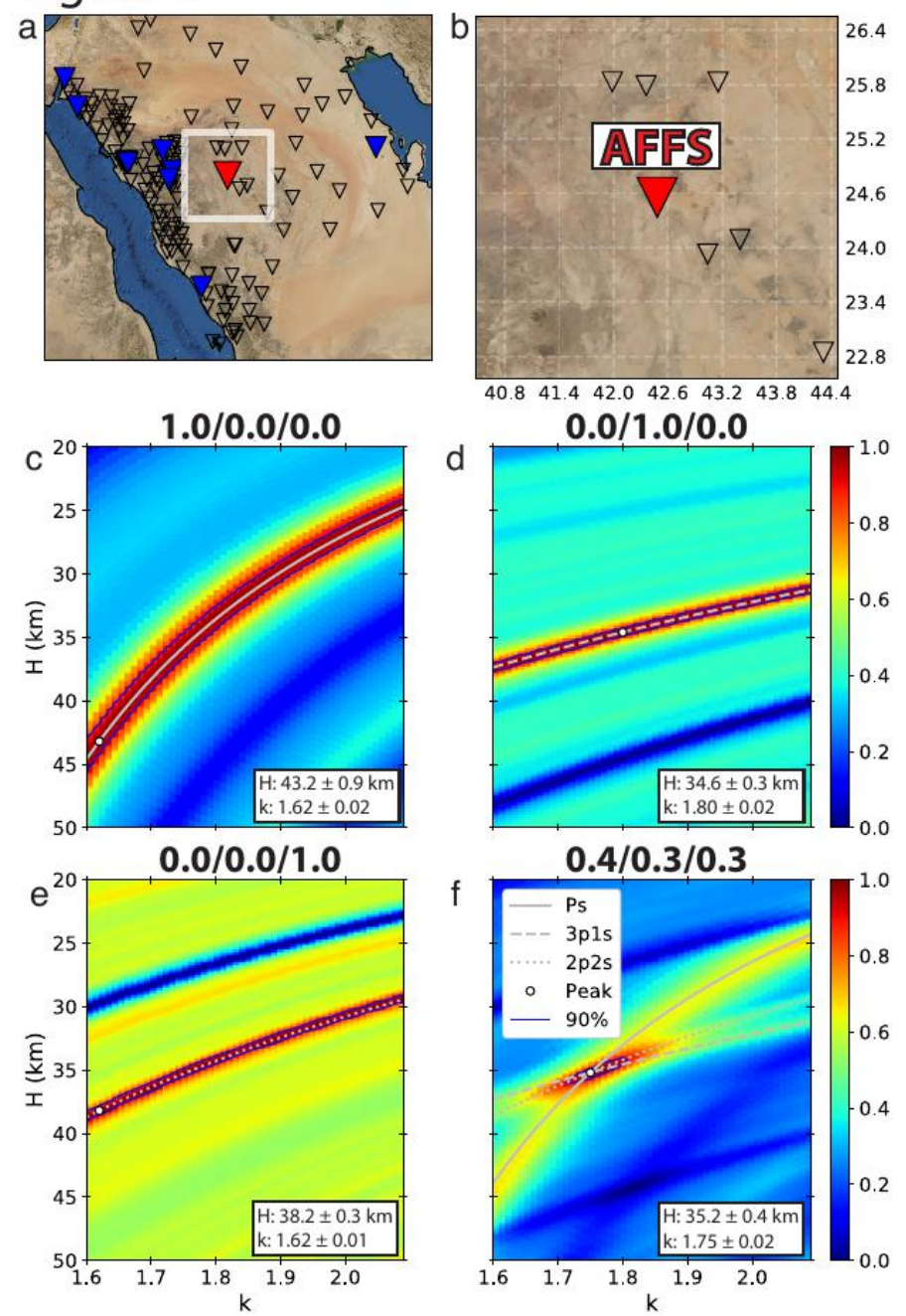

Figure 2. Schematic ray paths of $\mathrm{P}$-wave receiver function phases from a shallow earthquake at $30^{\circ}$ distance, for a 35-km-deep Moho separating crust $\left(\mathrm{V}_{\mathrm{p}}=\right.$ $\left.6.1 \mathrm{~km} . \mathrm{s}^{-1}, \mathrm{k}=1.73\right)$ and upper mantle $\left(\mathrm{V}_{\mathrm{p}}=8.04 \mathrm{kms}^{-1}\right.$, $\mathrm{k}=1.80$ ). a) Direct P-wave. b) Ps phase. c) PpPs (or 3p1s) phase. d) PsPs (or 2p2s) phase. e) PpSs phase (also a 2p2s phase). Red lines are the labelled phase; black lines are the phase(s) in the previous panels.

Figure 3. Receiver function analysis for station AFFS. a) Location map. Red triangle is the station presented. Blue triangles are stations presented in other figures. Open triangles are all other stations. b) Expanded location map. c) Ps single-phase H-k stack (1/0/0). d) 3p1s singlephase $\mathrm{H}-\mathrm{k}$ stack $(0 / 1 / 0)$. e) $2 \mathrm{p} 2 \mathrm{~s}$ single-phase $\mathrm{H}-\mathrm{k}$ stack (0/0/1). f) Optimized 0.4/0.3/0.3 H-k stack indicating a crustal thickness $(\mathrm{H})$ of $35.2 \pm 0.4 \mathrm{~km}$ and $\mathrm{V}_{\mathrm{p}} / \mathrm{V}_{\mathrm{s}}$ ratio $(\mathrm{k})$ of $1.75 \pm 0.02$. 
H-k stacking (Zhu and Kanamori, 2000) is a standard approach used to analyze PRFs for $\mathrm{H}$ and $\mathrm{k}$ beneath a given seismic station, normally assuming a homogenous isotropic layer over a half-space beneath the seismic station. Standard H-k stacking employs a grid-search over H-k space for the stacking amplitude:

$$
s(H, k)=\frac{1}{N} \sum_{n=1}^{N}\left[w_{1} r_{n}\left(t_{P s}\right)+w_{2} r_{n}\left(t_{3 p 1 s}\right)-w_{3} r_{n}\left(t_{2 p 2 s}\right)\right]
$$

where the $r_{n}$ are the amplitudes of the $\mathrm{n}^{\text {th }}$ radial receiver function for this station at the predicted phase arrival times for the appropriate $\left(\mathrm{H}, \mathrm{k}, \mathrm{V}_{\mathrm{p}}, p\right)$, and $\mathrm{w}_{\mathrm{i}}$ are the stacking weights for each phase. The normalization condition applied to the weights is $w_{1}+w_{2}+w_{3}=1$, and we describe H-k stacks and their results as ' $\mathrm{w}_{1} / \mathrm{w}_{2} / \mathrm{w}_{3}$ ' to emphasize the weights used. The third term represents the $2 \mathrm{p} 2 \mathrm{~s}$ phases and is subtracted because it has the opposite polarity with respect to the other phases. The sum, s, reaches its maximum value for any seismic station at the average crustal thickness and velocity ratio beneath that station. We searched over a grid spanning $20 \leq \mathrm{H} \leq 80 \mathrm{~km}$ and $1.60 \leq \mathrm{k} \leq 2.10$ to sample all plausible crustal thicknesses and compositions, using an assumed average crustal wavespeed $\left(\mathrm{V}_{\mathrm{p}}\right.$ avg $=6.5 \mathrm{~km} \cdot \mathrm{s}^{-1}$; Mooney and others, 1985). H-k estimates only vary weakly with $\mathrm{V}_{\mathrm{p}}{ }^{\text {avg }}$, increasing $\mathrm{H}$ by $<\sim 10 \mathrm{~km}$ per $\mathrm{km} . \mathrm{s}^{-1}$ and $\mathrm{k}$ by $<\sim 0.05$ per km.s $\mathrm{s}^{-1}$ (e.g. Karplus and others, 2019). Conventionally the uncertainty in $\mathrm{H}$ and $\mathrm{k}$ values is computed using:

$$
\begin{aligned}
\sigma_{H}^{2} & =2 \sigma_{s}\left(\frac{\partial^{2} s}{\partial H^{2}}\right)^{-1} \\
\sigma_{k}^{2} & =2 \sigma_{s}\left(\frac{\partial^{2} s}{\partial k^{2}}\right)^{-1}
\end{aligned}
$$

where $\sigma_{H}, \sigma_{k}$, and $\sigma_{s}$ are the standard deviations of $\mathrm{H}, \mathrm{k}$, and the stack amplitude evaluated at the $\mathrm{H}$ and $\mathrm{k}$ values that maximize the stack (Zhu and Kanamori, 2000). We cite uncertainties of $\pm 2 \sigma$ throughout this paper for individual stations, and in Tables, except in the Discussion section, where we cite uncertainties of $\pm 1 \sigma$ for ensemble means.

It is common to use a default set of stacking weights, regardless of the signal-to-noise ratios of the different phases at different stations. Instead, we examined the individual contribution of each converted phase at each station to determine the final weights, selecting from among three options $(0.4 / 0.3 / 0.3 ; 0.33 / 0.33 / 0.33$; 0.5/0.5/0.0) to give the visually best focused result for the Moho conversions (cf. Ogden and others, 2019). Additional combinations were used to stack shallower conversions, within or at the base of the sedimentary cover, as discussed below. For example, at shield station AFFS (fig. 3), each phase (fig. 3c-e) provides clean constraints in H-k space. We generated H-k solutions for multiple combinations of weights and compared the predicted moveout curves of each phase for each $\mathrm{H}-\mathrm{k}$ solution with the data to ensure the H-k solutions represent stacked coherent signal, not noise (fig. 4). For station AFFS, our preferred weights are 0.4/0.3/0.3 (fig. 3f).

In contrast to AFFS, at coastal station MWLHS (fig. 5), the 2p2s phases provide potentially misleading information (fig. 5e), and our preferred stacking weights are $0.5 / 0.5 / 0.0$. We illustrate this issue in figure 6: the 2p2s stack (fig. 5e) suggests possible Moho depths of about $21 \mathrm{~km}$ or about $43 \mathrm{~km}$. However, the predicted $2 \mathrm{p}_{21} 1 \mathrm{~s}$ and $2 \mathrm{p}_{43} 1 \mathrm{~s}$ arrivals (where subscripts denote depth of model converter) correspond to unusually high amplitudes on the more numerous PRFs with a small slowness of $p \sim 0.45 \mathrm{~s} . \mathrm{km}^{-1}$ (the most distant earthquakes from the northeast) and not to any corresponding negative (blue) amplitudes on the sparse PRFs with larger $p$. Hence, we ignore the $2 p 1 \mathrm{~s}$ stack in selecting our final weighting of 0.5/0.5/0.0 (Fig. 5f). It should be noted that although standard deviations calculated via equations (5) and (6) are appropriate for well-resolved H-k plots with sub-equal contributions from the various phases (e.g. figs. $3 \mathrm{f}$ and $5 \mathrm{f}$ ), they are gross under-estimates for poor data quality particularly where only a single phase is available or dominates the stacks (e.g. figs $3 \mathrm{c}-\mathrm{e}$ and $5 \mathrm{c}-\mathrm{e})$. For AFFS, our preferred result $(\mathrm{H}=35.2 \pm 0.4 \mathrm{~km}, \mathrm{k}=1.75 \pm 0.02)$ is $8 \sigma_{\mathrm{H}}$ and $6 \sigma_{\mathrm{k}}$ from the value given by only the Ps phase (fig. 3c). 


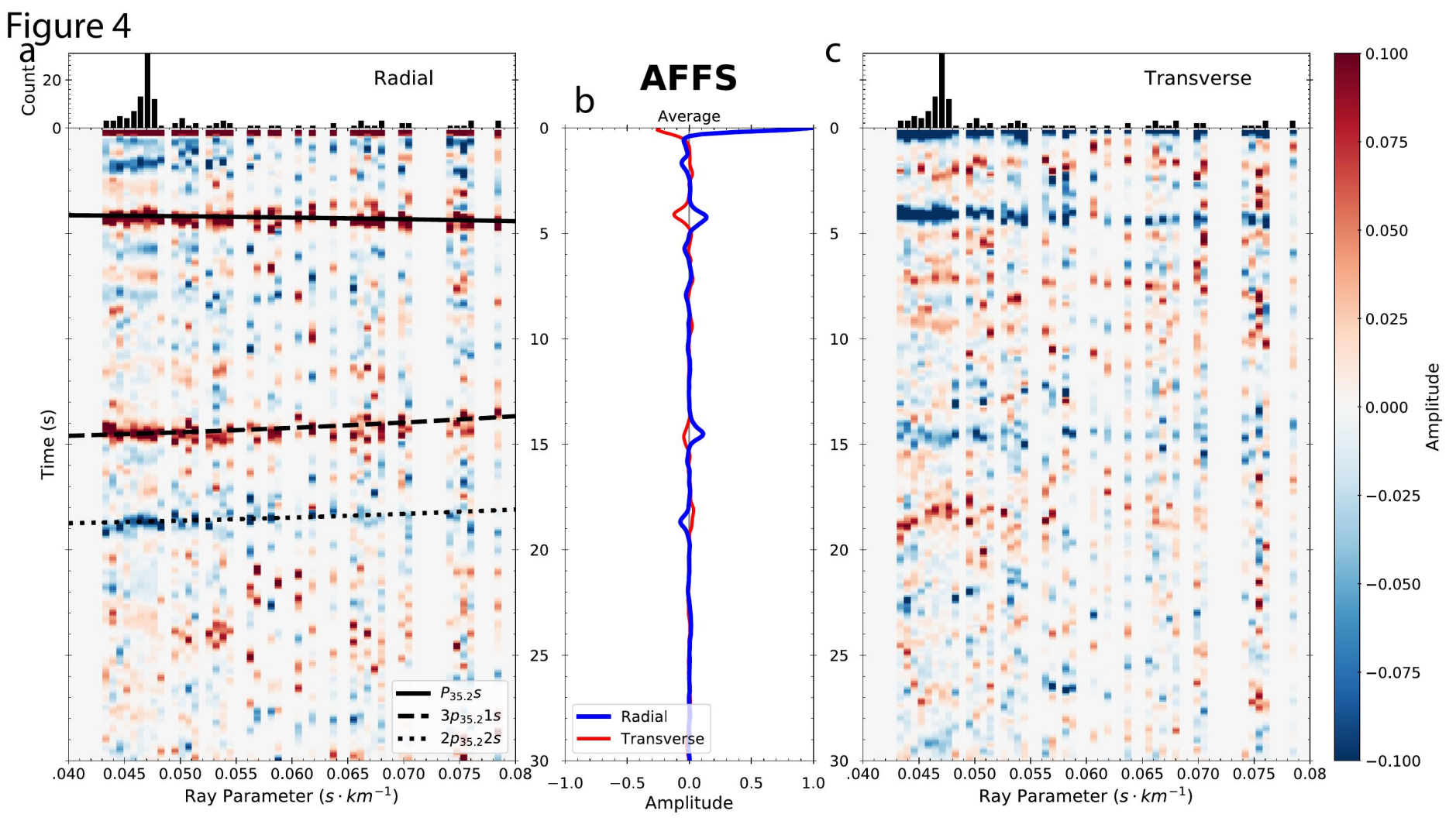

Figure 4. Receiver-function gather for station AFFS. a) Radial component of PRFs plotted against ray parameter. Individual PRFs are normalized to the maximum amplitude within the time window shown, binned, and normalized by the number of traces per bin. b) Average of every individual normalized radial receiver function (blue) and average of every individual normalized transverse receiver function, divided by three (red). c) Transverse component of PRFs plotted against ray parameter, normalized as in part a) and multiplied by 0.3 . Multiplication by 0.3 is an arbitrary scaling to make the normalized energy on the radial plot (part a) and transverse plot (part c) appear more similar.

\section{Multiple removal to improve H-k Stacking}

Standard H-k stacking works well at recovering the thickness of the crust, provided that the Moho is the only layer with a sharp enough impedance contrast to generate strong P-wave to S-wave conversions (Langston, 2011; Yu and others, 2015) and that the crust can be reasonably well-characterized with a single average wavespeed. However, some stations on the Arabian Platform are underlain by as much as 10-km of low-wavespeed sedimentary rocks (fig. 1b) (Stern and Johnson, 2010), producing inter-bed conversions and multiples (reverberations) that can interfere with the Moho Ps arrival and its subsequent multiples. A significant number (21 out of 174) of the seismic stations analyzed here were affected by sedimentary multiples and required additional analysis.

We attempted direct removal of the sedimentary reverberations from these PRFs using a resonanceremoval filter calculated from the auto-correlations of the PRFs (Yu and others, 2015). This method estimates the apparent thickness and $\mathrm{V}_{\mathrm{p}} / \mathrm{V}_{\mathrm{s}}$ ratio of the sedimentary layer, as well as a thickness and $\mathrm{V}_{\mathrm{p}} / \mathrm{V}_{\mathrm{s}}$ ratio for the sub-sedimentary crystalline crust. This approach works best for sedimentary layers $>\sim 0.25 \mathrm{~km}$ thick for which the reverberations have frequencies and travel-times that interfere with the Moho conversions. However, this method may be inapplicable for layers $>\sim 8 \mathrm{~km}$ for which the wavespeed contrast at the sedimentary/basement contact is often sufficiently small or gradational that the reverberations do not have a high amplitude. We successfully filtered 15 stations with $2.6-10.7 \mathrm{~km}$ of sedimentary rock (thicknesses from Stern and Johnson, 2010). We then determined the crustal thicknesses using the H-k method on the filtered PRFs. 


\section{Figure 5}

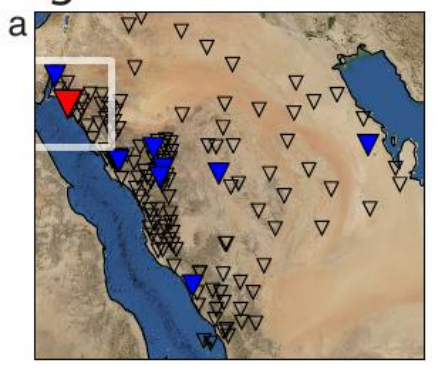

$1.0 / 0.0 / 0.0$
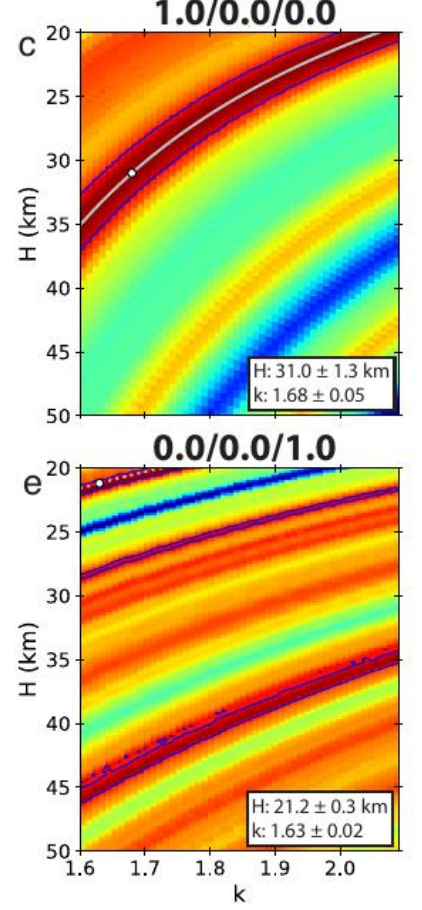

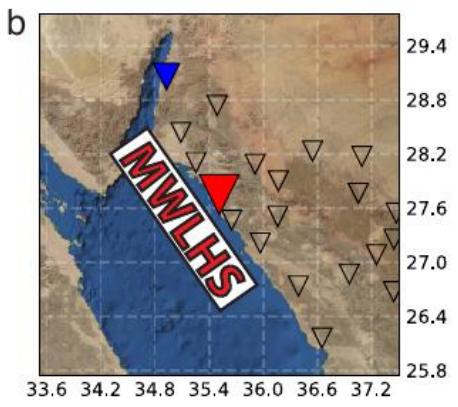

$0.0 / 1.0 / 0.0$

d
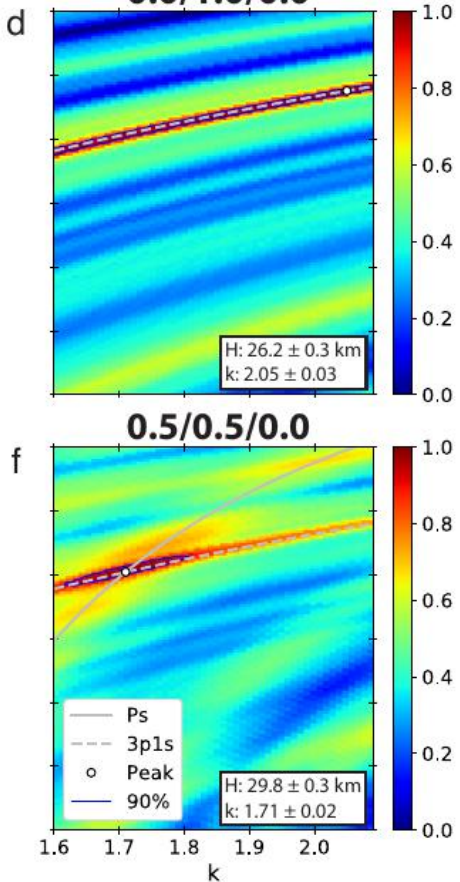

Figure 5. Receiver function analysis for station MWLHS. Presentation format as in Figure 3. Weights of optimized stack (f) are 0.5/0.5/0.0. The optimal solution is a crustal thickness $(\mathrm{H})$ of $29.8 \pm 0.3 \mathrm{~km}$ and $\mathrm{V}_{\mathrm{p}} / \mathrm{V}_{\mathrm{s}}$ ratio $(\mathrm{k})$ of $1.71 \pm$ 0.02 .

As in conventional $\mathrm{H}-\mathrm{k}$ stacking, to get a sedimentary thickness $\mathrm{h}_{\mathrm{s}}$ we assume a sedimentary Pwavespeed. We use $4.0 \mathrm{~km} . \mathrm{s}^{-1}$, based on refraction-profiling results showing $\mathrm{V}_{\mathrm{p}}=2.0-5.7 \mathrm{~km} \cdot \mathrm{s}^{-1}$ in the northern platform (Seber and others, 1993; Brew and others, 1997) and 3-5 km. $\mathrm{s}^{-1}$ within the western platform (Mooney, 1984), and carry out a grid search over H-k space. The sedimentary thickness, $\mathrm{h}_{\mathrm{s}}$, is reasonably well determined by the Ps conversion from the sediment/basement interface, but determining the sedimentary $V_{p} / V_{s}$ ratio, $\mathrm{k}_{\mathrm{s}}$, requires good constraints on the corresponding $3 \mathrm{p} 1 \mathrm{~s}$ and $2 \mathrm{p} 2 \mathrm{~s}$ multiples that tend to have low amplitudes.

\section{Phase-Weighted H-k Stacking}

At five stations on the Red Sea rift margin (i.e. the coastal plain) for which neither the standard H-k stacking nor the resonance-removal filter proved useful, we successfully applied Phase-Weighted Stacking (PWS) (Crotwell, 2007; Ogden and others, 2019) to remove incoherent noise from the data. In this method, the coherency between the converted (Ps) and multiple (3p1s, 2p2s) arrivals is used to modulate the stacking amplitude $s(H, k)$ :

$$
\begin{gathered}
s(H, k)=\frac{1}{3 N}\left|\sum_{n=1}^{N}\left[e^{i \phi_{n}\left(t_{P s}\right)}+e^{i \phi_{n}\left(t_{3 p 1 s}\right)}-e^{i \phi_{n}\left(t_{2 p 2 s}\right)}\right]\right|^{v} . \\
\sum_{n=1}^{N}\left[w_{1} r_{n}\left(t_{P s}\right)+w_{2} r_{n}\left(t_{3 p 1 s}\right)-w_{3} r_{n}\left(t_{2 p 2 s}\right)\right]
\end{gathered}
$$


where $\phi_{n}$ are the instantaneous phases of the PRF (derived from the Hilbert transform of the PRF) at the predicted $\mathrm{Ps}, 3 \mathrm{p} 1 \mathrm{~s}$, and $2 \mathrm{p} 2 \mathrm{~s}$ arrival times for the appropriate $(\mathrm{H}, \mathrm{k})$, and $v$ is an arbitrary exponent. Using $v=0$ corresponds to regular H-k stacking, with $v=1$ (Crotwell, 2007, and this chapter), and $v=2$ (Ogden and others, 2019) representing progressively more aggressive PWS. PWS uses the relative coherence of the arrivals to determine their contribution to the H-k stack. If the instantaneous phase $\phi$ of the PRFs at the three predicted arrival times is equal (as expected for noise-free data), the weighted sum of the PRFs at these three times is given full weight in the H-k stack, whereas if $\phi$ at the three arrival times is contradictory (as one would expect from random noise), the weighted sum of the PRFs is given much lower, or zero weight. In our application of PWS, we did not try to select optimum weights $w$ for Ps, $3 p 1 s$, and $2 p 2 s$, but rather assigned each phase a value of $1 / 3$. We attempted PWS H-k stacking only for stations for which we could not otherwise obtain reliable results. We obtained reliable results from an additional six stations. The remaining 14 stations defied our efforts to obtain a reliable crustal thickness, due to either the very low signal-to-noise ratios and/or very few PRFs at these stations.

Figure 6

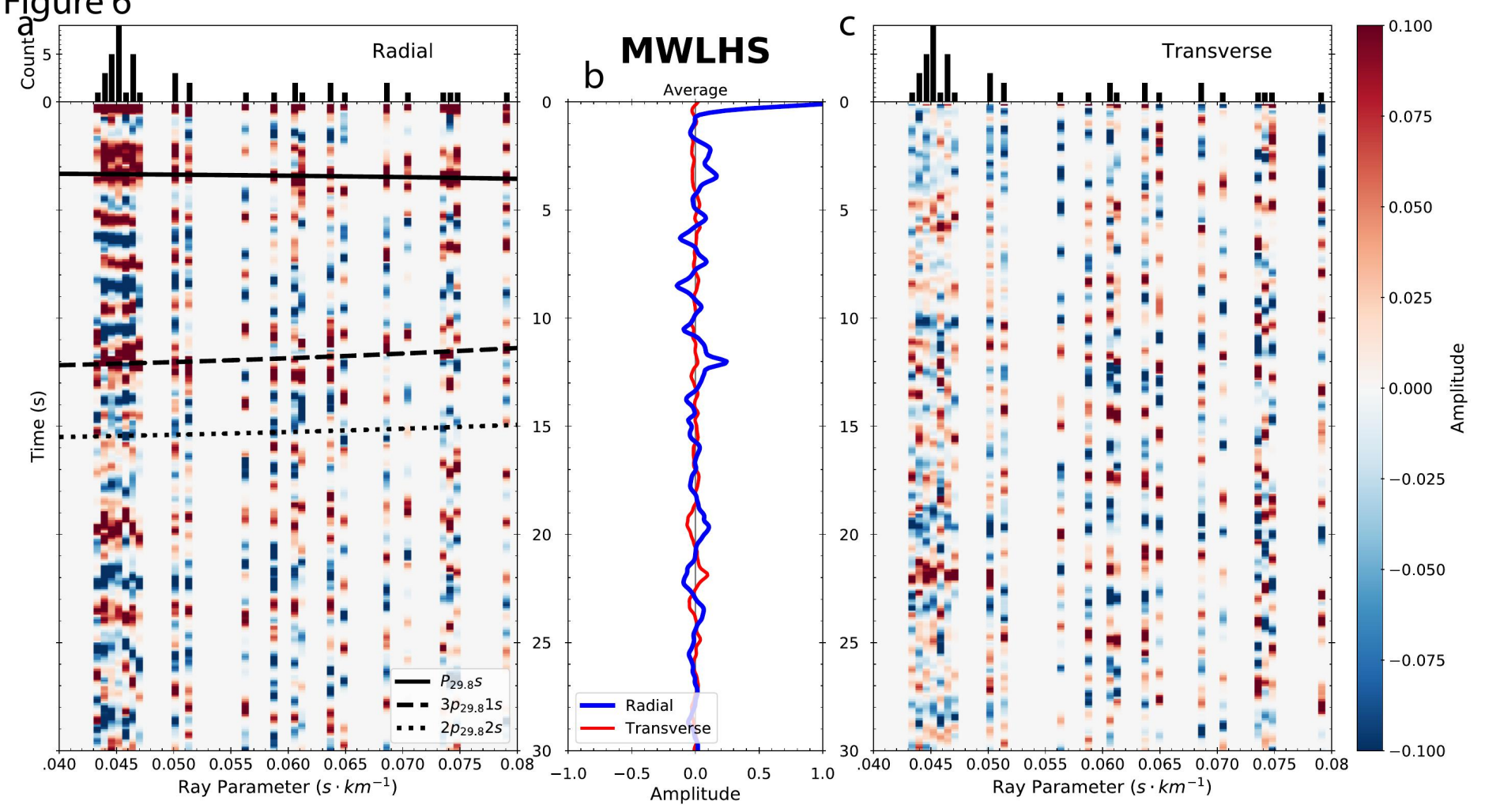

Figure 6. Receiver-function gather for station MWLHS. Presentation format as in Figure 4.

\section{Sedimentary corrections to crustal thickness}

Our single-layer interpretations of our H-k stacks (whether conventional or using PWS) assume a constant wavespeed for the entire crust. However, the traveltime of the Ps phase per kilometer of sedimentary rock (in a lower- $\mathrm{V}_{\mathrm{p}}$, higher-k basin) is larger than in the higher- $\mathrm{V}_{\mathrm{p}}$, lower-k crystalline crust. Hence, the presence of a basin makes crustal thicknesses directly measured from H-k stacking $\left(\mathrm{H}_{\text {raw }}\right)$ too large by an amount that increases in proportion to the basin thickness. For a sedimentary layer thickness, $\mathrm{h}_{\mathrm{s}}$ above a crystalline crust thickness $h_{b}$ (such that true crustal thickness $H_{\text {corrected }}=h_{s}+h_{b}$ ), the travel time of the converted Ps phase with respect to direct $\mathrm{P}$ is given by:

$$
t_{P s}=h_{b}\left(\sqrt{\frac{k_{b}^{2}}{V_{p b}^{2}}-p^{2}}-\sqrt{\frac{1}{V_{p b}^{2}}-p^{2}}\right)+h_{s}\left(\sqrt{\frac{k_{s}^{2}}{V_{p s}^{2}}-p^{2}}-\sqrt{\frac{1}{V_{p s}^{2}}-p^{2}}\right)
$$

where the subscripts " $b$ " and "s" denote crystalline basement and sedimentary values; so $\mathrm{H}_{\mathrm{raw}}$ is given by: 


$$
H_{\text {raw }}=\frac{t_{P s}-h_{s}\left(\sqrt{\frac{k_{s}^{2}}{V_{p s}^{2}}-p^{2}}-\sqrt{\frac{k_{b}^{2}}{V_{p b}^{2}}-p^{2}}+\sqrt{\frac{1}{V_{p b}^{2}}-p^{2}}-\sqrt{\frac{1}{V_{p s}^{2}}-p^{2}}\right)}{\sqrt{\frac{k_{c}^{2}}{V_{p c}^{2}}-p^{2}}-\sqrt{\frac{1}{V_{p c}^{2}}-p^{2}}}
$$

where subscript "c" denotes the assumed whole crustal values for the $\mathrm{P}$ wavespeed and the $\mathrm{V}_{\mathrm{p}} / \mathrm{V}_{\mathrm{s}}$ ratio used in the H-k stacking.

\section{Figure 7}
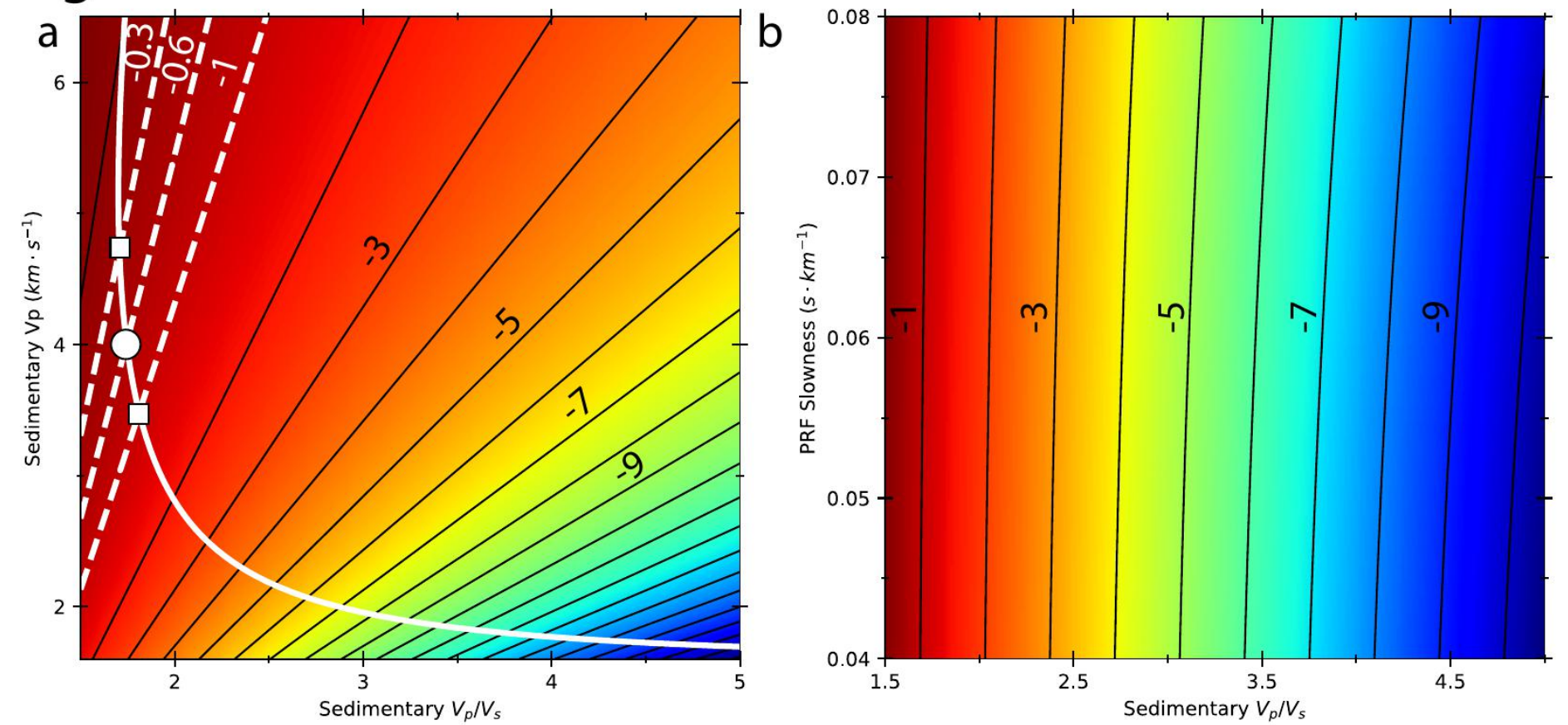

Figure 7. a) Values of $\frac{\partial \varepsilon}{\partial h_{s}}$ for varying sedimentary $V_{p}$ and $k$, for a crystalline crust with $V_{p}=6.5 \mathrm{~km} \cdot \mathrm{s}^{-1}$ and $\mathrm{k}=1.73$. Solid white line is an empirical relationship between sedimentary $\mathrm{V}_{\mathrm{p}}$ and $\mathrm{k}$ (Brocher, 2005). Dashed white lines are the range of corrections tested. b) Values of $\frac{\partial \varepsilon}{\partial h_{s}}$ for varying source-earthquake slowness $p$ and sedimentary $\mathrm{k}_{\mathrm{s}}$.

To correct $\mathrm{H}_{\text {raw }}$ to the true Moho depth $\mathrm{H}$, we use the sedimentary thickness $\mathrm{h}_{\mathrm{s}}$ (equivalent to the basement depth) that is well-known across the Arabian platform from extensive hydrocarbon exploration (e.g. Stern and Johnson, 2010) (fig. 1b). We define the difference between the true crustal thickness and the raw thickness as the error, $\varepsilon=H_{\text {final }}-H_{\text {raw }}$. For PRFs the ray-parameter, $p$, ranges from 0.04 s.km-1 to 0.08 s.km ${ }^{-1}$, and in figure 7a, we show the variation of $\varepsilon$ with sedimentary thickness $h_{s}$ (i.e. $\frac{\partial \varepsilon}{\partial h_{s}}$ ) as a function of sedimentary $\mathrm{V}_{\mathrm{p}}$ and $\mathrm{V}_{\mathrm{p}} / \mathrm{V}_{\mathrm{s}}$ ratios for constant $p=0.06 \mathrm{s.km}{ }^{-1}$. For a sedimentary layer thickness of $\mathrm{h}_{\mathrm{s}}$, with $\mathrm{V}_{\mathrm{p}}=$ $4.0 \mathrm{~km} . \mathrm{s}^{-1}$ and $\mathrm{k}_{\mathrm{s}}=1.75$ (Brocher, 2005; fig. 7), $\mathrm{H}_{\text {raw }}$ must be reduced by $\sim 0.6 \mathrm{~h}_{\mathrm{s}}$. Figure $7 \mathrm{~b}$ shows the variation of $\varepsilon$ with slowness $p$ (i.e. $\frac{\partial \varepsilon}{\partial p}$ ) is irrelevant for the range of $p$ used here. In the following sections, we present the full crustal thickness $\mathrm{H}$ (Moho depth below the surface), after reduction by $0.6 \mathrm{~h}_{\mathrm{s}}$ using sedimentary thicknesses from Stern and Johnson (2010), and we also discuss crystalline crustal thickness $h_{b}=H-h_{s}$. At stations for which we performed the resonance-removal and sedimentary stacking method ( $\mathrm{Yu}$ and others, 2015), we applied the $0.6 h_{s}$ reduction to the difference between the H-k sedimentary thicknesses and the known sedimentary thicknesses. This correction was applied because, in general, the H-k sedimentary thicknesses are less than the known sedimentary thicknesses, meaning we are still over-estimating the total crustal thickness. 
There are exactly two stations for which we obtained sedimentary H-k values greater than the thicknesses we expected, therefore, at those two stations, the correction is in the opposite direction.

\section{Comparison of H-k to common-conversion-point (CCP) processing}

The importance of the sedimentary correction is shown by comparing H-k results before and after correction, overlain on common-conversion-point (CCP) images (fig. 8) along Red Sea-"parallel" and "orthogonal" profiles (fig. 1a). The CCP stacks were calculated on a latitude/longitude grid with 50-km spacing between nodes in each horizontal direction and 2-km spacing vertically. Each CCP node had a 50-km radius, over which rays were stacked, i.e. rays parallel to each profile are used by two adjacent CCP nodes; orthogonal rays are used only once. Hence the alignment of the "orthogonal" profile towards the greatest earthquake density (fig. 1c) is one reason the "orthogonal" CCP image (fig. 8b) is smoother than the "parallel" CCP image (fig. 8a). To create grid-oblique CCP cross sections, we chose only grid nodes within $25 \mathrm{~km}$ of the transect. Points along the transects that had more than one node within the 25-km distance limit are composed of the average of the nodes. On the Red Sea-parallel section, the H-k stacking and CCP stacking results are mostly in good agreement, including in places where there are very large abrupt shifts in imaged Moho depth, e.g. near $24^{\circ} \mathrm{N}$, where the station layout along our linear profile switches from stations only on the shield (Moho at $\sim 40$ $\mathrm{km}$ ) to a station only on the coastal plain ( $20 \mathrm{~km}$ Moho) and back on the shield again (fig. 8a). Minor discrepancies likely result from assuming the same 1D velocity model across all stations for CCP stacking, whereas H-k stacking solves for a unique layer over a half-space velocity model at each station. An additional source of discrepancy comes from CCP stacking using multiple stations at some nodes, whereas H-k stacking is purely single-station. Large differences (e.g. $\sim 27.5^{\circ} \mathrm{N}$ ) appear due the inability of CCP stacking to handle multiple candidate Ps peaks, whereas H-k stacking enforces consistency between the Ps, $3 \mathrm{p} 1 \mathrm{~s}$, and $2 \mathrm{p} 2 \mathrm{~s}$ phases. The Red Sea-orthogonal section shows a consistent sense of offset, with the H-k Moho shallower than the CCP stacking Moho by up to $8 \mathrm{~km}$ where the sedimentary section is thickest along our profile, as expected from our analysis as described above. In spite of the apparently well-resolved Moho on the CCP image, it is clear that care must be taken in interpretation of such an image due to the additional travel-time delay of the sediments.

\section{Results}

We next show $\mathrm{H}-\mathrm{k}$ analyses corroborated by direct inspection of $\mathrm{P}$-wave receiver functions, including examples from and compiling crustal-thickness results for each of the geological regions (Harrats, Coastal Plain, Shield, Platform; fig. 1a).

\section{Harrat Lunayyir}

Harrat Lunayyir (fig. 1a, 9a) has the greatest station density of the SGS network, with 18 seismometers within an $\sim 50$-by-50 km area (Blanchette and others, 2018; this volume), which were installed during and following the 2009 dike intrusion. This dike intrusion was accompanied by $>30,000$ earthquakes, up to $\mathrm{M}_{\mathrm{w}} 5.7$ (Pallister and others, 2010). One station (LNY07) in this sub-network is $<250 \mathrm{~km}$ from the Red Sea rift axis and has elevation $<400 \mathrm{~m}$ above sea-level and is here considered to be a 'coastal' station.

LNY02 is a representative seismic station near the center of Harrat Lunayyir (fig. 9a). The PRFs at station LNY02 (fig. 10a) show a coherent arrival that we identify as Ps, with a positive amplitude (red), arriving 4-5 s after the initial $\mathrm{P}$-wave arrival. Assuming a simplified $1 \mathrm{D}$ velocity model $\left(\mathrm{V}_{\mathrm{p}}=6.5 \mathrm{k} \cdot \mathrm{ms}^{-1}, \mathrm{k}=1.80\right)$, with zero sediment thickness $\left(\mathrm{h}_{\mathrm{s}}\right)$ and 34-km Moho depth, we can reasonably match the travel-times of this arrival as $\mathrm{P}_{34 \mathrm{~S}}$ (Moho conversion from $34 \mathrm{~km}$ depth), and the later positive arrival at a delay-time of $\sim 14 \mathrm{~s}$ as $\mathrm{P}_{34} \mathrm{pP} \mathrm{P}_{34 \mathrm{~S}}$, i.e. the 3p1s Moho multiple. In practice, we examined the H-k stacks (fig. 9c-e) and corroborated with the PRF displays (fig. 10a) before selecting our final choice of weights (fig. 9f). At station LNY02, the Ps phase alone (fig. 9c) provides a well-defined zone in H-k space of possible solutions, but it is insensitive to the actual solution along this trade-off curve. Similarly, the PpPs phase (fig. 9d) provides a different but still well-defined zone of possible solutions in $\mathrm{H}-\mathrm{k}$ space, that is also insensitive to $\mathrm{H}$ and, particularly, $\mathrm{k}$. Although the $2 \mathrm{p} 2 \mathrm{~s}$ multiples can be used to form a H-k stack (fig. 9e), this does not conform to the other two phases, and is seen to 
correspond to a diffuse region of negative and low-amplitude energy on the PRF (fig. 10a). We chose stacking weights $0.5 / 0.5 / 0.0$ at this station and obtain $\mathrm{H}$ and $\mathrm{k}$ values of $34.0 \pm 0.6 \mathrm{~km}$ and $1.80 \pm 0.04$. These values match those of Tang and others (2016), who reported $\mathrm{H}=34.1 \pm 0.4 \mathrm{~km}$ and $\mathrm{k}=1.80 \pm 0.02$ ( $2 \sigma$ uncertainties). Results from equivalent analyses of all Harrat Lunayyir stations are given in Table 1, with average Moho depths of $33.7 \mathrm{~km}$ and crustal $\mathrm{k}$ of 1.78 .

\section{Figure 8}

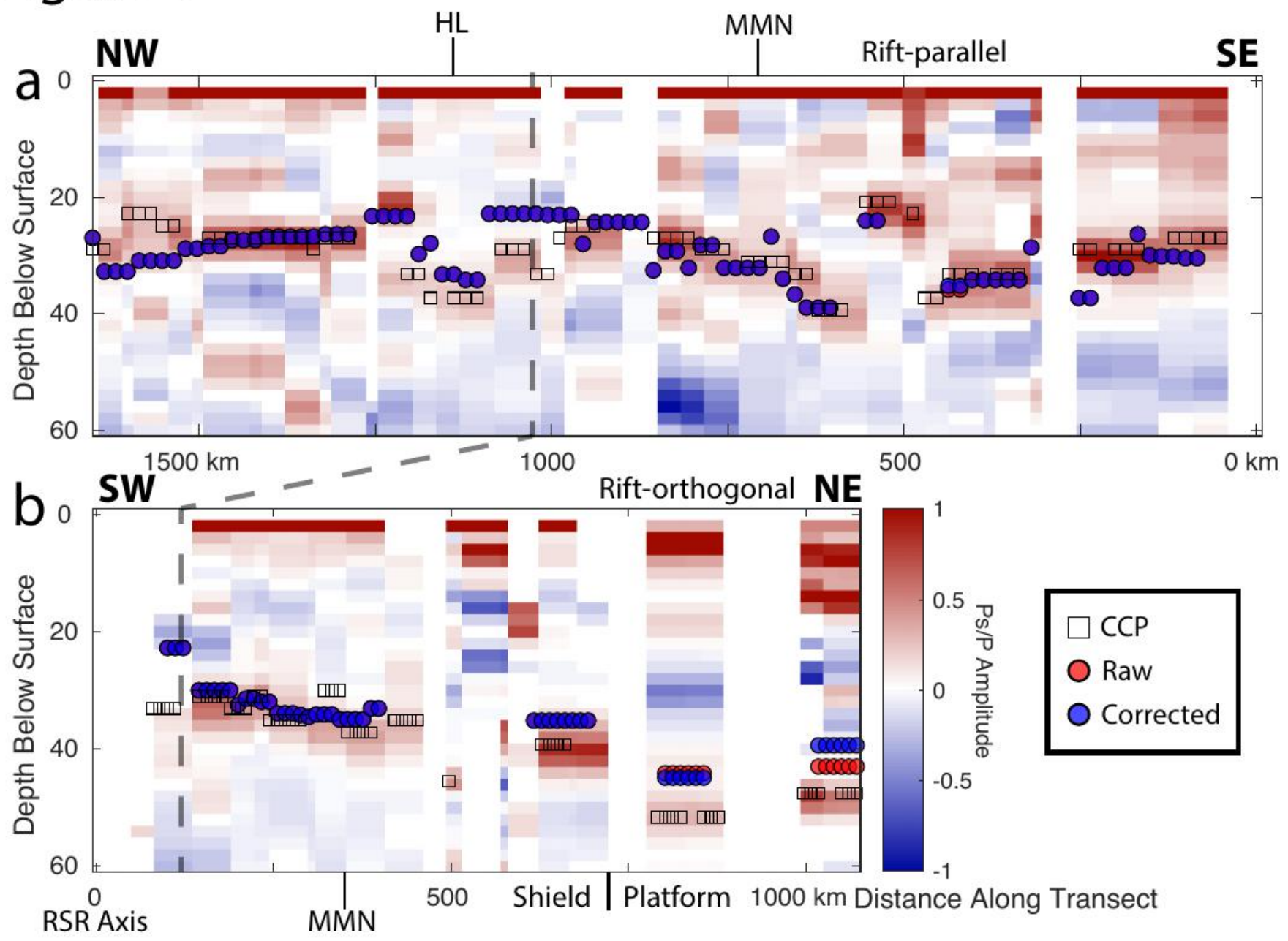

Figure 8. Common Conversion Point (CCP) cross-sections. a) Red Sea rift-"parallel” CCP stack, $0 \mathrm{~km}$ is at south end of line shown in Figure 1a. b) Red Sea-"orthogonal" CCP stack, distance axis same as in Figure $32 \mathrm{a}, 0 \mathrm{~km}$ is at the RSR axis. Open squares are crustal thickness inferred from CCP stacks. Red circles are raw crustal thickness values from H-k stacking (no sediment correction). Blue circles are corrected (preferred) crustal thickness values from H-k stacking. Dashed gray line marks the intersection of the two transects. Because different stations are projected onto the two profiles, different images and $\mathrm{H}-\mathrm{k}$ depths appear at the intersection. Amplitude color scale is calculated as for Figure 4, etc., but CCP conversion amplitudes are higher than shown for H-k averages (Figure $4 \mathrm{~b}$ ) because velocity corrections are applied for different ray parameters, and because multiple stations are summed.

In a 1D and isotropic Earth model, we expect the transverse component of the PRF to be composed purely of noise (Savage, 1998; Schulte-Pelkum and Mahan, 2014), so coherent transverse energy (fig. 10b and c) likely represents an obliquely dipping boundary beneath the station. It is possible that such a dipping structure and corresponding lateral velocity heterogeneity has defocused the $2 \mathrm{p} 2 \mathrm{~s}$ multiple (fig. 10a). Such considerations suggest a heuristic uncertainty of at least $\pm 1 \mathrm{~km}$ in Moho depth and \pm 0.05 in $\mathrm{V}_{\mathrm{p}} / \mathrm{V}_{\mathrm{s}}$ ratios. 


\section{Figure 9}

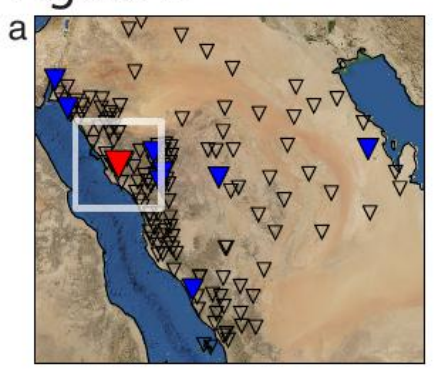

$1.0 / 0.0 / 0.0$

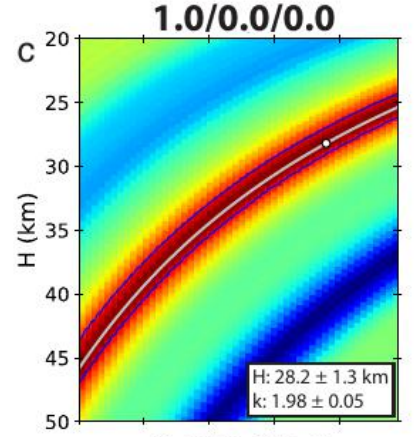

$0.0 / 0.0 / 1.0$

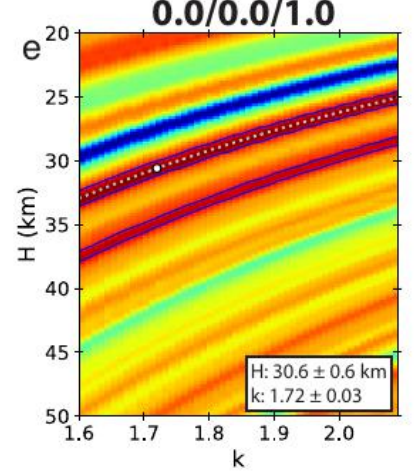

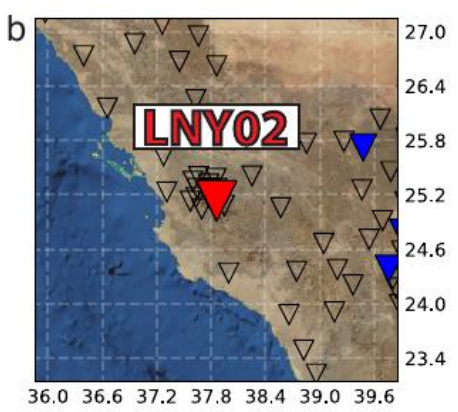

$0.0 / 1.0 / 0.0$

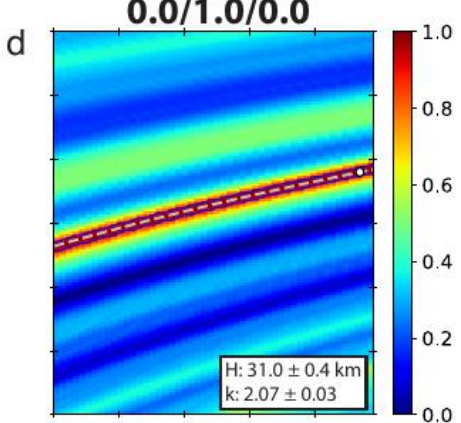

$0.5 / 0.5 / 0.0$

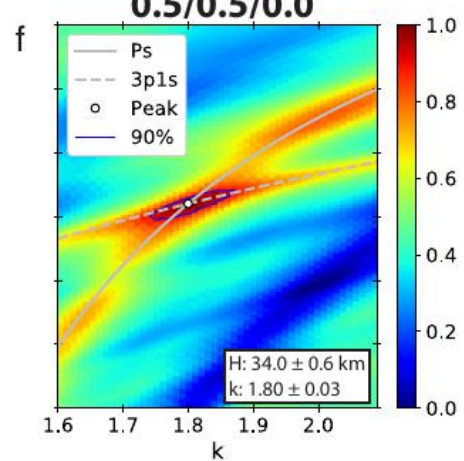

Figure 9. Receiver-function gather for station LNY02, presented as in Figure 4. Gray dashed-lines are theoretical moveout curves for phases generated through a mantle lid with $\mathrm{V}_{\mathrm{p}}=8.04 \mathrm{~km} \cdot \mathrm{s}^{-1}$ and $\mathrm{V}_{\mathrm{p}} / \mathrm{V}_{\mathrm{s}}$ ratio of 1.94 , that extends from 34.0 to $51.4 \mathrm{~km}$.

The coherent arrival between the Ps and $3 p 1 s$ phases $(6-7 \mathrm{~s})$ cannot be explained as a conversion or a multiple from the Moho; nor is it a sidelobe of the Moho $\mathrm{P}_{34 \mathrm{~S}}$, behind which it is delayed by $\geq 2 \mathrm{~s}$, clearly more than the central period of our data $(\mathrm{T} / 2<1.5 \mathrm{~s})$. The negative amplitude of this arrival is, however, consistent with a P-to-S conversion from a deeper, negative, velocity discontinuity with wavespeed decreasing downwards. We identify this arrival as the Ps conversion at the lithosphere-asthenosphere boundary LAB (Blanchette and others, 2018; this volume). The incoherence of the expected $2 \mathrm{p}_{34} 2 \mathrm{~s}$ phases is not due to superposition with the LAB-generated phases (fig. 10a). The seismic velocity contrast across the LAB is thought to be of smaller magnitude and spread over a wider vertical transition zone than the contrast across the Moho (Artemieva, 2011). These factors would yield a lower-frequency, lower-amplitude signal than the Moho conversion, the reason, we believe, we did not observe multiple arrivals from the LAB on this or any other station. Although this LAB arrival is evident on numerous stations, in this paper we reserve attention for the Moho.

There is one Harrat Lunayyir station, LNY06, for which H-k stacking is ambiguous. LNY06 is only 12 km from station LNY02 (fig. 11a), but has very 'ringy' data (many coherent phases, possibly multiple reflections from within or at the base of basalt flows) (fig. 12a), and shows two distinct peaks in H-k space (fig. 11f) at depths of $30.4 \pm 0.5 \mathrm{~km}$ and $34.4 \pm 0.5 \mathrm{~km}$. Although we would be unable to pick the correct Moho conversion from this station alone, the other 17 nearby stations over Harrat Lunayyir have $31.2<\mathrm{H}<37.4 \mathrm{~km}$, so that the most plausible result at station LNY02 for $\mathrm{H}$ is $34.4 \pm 0.5 \mathrm{~km}$, which we report here. 
Table 1. Harrat Lunayyir H-k stacking results.

\begin{tabular}{lccccccccc}
\hline Station & $\begin{array}{c}\text { Latitude } \\
\left({ }^{\circ} \mathbf{N}\right)\end{array}$ & $\begin{array}{c}\text { Longitude } \\
\left({ }^{\circ} \mathbf{E}\right)\end{array}$ & $\mathbf{w}_{\mathbf{1}}$ & $\mathbf{w}_{\mathbf{2}}$ & $\mathbf{w}_{\mathbf{3}}$ & $\mathbf{H}$ & $\mathbf{2 \sigma}_{\boldsymbol{H}}$ & $\mathbf{k}$ & $\mathbf{2 \sigma}_{\boldsymbol{k}}$ \\
\hline & & & & & & & & & \\
\hline LNY01 & 25.22 & 37.96 & 0.4 & 0.3 & 0.3 & 32.6 & 0.6 & 1.85 & 0.04 \\
LNY02 & 25.14 & 37.86 & 0.5 & 0.5 & 0.0 & 34.0 & 0.6 & 1.80 & 0.03 \\
LNY03 & 25.38 & 37.85 & 0.5 & 0.5 & 0.0 & 36.0 & 0.6 & 1.68 & 0.03 \\
LNY04 & 25.27 & 37.65 & 0.4 & 0.3 & 0.3 & 32.4 & 0.7 & 1.86 & 0.04 \\
LNY05 & 25.05 & 37.70 & 0.4 & 0.3 & 0.3 & 37.4 & 0.7 & 1.61 & 0.03 \\
LNY06 & 25.21 & 37.78 & 0.5 & 0.5 & 0.0 & 34.4 & 0.5 & 1.81 & 0.03 \\
LNY08 & 25.03 & 37.85 & 0.5 & 0.5 & 0.0 & 35.0 & 0.6 & 1.78 & 0.03 \\
LNY09 & 25.40 & 37.66 & 0.4 & 0.3 & 0.3 & 37.0 & 0.5 & 1.64 & 0.02 \\
LNY10 & 25.27 & 37.86 & 0.4 & 0.3 & 0.3 & 33.0 & 0.5 & 1.84 & 0.03 \\
LNY11 & 25.32 & 37.77 & 0.4 & 0.3 & 0.3 & 31.8 & 0.4 & 1.97 & 0.03 \\
LNY12 & 25.27 & 37.77 & 0.5 & 0.5 & 0.0 & 32.8 & 0.9 & 1.75 & 0.05 \\
LNY13 & 25.17 & 37.63 & 0.4 & 0.3 & 0.3 & 31.2 & 0.5 & 1.85 & 0.03 \\
LNY14 & 25.25 & 37.77 & 0.4 & 0.3 & 0.3 & 33.0 & 0.7 & 1.82 & 0.04 \\
LNY15 & 25.26 & 37.80 & 0.4 & 0.3 & 0.3 & 33.0 & 0.6 & 1.80 & 0.03 \\
LNY16 & 25.35 & 37.60 & 0.4 & 0.3 & 0.3 & 32.6 & 0.8 & 1.75 & 0.04 \\
LNY17 & 25.24 & 37.80 & 0.5 & 0.5 & 0.0 & 33.8 & 0.7 & 1.79 & 0.04 \\
LNYS & 25.08 & 37.94 & 0.5 & 0.5 & 0.0 & 35.2 & 0.7 & 1.76 & 0.04 \\
MURBA & 25.41 & 38.25 & 0.5 & 0.5 & 0.0 & 31.6 & 0.5 & 1.73 & 0.03 \\
TRAS & 25.06 & 38.57 & 0.4 & 0.3 & 0.3 & 35 & 0.7 & 1.62 & 0.03 \\
\hline
\end{tabular}

${ }^{*}$ See text for discussion of multiple peaks.

Figure 10

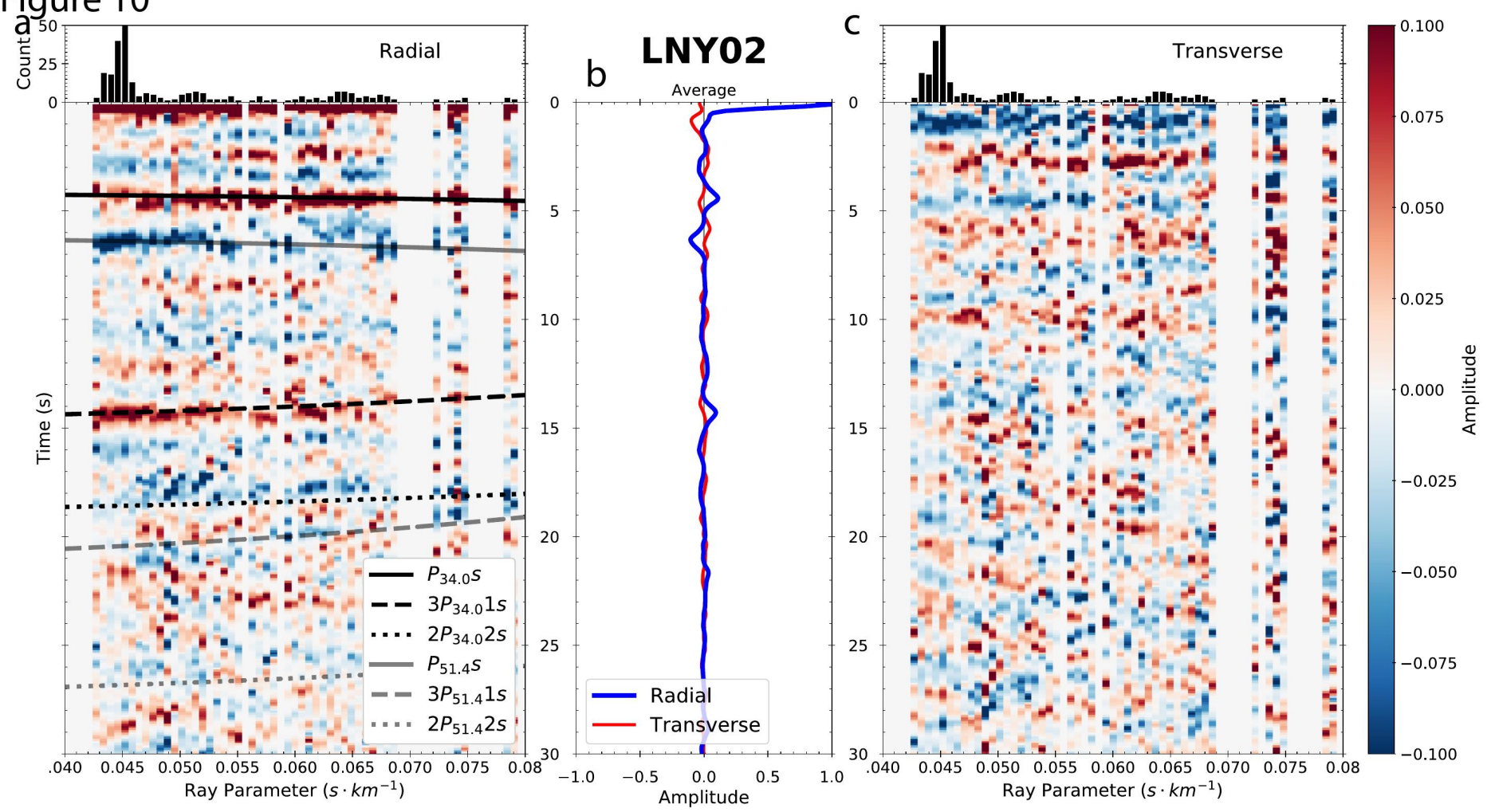

Figure 10. Receiver function analysis of station LNY02. Optimized stack weights are 0.5/0.5/0.0.

Presentation as in Figure 3.

LNY06 and LNY02 both appear to show a converter from the LAB but at delay times respectively of $\sim 6.25 \mathrm{~s}$ and $\sim 6.5 \mathrm{~s}$, suggesting variable LAB depth (figs. 10, 12). 

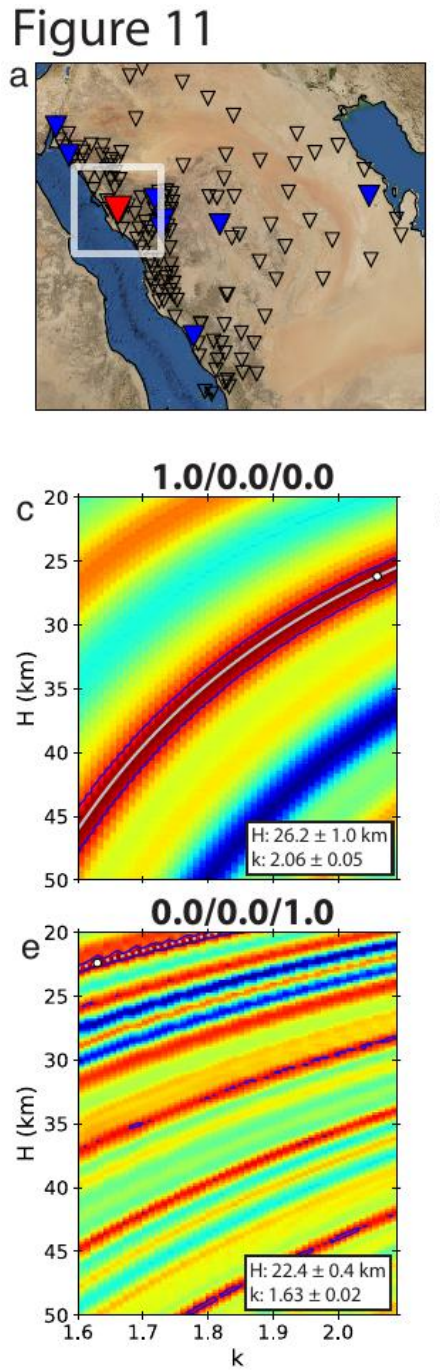

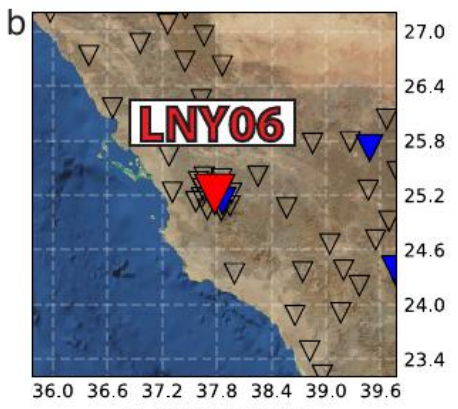

$0.0 / 1.0 / 0.0$

d

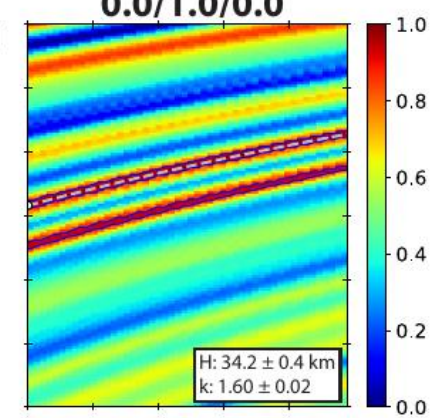

$0.5 / 0.5 / 0.0$

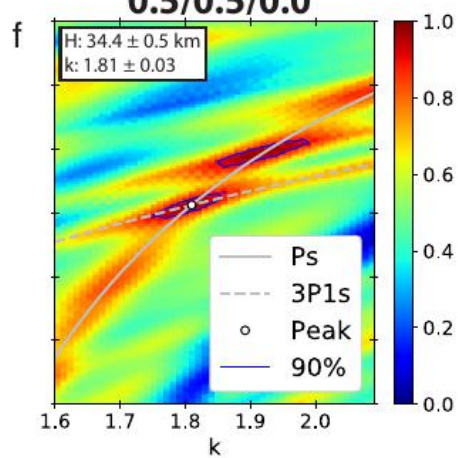

Figure 11. Receiver function analysis of station LNY06. Optimized stack weights are 0.5/0.5/0.0. Presentation as in Figure 3.

\section{Harrat Khaybar}

Harrat Khaybar is the northernmost harrat along the Makkah-Medina-Nafud (MMN) line (Camp and Roobol, 1992) (fig. 1) of alkalic volcanism that was emplaced since 12 Ma during the second stage of Red Sea rifting (Blanchette and others, 2018). Whereas prior to 2012 there was only one seismometer on the western edge of Harrat Khaybar (KBRS), there is now an array of 10 stations within Harrat Khaybar (fig. 1).

The seismometer KBR08, on the western edge of Harrat Khaybar (fig. 13a), has PRFs (fig. 14a) that share many similarities with the observations discussed for Harrat Lunayyir stations (fig. 12a). There is a coherent, positive-amplitude (red) Moho Ps phase at 4-5 s delay time, followed by a negative-polarity LAB Ps phase at $\sim 7 \mathrm{~s}$. The $3 \mathrm{p} 1 \mathrm{~s}$ phase is coherent and arrives between $\sim 14-15 \mathrm{~s}$. As for LNY02 there is a hint of 2p2s at $\sim 17-20 \mathrm{~s}$, but the 3-s time span and low amplitude suggest lateral wavespeed heterogeneity. Significant Moho dip is ruled out by the consistent phase of Ps at all back-azimuths (not shown; see Blanchette and others, 2021) (Schulte-Pelkum and Mahan, 2014).

These observations from the KBR08 receiver functions are consistent with its single-phase H-k stacks (fig. 13 c-e). The Ps stack (fig. 13c) and 3p1s stack (fig. 13d) are well resolved, but the 2p2s arrivals (fig. 13e) are too diffuse, spanning too broad a range of $\mathrm{H}$ to provide much sensitivity. We use $0.5 / 0.5 / 0.0$ to obtain $\mathrm{H}=$ $36.4 \pm 0.7 \mathrm{~km}$ and $\mathrm{k}=1.72 \pm 0.02$, identical within uncertainty to previous results $(35.1 \pm 0.6 \mathrm{~km}$ and $1.74 \pm$ 0.04) for station KBRS, which is just $23 \mathrm{~km}$ distant (Tang and others, 2016). Our own analysis for station $\mathrm{KBRS}$ results in $\mathrm{H}$ and $\mathrm{k}$ values of $38.2 \pm 0.5 \mathrm{~km}$ and $1.76 \pm 0.02$, emphasizing the distinction between formal 
and heuristic uncertainties. Results for all Harrat Khaybar stations are given in Table 2, with an average Moho depth of $35.5 \mathrm{~km}$ and crustal $\mathrm{k}$ of 1.75 .

Figure12

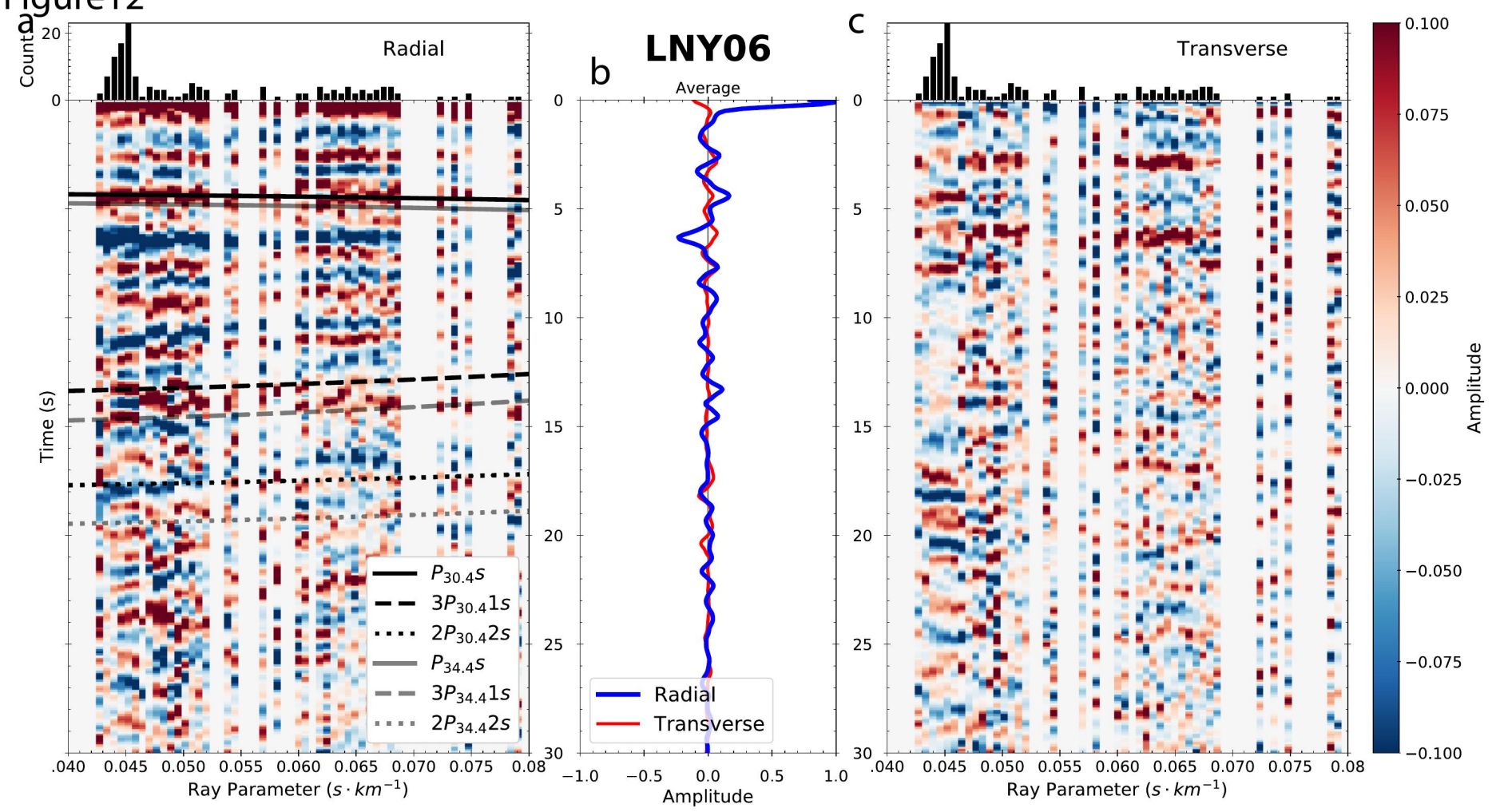

Figure 12. Receiver function gather for station LNY06. Presentation as in Figure 4.

Table 2. Harrat Khaybar H-k stacking results.

\begin{tabular}{lccccccccc}
\hline Station & $\begin{array}{c}\text { Latitude } \\
\left({ }^{\circ} \mathbf{N}\right)\end{array}$ & $\begin{array}{c}\text { Longitude } \\
\left({ }^{\circ} \mathbf{E}\right)\end{array}$ & $\mathbf{w}_{\mathbf{1}}$ & $\mathbf{w}_{\mathbf{2}}$ & $\mathbf{w}_{\mathbf{3}}$ & $\mathbf{H}$ & $\mathbf{2 \sigma}_{\boldsymbol{H}}$ & $\mathbf{k}$ & $\mathbf{2 \sigma}_{\boldsymbol{k}}$ \\
\hline & & & & & & & & & \\
\hline KBR01 & 25.46 & 39.78 & 0.4 & 0.3 & 0.3 & 36.2 & 0.7 & 1.74 & 0.04 \\
KBR02 & 25.23 & 40.24 & 0.4 & 0.3 & 0.3 & 35.8 & 0.5 & 1.78 & 0.02 \\
KBR03 & 25.82 & 39.95 & 0.4 & 0.3 & 0.3 & 36.2 & 0.5 & 1.76 & 0.02 \\
KBR04 & 25.98 & 40.28 & 0.5 & 0.5 & 0.0 & 34.0 & 0.4 & 1.77 & 0.02 \\
KBR05 & 25.57 & 40.31 & 0.5 & 0.5 & 0.0 & 34.0 & 0.5 & 1.79 & 0.04 \\
KBR06 & 26.11 & 40.03 & 0.5 & 0.5 & 0.0 & 34.6 & 0.5 & 1.76 & 0.03 \\
KBR07 & 25.26 & 39.46 & 0.5 & 0.5 & 0.0 & 35.0 & 0.5 & 1.75 & 0.02 \\
KBR08 & 25.72 & 39.48 & 0.5 & 0.5 & 0.0 & 36.4 & 0.5 & 1.72 & 0.02 \\
KBR09 & 26.03 & 39.67 & 0.4 & 0.3 & 0.3 & 36.6 & 0.6 & 1.70 & 0.02 \\
KBR10 & 25.13 & 39.94 & 0.5 & 0.5 & 0.0 & 35.0 & 0.7 & 1.77 & 0.02 \\
KBR13 & 25.77 & 38.85 & 0.5 & 0.5 & 0.0 & 34.0 & 0.5 & 1.75 & 0.02 \\
KBRS & 25.79 & 39.26 & 0.4 & 0.3 & 0.3 & 38.2 & 0.5 & 1.76 & 0.02 \\
\hline
\end{tabular}

\section{Harrat Rahat}

Northern Harrat Rahat last erupted in 1256 C.E. (Camp and others, 1987) and was the focus of the 2013-2017 cooperative SGS-USGS project to investigate volcano and seismic hazards to the City of Medina. There are 14 seismic stations within the densely instrumented northern portion of Harrat Rahat (fig. 1 and $15 \mathrm{~b}$ ). Three stations within this sub-network, RHT05, RHT06, and RHT13, are $>30 \mathrm{~km}$ ( one crustal thickness) from Cenozoic basalt flows (Pollastro, 1998a) and are here considered 'shield' stations; RHT16 and six other stations were installed in the southern portion of Harrat Rahat, the southern extent of the MMN line (fig. 1a), and are included here as "harrat" stations. 


\section{Figure 13}
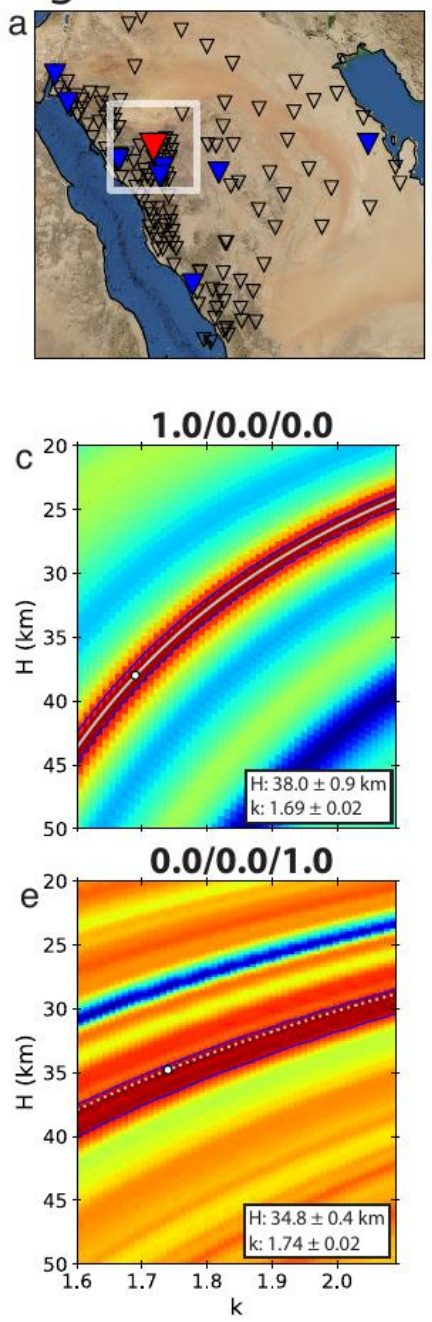

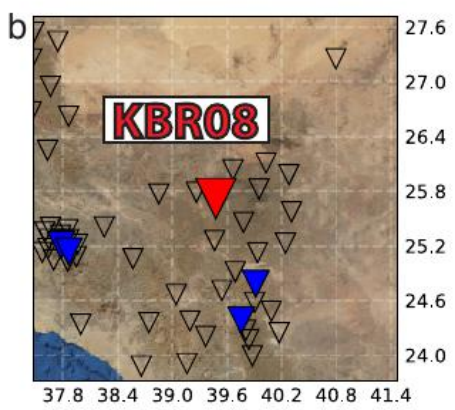

$0.0 / 1.0 / 0.0$
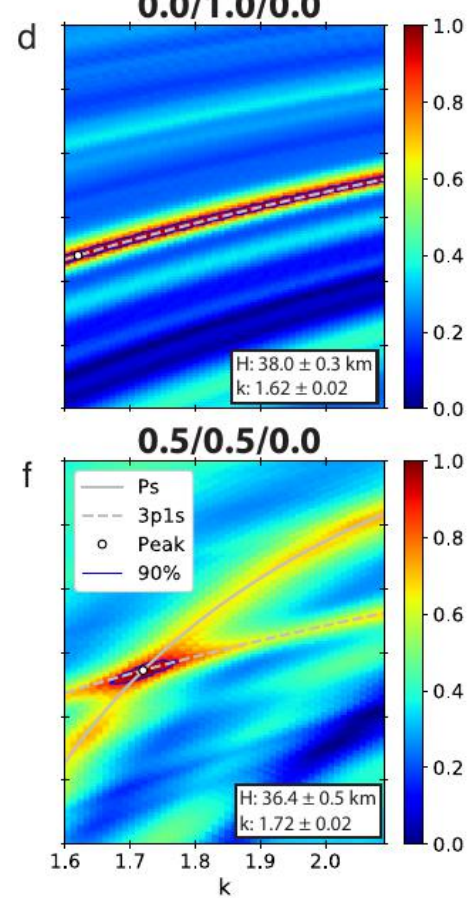

Figure 13. Receiver function analysis of station KBR08. Optimized stack weights are 0.5/0.5/0.0. Presentation as in Figure 3.

Station RHT09 is on lava flows north of Medina between Harrat Rahat and Harrat Khaybar (fig. 15a). The receiver functions at this station (fig. 16a) are as clear as those at KBR08. There is a broad, low-amplitude positive arrival between 0-2 seconds, with a moveout opposite to that expected from a shallow Ps conversion. This phase appears to have slightly smaller differential travel-times from events originating with a back-azimuth of $\sim 70-130^{\circ}$, unlike the Ps phase. The Moho Ps arrival and the $3 \mathrm{p} 1 \mathrm{~s}$ phase are both narrow and high-amplitude. The $2 \mathrm{p} 2 \mathrm{~s}$ arrivals are strongest at ray-parameters $(p) \leq 0.055 \mathrm{~s} . \mathrm{km}^{-1}$, likely due to our uneven earthquake source distribution (figs. 1b, 16a). These phases are consistent with the single-phase stacks (fig. $15 \mathrm{c}-$ e), and the stacking results are relatively insensitive to our choice of weights (fig. 15f). We chose to use $0.4 / 0.3 / 0.3$ as our stacking weights with resulting $\mathrm{H}$ and $\mathrm{k}$ of $35.0 \pm 0.6 \mathrm{~km}$ and $1.75 \pm 0.03$, essentially identical to those of Tang and others (2016) who obtained $\mathrm{H}$ of $35.1 \pm 0.4 \mathrm{~km}$ and a $\mathrm{V}_{\mathrm{p}} / \mathrm{V}_{\mathrm{s}}$ ratio of $1.74 \pm 0.02$.

Station RHT14 is located on the youngest lava flows close to Medina (fig. 17a). The P-wave receiver functions for this station are dominated by strong ringing that was not significantly reduced by the resonance filter (fig. 18a) but still contain useful information about the crust. There is a positive arrival of unknown origin following the direct P-wave by $<1 \mathrm{~s}$ : the 1256 C.E. lavas are $\leq 100 \mathrm{~m}$ thick (Downs and others, 2018), so would produce a signal delayed by only $\sim 0.02 \mathrm{~s}$, but these lavas obscure the deeper geology.

Like the direct P-wave, the Moho Ps (4-5 s) is also followed by complicated reverberations. There are weak and diffuse $3 \mathrm{p} 1 \mathrm{~s}$ and $2 \mathrm{p} 2 \mathrm{~s}$ arrivals that are better identified by their agreement with predicted arrival times than by their absolute amplitudes (fig. 18a). These $3 \mathrm{p} 1 \mathrm{~s}$ and $2 \mathrm{p} 2 \mathrm{~s}$ arrivals provide very streaky images in the single-phase H-k stacks (fig. 17c, d). Although the analytical uncertainty would be lower if we excluded the $2 \mathrm{p} 2 \mathrm{~s}$ arrivals from the H-k analysis, we chose $0.4 / 0.3 / 0.3$ stacking weights to incorporate the information in the $2 \mathrm{p} 2 \mathrm{~s}$ phase and obtained $\mathrm{H}$ and $\mathrm{k}$ values of $35.8 \pm 1.0 \mathrm{~km}$ and $1.76 \pm 0.03$, respectively. The H-k stacking 
results for the rest of the Harrat Rahat stations are listed in Table 3. The average Moho depth is $35.2 \mathrm{~km}$ and crustal $\mathrm{k}$ is 1.75 .

Figure14
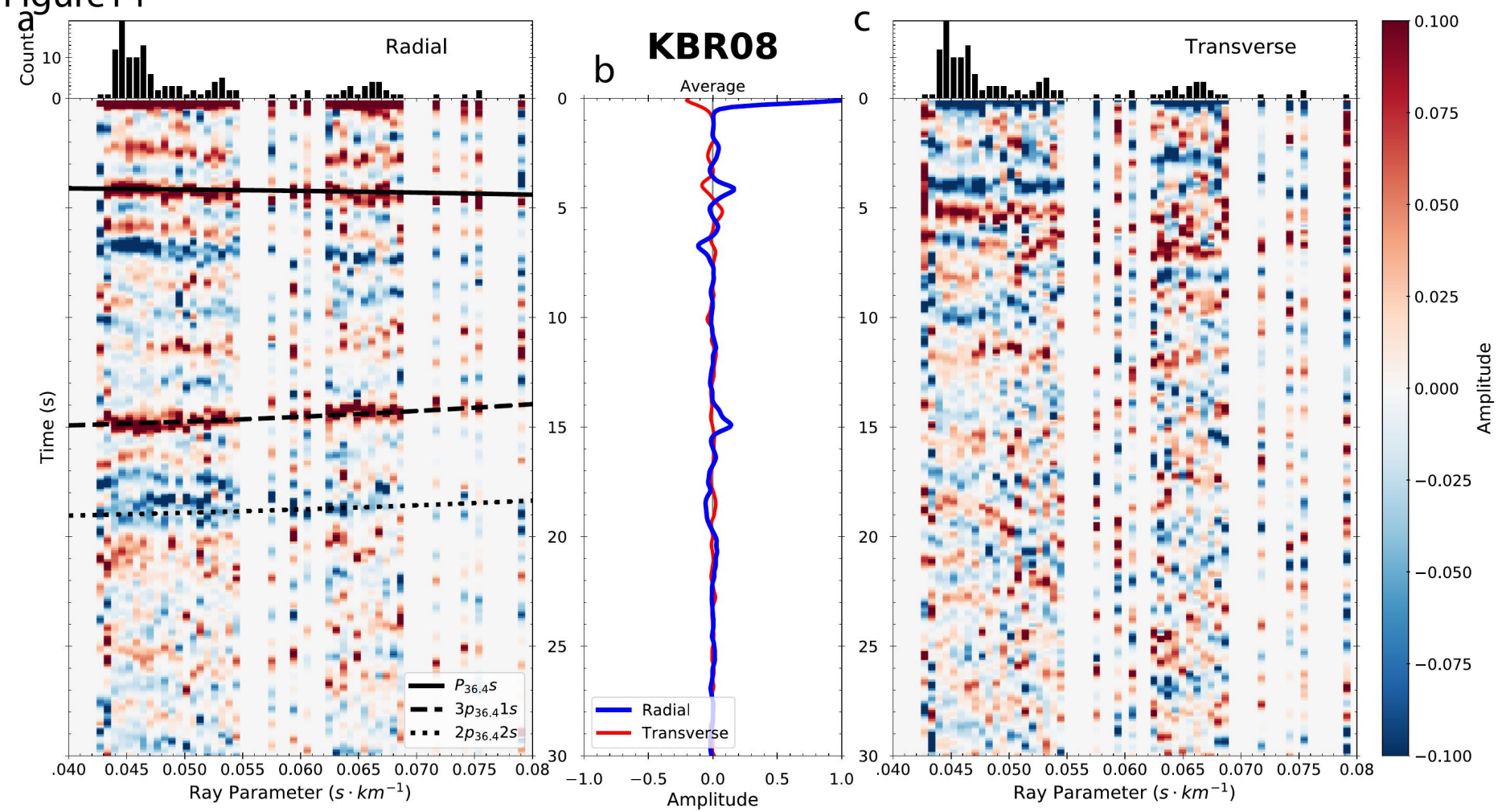

Figure 14. Receiver function gather for station KBR08. Presentation as in Figure 4.

Table 3. Harrat Rahat H-k stacking results.

\begin{tabular}{lccccccccc}
\hline Station & $\begin{array}{c}\text { Latitude } \\
\left({ }^{\circ} \mathbf{N}\right)\end{array}$ & $\begin{array}{c}\text { Longitude } \\
\left({ }^{\circ} \mathbf{E}\right)\end{array}$ & $\mathbf{w}_{\mathbf{1}}$ & $\mathbf{w}_{\mathbf{2}}$ & $\mathbf{w}_{\mathbf{3}}$ & $\mathbf{H}$ & $\mathbf{2 \sigma}_{\boldsymbol{H}}$ & $\mathbf{k}$ & $\mathbf{2 \sigma}_{\boldsymbol{k}}$ \\
\hline & & & & & & & & & \\
\hline FDAS & 21.83 & 40.36 & 0.4 & 0.3 & 0.3 & 36.8 & 0.7 & 1.68 & 0.03 \\
GHASH & 22.72 & 40.23 & 0.5 & 0.5 & 0.0 & 36.0 & 0.4 & 1.73 & 0.02 \\
HAJR & 22.90 & 39.67 & 0.5 & 0.5 & 0.0 & 36.0 & 0.5 & 1.68 & 0.03 \\
JURS & 21.87 & 39.80 & 0.4 & 0.3 & 0.3 & 33.0 & 0.6 & 1.73 & 0.03 \\
MDRK2 & 22.29 & 40.26 & 0.5 & 0.5 & 0.0 & 34.8 & 0.4 & 1.77 & 0.02 \\
MDRS & 22.09 & 40.00 & 0.4 & 0.3 & 0.3 & 36.2 & 0.4 & 1.68 & 0.02 \\
RHT01 & 24.27 & 39.81 & 0.5 & 0.5 & 0.0 & 34.4 & 0.5 & 1.86 & 0.03 \\
RHT02 & 24.48 & 40.09 & 0.4 & 0.3 & 0.3 & 34.8 & 0.5 & 1.77 & 0.03 \\
RHT03 & 24.25 & 40.17 & 0.4 & 0.3 & 0.3 & 35.8 & 0.8 & 1.73 & 0.03 \\
RHT04 & 23.99 & 39.88 & 0.4 & 0.3 & 0.3 & 35.4 & 0.6 & 1.77 & 0.03 \\
RHT07 & 24.67 & 39.04 & 0.4 & 0.3 & 0.3 & 32.4 & 0.6 & 1.71 & 0.02 \\
RHT08 & 24.71 & 39.54 & 0.4 & 0.3 & 0.3 & 34.8 & 0.5 & 1.76 & 0.03 \\
RHT09 & 24.78 & 39.91 & 0.4 & 0.3 & 0.3 & 35.0 & 0.6 & 1.75 & 0.03 \\
RHT10 & 24.58 & 39.90 & 0.4 & 0.3 & 0.3 & 34.6 & 0.5 & 1.78 & 0.02 \\
RHT11 & 24.92 & 39.69 & 0.5 & 0.5 & 0.0 & 35.4 & 0.5 & 1.73 & 0.03 \\
RHT14 & 24.39 & 39.76 & 0.4 & 0.3 & 0.3 & 35.8 & 1.0 & 1.76 & 0.03 \\
RHT15 & 24.17 & 39.84 & 0.4 & 0.3 & 0.3 & 35.4 & 0.4 & 1.80 & 0.02 \\
RHT16 & 23.47 & 40.17 & 0.4 & 0.3 & 0.3 & 36.4 & 0.4 & 1.74 & 0.02 \\
\hline
\end{tabular}

\section{Red Sea Rift}

A total of 29 SGS stations are within $250 \mathrm{~km}$ of the Red Sea rift axis and at elevations $\leq 400 \mathrm{~m}$ a.s.l. (fig. 1a). The Great Escarpment, a prominent topographic feature defining the Red Sea rift shoulder, is typically $\sim 100 \mathrm{~km}$ from the coast, and rises above 1,000 $\mathrm{m}$ in southern Saudi Arabia, becoming lower north of Jeddah 
and eventually indiscernible to the north (fig. 1b). We include these 29 stations as lying within the Red Sea rift, including two stations close to the Gulf of Aqaba/Dead Sea Transform, and two stations on Farasan Island.

Figure 15
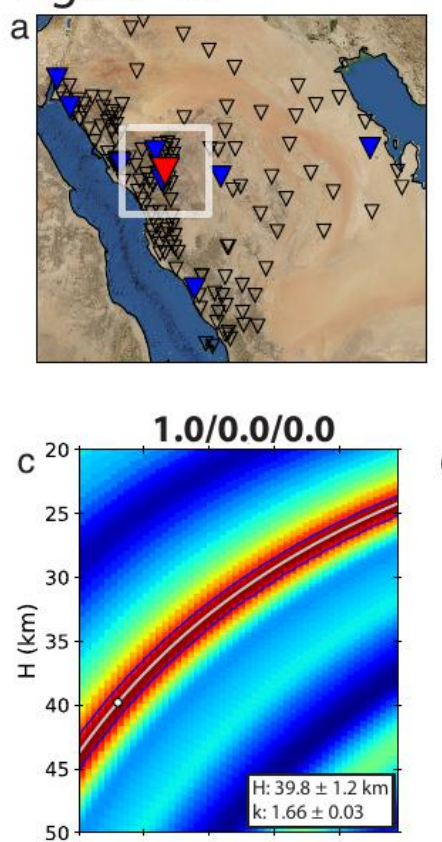

$0.0 / 0.0 / 1.0$

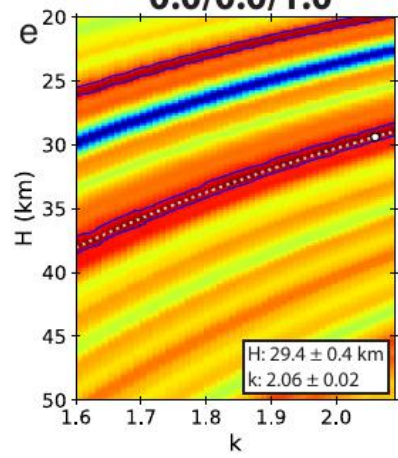

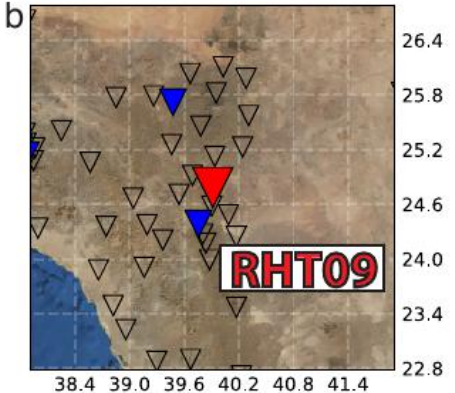

$0.0 / 1.0 / 0.0$

d

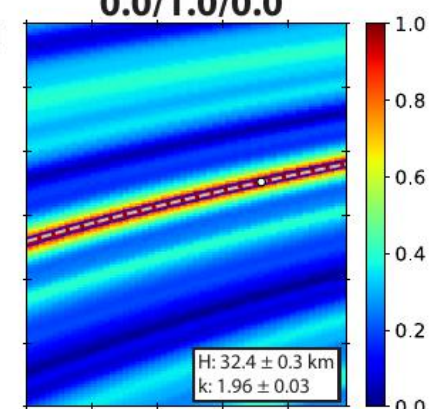

$0.4 / 0.3 / 0.3$

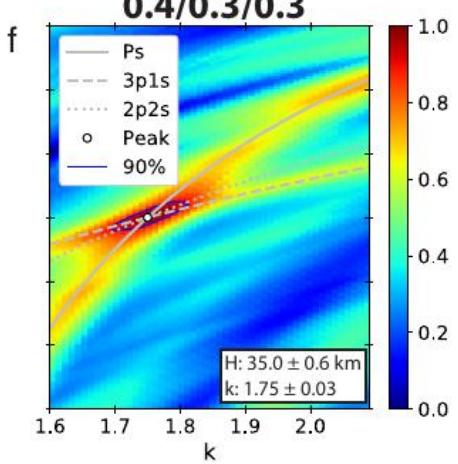

Figure 15. Receiver function analysis of station RHT09. Optimized stack weights are 0.4/0.3/0.3. Presentation as in Figure 3.

The two northernmost coastal stations lie on the Dead Sea Transform (DST), the $\sim 1,000$-km-long rightlateral strike-slip fault that stretches from the northern tip of the Red Sea to the East Anatolian Fault. The crust near the DST has been previously measured to be 32-37 km thick from wide-angle reflection/refraction experiments (El-Isa and others, 1987; DESERT Group, 2004; ten Brink and others, 2006; Mechie and others, 2009) and PRF analyses (Mohsen and others, 2005 and 2011). Because of the extensive previous work on this structure, we simply report results from the two SGS seismic stations $\sim 15$ and $50 \mathrm{~km}$ from the DST, HAQS, and BDAS (Tables 4 and 5). We show HAQS (Figs. 19, 20) as exemplary of these northernmost stations, even though we list it in Table 5, as a Shield station, due to its elevation of $450 \mathrm{~m}$. At station HAQS, we chose optimal weights of $0.4 / 0.3 / 0.3$ and obtain $\mathrm{H}$ and $\mathrm{k}$ values of $28.0 \pm 0.7 \mathrm{~km}$ and $1.77 \pm 0.03$, respectively.

Station QNF01 lies on the coast of the southern Red Sea rift margin (fig. 21a) and is one of the stations at which we were unable to obtain a reliable estimate of $\mathrm{H}$ and $\mathrm{k}$ via standard $\mathrm{H}-\mathrm{k}$ stacking, as both the $\mathrm{H}-\mathrm{k}$ plots (fig. 21c-e) and the PRFs (fig. 22) are noisy. Instead, we used PWS H-k stacking (fig. 21f) that requires consistency between the Ps (fig. 21a), 3p1s (fig. 21b), and 2p2s (fig. 21c) phases and yielded $\mathrm{H}=36.6 \pm 0.3 \mathrm{~km}$ and $\mathrm{k}=1.71 \pm 0.01$. Moveout curves for each of these phases are plotted in figure 22a and appear to match coherent signal in the PRFs, even though the resulting crustal thickness of $36.6 \mathrm{~km}$ indicates a surprising lack of crustal thinning here.

Tertiary sedimentary rocks are locally more than $4 \mathrm{~km}$ thick at the coast (e.g. Cole and others 1995), but most of the seismic stations are deployed on or close to crystalline basement and were not corrected for overlying sediments. The probable exceptions are QNF01 (fig. 21 and 22) in the Ghawwas sub-basin (for which phase-weighted stacking was required to achieve a solution), which we corrected for an assumed 1-km 
sedimentary thickness (Hughes and Johnson, 2005), and the Farasan Island stations (FRSS and FRSS2), which we corrected for $0.6 \mathrm{~km}$ of sedimentary rocks (Almalki and Bantan, 2016). Table 4 gives H-k results for all the 'rift' or 'coastal' stations.

Figure16

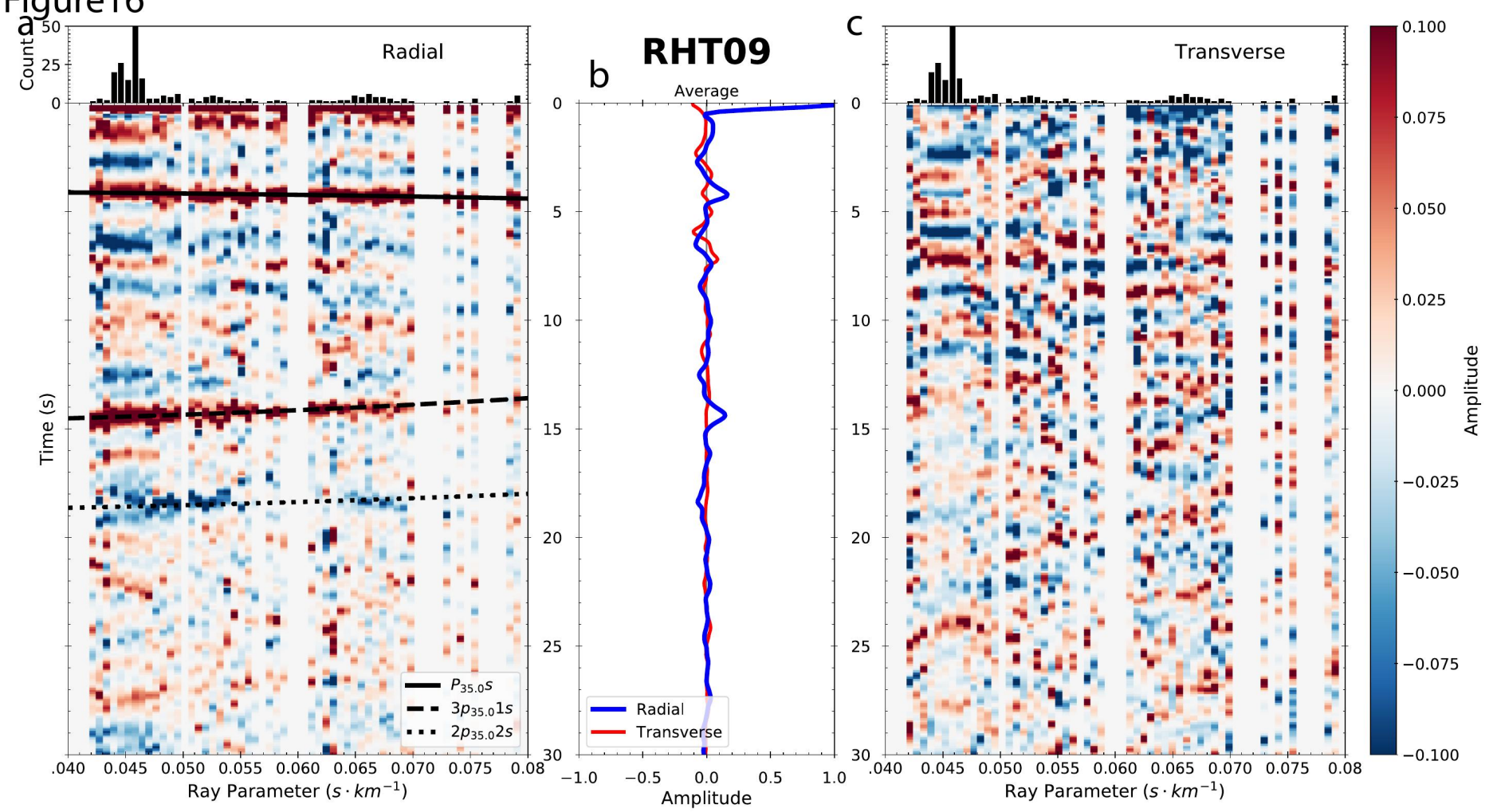

Figure 16. Receiver function gather for station RTH09. Presentation as in Figure 4.

\section{Shield}

Station AFFS (fig. 3a) lies just west of the boundary between the Arabian shield and platform and is installed on crystalline basement. The clear Moho Ps at 4-5 s (fig. 4a) resembles the harrat stations (e.g. LNY02, KBR08, and RHT09; figs. 8, 12, and 16). The transverse component of the PRF for this station is as clear as the radial component on the amplitude-normalized sections (fig. 4b), perhaps due to dipping structure at the Moho. H-k stacking results for all the shield stations are listed in Table 5.

\section{Platform}

Platform stations have predictably worse data quality than shield stations (due to higher noise levels compared to stations on hard rock), with only $12 \%$ of shield stations (but $\sim 25 \%$ of platform stations) not producing an acceptable H-k result (fig. 1b). Data quality typically worsens, and the number of acceptable PRFs decreases, as the sedimentary thickness increases to the east and intra-sedimentary reverberations become stronger (fig. 1b). We show one example of a station (BOQS) near the Arabian Gulf (fig. 23a) for which resonance removal was required.

The raw H-k stacks (fig. $23 \mathrm{c}$ and d) are multi-peaked and dominated by the two possible Ps arrival peaks at $\sim 5$ and $\sim 6 \mathrm{~s}$ (fig. 24 ), with $\mathrm{H}-\mathrm{k}$ maxima at $\sim 44 \mathrm{~km}$ (earlier and higher-amplitude $\sim 6 \mathrm{~s}$ peak $\left(\mathrm{P}_{43.8} \mathrm{~s}\right.$, fig. $24 \mathrm{c}$ ), and $\sim 47 \mathrm{~km}$ (lower-amplitude, $\sim 5 \mathrm{~s}$ peak, $\mathrm{P}_{47.2 \mathrm{~S}}$ highlighted in fig. $24 \mathrm{c}$ ). Resonance removal (fig. 23e) successfully merges the two bands of high likelihood at $\sim 38$ and $\sim 48 \mathrm{~km}$ (fig. $23 \mathrm{c}$ and d) into a single focus typical of H-k stacks lacking sedimentary effects (e.g. fig. 13f). In fig. 24, we show the filtered (fig. 24a) and unfiltered (fig. 24c) data and moveout curves for different H-k stacking results. Our preferred Moho depth of $40.5 \mathrm{~km}$ is interpreted as the sub-sedimentary crustal thickness, assuming a constant $\mathrm{V}_{\mathrm{p}}$ of $6.5 \mathrm{~km} . \mathrm{s}^{-1}$. The sedimentary H-k stack (fig. 23f) is less well constrained, with implied sedimentary thickness $\mathrm{h}_{\mathrm{s}} \sim 1.5-3.0 \mathrm{~km}$ and $\mathrm{k} \sim 3-5$. These values of $\mathrm{k}$ suggest $\mathrm{V}_{\mathrm{p}}<2 \mathrm{~km} \cdot \mathrm{s}^{-1}$ based on global compilations (fig. 7) but $\mathrm{V}_{\mathrm{p}}$ is likely higher given the sedimentary H-k stack was made assuming the basin-wide average $V_{p}=4 \mathrm{~km}^{-1}{ }^{-1}$. Clearly the 
strong Ps conversion at $1.5 \mathrm{~s}$ (fig. 24) is from a very shallow converter, far shallower than the $\sim 7-\mathrm{km}$ Phanerozoic sedimentary thickness known in this area (fig. 1b). This example illustrates the need to correct our raw crustal thicknesses for the entire Phanerozoic basin thicknesses taken from Stern and Johnson (2010) (fig. 1b). H-k stacking results for all platform stations are given in Table 6 below.

Figure 17
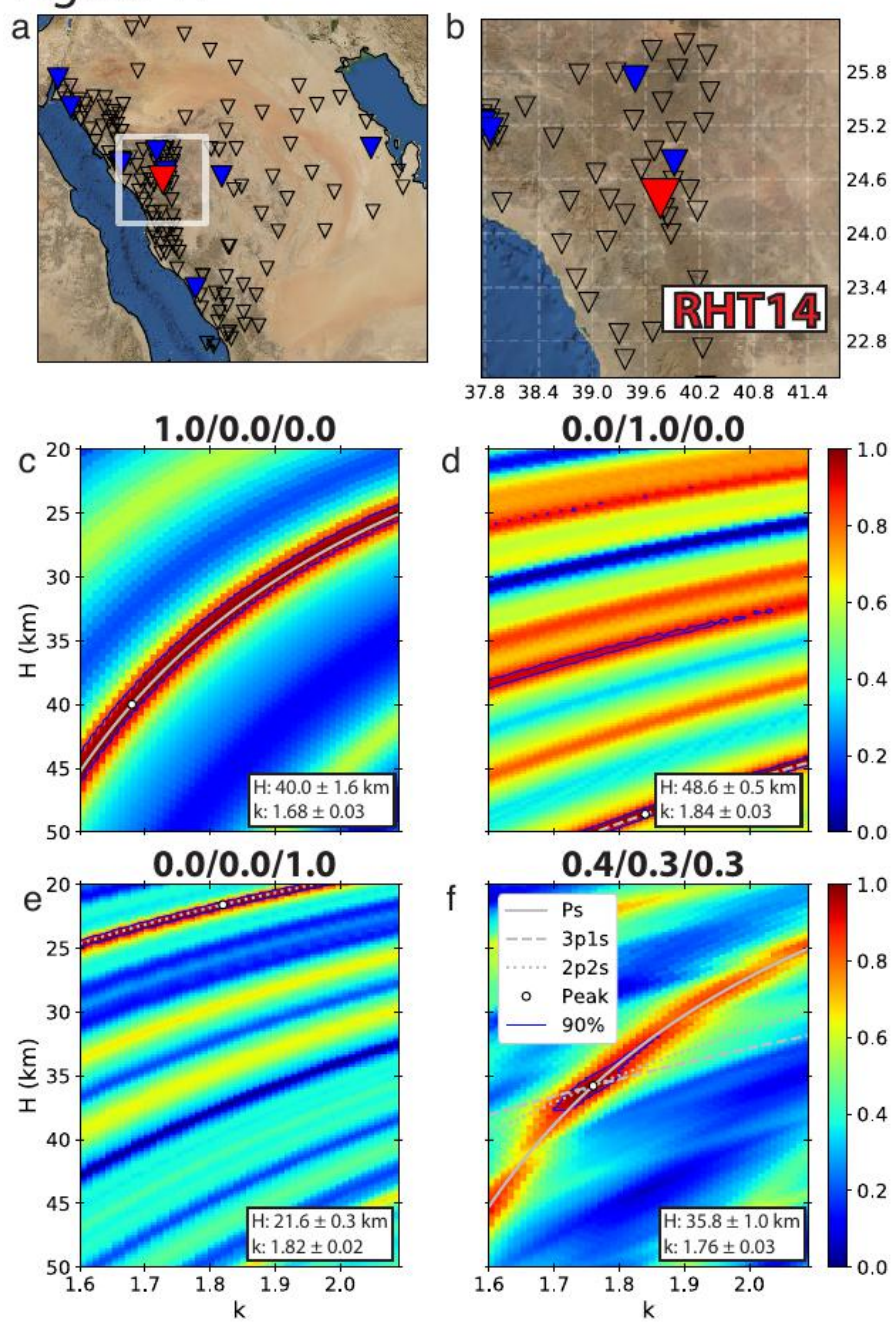

$0.0 / 1.0 / 0.0$

d

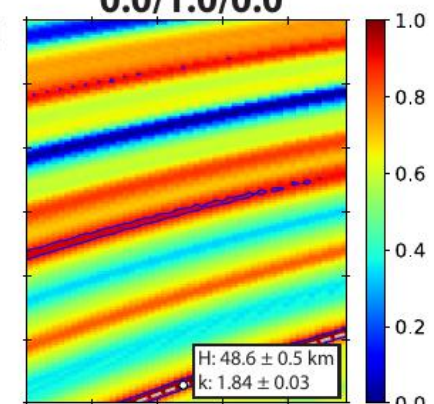

$0.4 / 0.3 / 0.3$

$f$

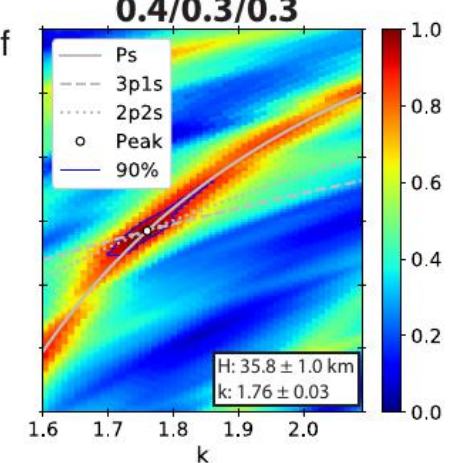

Figure 17. Receiver function analysis of station RHT14. Optimized stack weights are 0.4/0.3/0.3. Presentation as in Figure 3.

\section{Discussion}

\section{Regional Averages}

Our H-k stacking results (fig. 25a \& b) show that crustal thickness of the Arabian plate is least near the coast of the Red Sea and increases away from the rifted margin, as expected. The average total thickness of the crust across the entire array is $34.9 \pm 4.7 \mathrm{~km}(1 \sigma$ uncertainty). The average total thicknesses of the rift-margin (coastal), shield, and platform crust $(29.1 \pm 4.1 \mathrm{~km}, 36.6 \pm 4.8 \mathrm{~km}$, and $38.4 \pm 3.4 \mathrm{~km}$, respectively) are all close to the global averages for these crustal types $(30.5 \pm 6.0 \mathrm{~km}, 40.8 \pm 7.0 \mathrm{~km}$, and $39.0 \pm 7.0 \mathrm{~km}$, respectively) (Mooney and others, 1998). Analytic errors underestimate the uncertainty in the value for the Arabian platform because of the inability of the sedimentary H-k stacking to obtain true sedimentary thicknesses and the necessity to assume an a priori sedimentary $\mathrm{V}_{\mathrm{p}}$ when making corrections for sedimentary thickness (as discussed in our methods section). The average total crustal thickness of the harrats is $34.7 \pm 1.6 \mathrm{~km}$. 
Table 4. Red Sea coastal plain H-k stacking results, organized north to south.

\begin{tabular}{|c|c|c|c|c|c|c|c|c|c|c|}
\hline Station & $\begin{array}{l}\text { Latitude } \\
\quad\left({ }^{\circ} \mathbf{N}\right)\end{array}$ & $\begin{array}{c}\text { Longitude } \\
\left({ }^{\circ} \mathbf{E}\right)\end{array}$ & $\mathbf{W}_{1}$ & $\mathbf{W}_{2}$ & $\mathbf{W}_{3}$ & $\mathbf{H}$ & $2 \sigma_{H}$ & $\mathbf{k}$ & $2 \sigma_{k}$ & $\begin{array}{c}\text { Corrected } \\
\text { Thickness } \\
(\mathrm{km})\end{array}$ \\
\hline BDAS & 28.43 & 35.09 & 0.5 & 0.5 & 0.0 & 33.6 & 0.5 & 1.64 & 0.03 & \\
\hline KRABS & 28.10 & 35.26 & 0.5 & 0.5 & 0.0 & 31.8 & 0.6 & 1.6 & 0.05 & \\
\hline MWLHS & 27.75 & 35.52 & 0.5 & 0.5 & 0.0 & 29.8 & 0.3 & 1.71 & 0.02 & \\
\hline NDEBA & 27.47 & 35.65 & 0.5 & 0.5 & 0.0 & 29.4 & 0.7 & 1.71 & 0.03 & \\
\hline DBAS & 27.21 & 35.97 & 0.5 & 0.5 & 0.0 & 28.4 & 0.8 & 1.71 & 0.03 & \\
\hline WJHS & 26.73 & 36.39 & 0.5 & 0.5 & 0.0 & 27.8 & 0.9 & 1.72 & 0.04 & \\
\hline EWJHS & 26.16 & 36.66 & 0.4 & 0.3 & 0.3 & 27.4 & 0.6 & 1.73 & 0.03 & \\
\hline UMJS & 25.23 & 37.31 & 0.4 & 0.3 & 0.3 & 25.4 & 0.5 & 1.63 & 0.02 & \\
\hline LNY07 & 25.13 & 37.57 & 0.4 & 0.3 & 0.3 & 32.4 & 0.5 & 1.77 & 0.03 & \\
\hline YOBS & 24.36 & 38.74 & 0.4 & 0.3 & 0.3 & 31.0 & 0.6 & 1.75 & 0.03 & \\
\hline YNBS & 24.34 & 37.99 & 0.4 & 0.3 & 0.3 & 24.0 & 0.7 & 1.94 & 0.04 & \\
\hline NSAFS & 23.49 & 38.82 & 0.4 & 0.3 & 0.3 & 29.0 & 0.7 & 1.67 & 0.03 & \\
\hline FRJS & 22.59 & 39.36 & 0.4 & 0.3 & 0.3 & 30.2 & 1.0 & 1.66 & 0.05 & \\
\hline KHLS2 & 22.26 & 39.52 & 0.4 & 0.3 & 0.3 & 33.0 & 0.4 & 1.72 & 0.02 & \\
\hline KHLS & 22.05 & 39.30 & 0.4 & 0.3 & 0.3 & 25.4 & 0.6 & 1.86 & 0.04 & \\
\hline JEDS & 21.72 & 39.42 & 0.5 & 0.5 & 0.0 & 27.6 & 0.6 & 1.64 & 0.04 & \\
\hline SHMS & 21.45 & 39.69 & 0.4 & 0.3 & 0.3 & 27.8 & 0.6 & 1.77 & 0.03 & \\
\hline LBNS & 21.05 & 39.90 & 0.5 & 0.5 & 0.0 & 31.0 & 0.6 & 1.78 & 0.03 & \\
\hline SHBS & 21.00 & 39.68 & 0.4 & 0.3 & 0.3 & 27.2 & 0.5 & 1.76 & 0.03 & \\
\hline \multirow[t]{2}{*}{ LTHS $^{1}$} & 20.28 & 40.41 & 0.4 & 0.3 & 0.3 & 23.6 & 0.4 & 1.68 & 0.05 & 25.2 \\
\hline & & & 0.05 & 0.70 & 0.25 & 1.55 & 0.10 & 1.50 & 0.40 & \\
\hline QNF012 & 19.39 & 41.28 & $1 / 3$ & $1 / 3$ & $1 / 3$ & 36.6 & 0.3 & 1.71 & 0.01 & 36.0 \\
\hline $\mathrm{QNF}^{2} 2^{2}$ & 19.06 & 41.49 & $1 / 3$ & $1 / 3$ & $1 / 3$ & 35.0 & 0.4 & 1.70 & 0.01 & \\
\hline AMGES $^{2}$ & 18.46 & 41.54 & $1 / 3$ & $1 / 3$ & $1 / 3$ & 29.6 & 0.2 & 1.94 & 0.01 & \\
\hline DRBS & 17.83 & 42.30 & 0.4 & 0.4 & 0.3 & 33.0 & 0.6 & 1.67 & 0.02 & \\
\hline BESHS & 17.37 & 42.84 & 0.4 & 0.3 & 0.3 & 34.4 & 0.7 & 1.71 & 0.02 & \\
\hline AKWA & 17.26 & 42.70 & 0.5 & 0.5 & 0.0 & 27.4 & 0.7 & 1.69 & 0.03 & \\
\hline JAZS & 17.07 & 42.92 & 0.4 & 0.3 & 0.3 & 31.4 & 1.2 & 1.64 & 0.04 & \\
\hline KRABS & 28.10 & 35.26 & 0.5 & 0.5 & 0.0 & 31.8 & 0.6 & 1.60 & 0.05 & \\
\hline FRSS2 & 16.85 & 41.79 & 0.5 & 0.5 & 0.0 & 25.4 & 0.5 & 1.97 & 0.03 & 25.0 \\
\hline FRSS $^{2}$ & 16.74 & 42.11 & $1 / 3$ & $1 / 3$ & $1 / 3$ & 16.0 & 0.3 & 1.77 & 0.03 & 15.6 \\
\hline
\end{tabular}

Stations are listed from north to south.

${ }^{1}$ Top values are sub-sedimentary crustal H-k, bottom values are sedimentary H-k obtained with the resonance-removal method.

${ }^{2}$ PWS H-k stacked. 
Table 5. H-k stacking results for the shield

\begin{tabular}{|c|c|c|c|c|c|c|c|c|c|}
\hline Station & $\begin{array}{c}\text { Latitude } \\
\left({ }^{\circ} \mathbf{N}\right)\end{array}$ & $\begin{array}{c}\text { Longitude } \\
\left({ }^{\circ} \mathbf{E}\right)\end{array}$ & $\mathbf{w}_{1}$ & $\mathbf{w}_{2}$ & $\mathbf{w}_{3}$ & $\mathbf{H}$ & $2 \sigma_{H}$ & $\mathbf{K}$ & $2 \sigma_{k}$ \\
\hline HAQS & 29.06 & 34.93 & 0.4 & 0.3 & 0.3 & 28.0 & 0.7 & 1.77 & 0.03 \\
\hline JLOS & 28.74 & 35.49 & 0.4 & 0.3 & 0.3 & 31.4 & 0.4 & 1.62 & 0.02 \\
\hline WTBKS & 28.08 & 35.91 & 0.5 & 0.5 & 0.0 & 32.4 & 0.5 & 1.93 & 0.03 \\
\hline SHQRE & 27.90 & 36.17 & 0.5 & 0.5 & 0.0 & 31.2 & 0.6 & 1.83 & 0.03 \\
\hline HIL04 & 27.76 & 42.76 & 0.4 & 0.3 & 0.3 & 39.0 & 0.6 & 1.79 & 0.02 \\
\hline DESA $^{2}$ & 27.51 & 36.16 & $1 / 3$ & $1 / 3$ & $1 / 3$ & 29.0 & 0.2 & 1.90 & 0.01 \\
\hline HIL03 & 27.25 & 40.80 & 0.4 & 0.3 & 0.3 & 36.2 & 0.7 & 1.77 & 0.02 \\
\hline URD04 & 27.08 & 37.26 & 0.4 & 0.3 & 0.3 & 36.8 & 0.6 & 1.73 & 0.02 \\
\hline URD01 & 26.95 & 37.66 & 0.4 & 0.3 & 0.3 & 38.2 & 0.5 & 1.75 & 0.02 \\
\hline BIDS & 26.87 & 36.96 & 0.4 & 0.3 & 0.3 & 35.6 & 0.6 & 1.72 & 0.03 \\
\hline QSMS & 26.67 & 42.69 & 0.5 & 0.5 & 0.0 & 36.0 & 0.7 & 1.80 & 0.02 \\
\hline URD03 & 26.67 & 37.45 & 0.4 & 0.3 & 0.3 & 36.8 & 0.8 & 1.74 & 0.03 \\
\hline URD02 & 26.62 & 37.86 & 0.5 & 0.5 & 0.0 & 37.8 & 0.9 & 1.69 & 0.03 \\
\hline OLAS & 26.25 & 37.63 & 0.5 & 0.5 & 0.0 & 36.2 & 0.5 & 1.73 & 0.03 \\
\hline HIL01 & 25.83 & 41.99 & 0.4 & 0.3 & 0.3 & 36.0 & 0.7 & 1.73 & 0.02 \\
\hline ARSS & 25.83 & 43.15 & 0.4 & 0.3 & 0.3 & 38.8 & 0.5 & 1.74 & 0.02 \\
\hline UQSK & 25.79 & 42.36 & 0.4 & 0.3 & 0.3 & 36.8 & 0.4 & 1.75 & 0.02 \\
\hline NUMJS & 25.63 & 37.27 & 0.4 & 0.3 & 0.3 & 24.4 & 0.4 & 1.80 & 0.02 \\
\hline AFFS & 24.56 & 42.48 & 0.4 & 0.3 & 0.3 & 35.2 & 0.4 & 1.75 & 0.02 \\
\hline DWDS & 24.54 & 44.84 & 0.4 & 0.3 & 0.3 & 42.8 & 0.6 & 1.74 & 0.03 \\
\hline RHT06 & 24.38 & 39.19 & 0.4 & 0.3 & 0.3 & 33.4 & 0.6 & 1.71 & 0.04 \\
\hline RHT13 & 24.21 & 39.37 & 0.5 & 0.5 & 0.0 & 36.2 & 0.6 & 1.71 & 0.03 \\
\hline BJDH & 24.09 & 43.40 & 0.5 & 0.5 & 0.0 & 35.6 & 0.6 & 1.75 & 0.02 \\
\hline AFIF & 23.93 & 43.04 & 0.4 & 0.3 & 0.3 & 36.8 & 0.6 & 1.72 & 0.02 \\
\hline RHT05 & 23.91 & 39.16 & 0.4 & 0.3 & 0.3 & 35.6 & 0.8 & 1.71 & 0.03 \\
\hline $\mathrm{BADR}^{2}$ & 23.88 & 36.66 & $1 / 3$ & $1 / 3$ & $1 / 3$ & 24.2 & 0.3 & 1.80 & 0.02 \\
\hline RAYN & 23.52 & 45.50 & 0.5 & 0.5 & 0.0 & 39.8 & 0.6 & 1.77 & 0.02 \\
\hline MSTR & 23.23 & 39.00 & 0.5 & 0.5 & 0.0 & 25.4 & 0.4 & 1.90 & 0.03 \\
\hline NUBA & 22.88 & 39.30 & 0.5 & 0.5 & 0.0 & 33.4 & 0.5 & 1.71 & 0.02 \\
\hline HALM & 22.85 & 44.32 & 0.4 & 0.3 & 0.3 & 36.4 & 0.4 & 1.75 & 0.02 \\
\hline HRML & 22.01 & 45.09 & 0.4 & 0.3 & 0.3 & 41.6 & 0.3 & 1.76 & 0.01 \\
\hline SHRS & 21.50 & 40.20 & 0.4 & 0.3 & 0.3 & 34.8 & 0.4 & 1.72 & 0.02 \\
\hline RYNS & 21.32 & 42.85 & 0.5 & 0.5 & 0.0 & 37.0 & 0.4 & 1.74 & 0.02 \\
\hline RANI & 21.31 & 42.78 & 0.4 & 0.3 & 0.3 & 38.6 & 0.7 & 1.70 & 0.02 \\
\hline TAIF & 21.28 & 40.35 & 0.4 & 0.3 & 0.3 & 37.4 & 0.4 & 1.76 & 0.02 \\
\hline FRAS & 21.06 & 40.52 & 0.4 & 0.3 & 0.3 & 39.6 & 0.7 & 1.72 & 0.03 \\
\hline KAMS & 20.30 & 44.57 & 0.4 & 0.3 & 0.3 & 39.2 & 0.4 & 1.78 & 0.01 \\
\hline BAHS & 19.97 & 41.60 & 0.4 & 0.3 & 0.3 & 38.0 & 0.6 & 1.73 & 0.03 \\
\hline BLJS & 19.96 & 41.61 & 0.4 & 0.3 & 0.3 & 38.0 & 0.6 & 1.73 & 0.02 \\
\hline BISH & 19.92 & 42.69 & 0.5 & 0.5 & 0.0 & 36.4 & 0.4 & 1.83 & 0.02 \\
\hline TATS & 19.54 & 43.48 & 0.4 & 0.3 & 0.3 & 39.0 & 0.7 & 1.83 & 0.03 \\
\hline NAMS & 19.17 & 42.20 & 0.4 & 0.3 & 0.3 & 41.6 & 0.5 & 1.71 & 0.02 \\
\hline RHWAS & 19.07 & 44.07 & 0.5 & 0.5 & 0.0 & 38.4 & 0.7 & 1.80 & 0.02 \\
\hline ENMS & 19.07 & 42.57 & 0.4 & 0.3 & 0.3 & 42.8 & 0.6 & 1.70 & 0.02 \\
\hline WBHS & 18.61 & 42.72 & 0.4 & 0.3 & 0.3 & 41.2 & 0.5 & 1.74 & 0.02 \\
\hline KNGHS & 18.29 & 43.50 & 0.5 & 0.5 & 0.0 & 45.4 & 0.6 & 1.76 & 0.02 \\
\hline SODA & 18.29 & 42.38 & 0.4 & 0.3 & 0.3 & 38.0 & 0.6 & 1.74 & 0.02 \\
\hline DJNS & 17.70 & 43.54 & 0.4 & 0.3 & 0.3 & 47.6 & 0.6 & 1.66 & 0.02 \\
\hline NJRNS & 17.65 & 44.19 & 0.4 & 0.3 & 0.3 & 41.2 & 0.5 & 1.82 & 0.02 \\
\hline
\end{tabular}

Stations are listed from north to south.

${ }^{2}$ PWS H-k stacked. 
Figure18

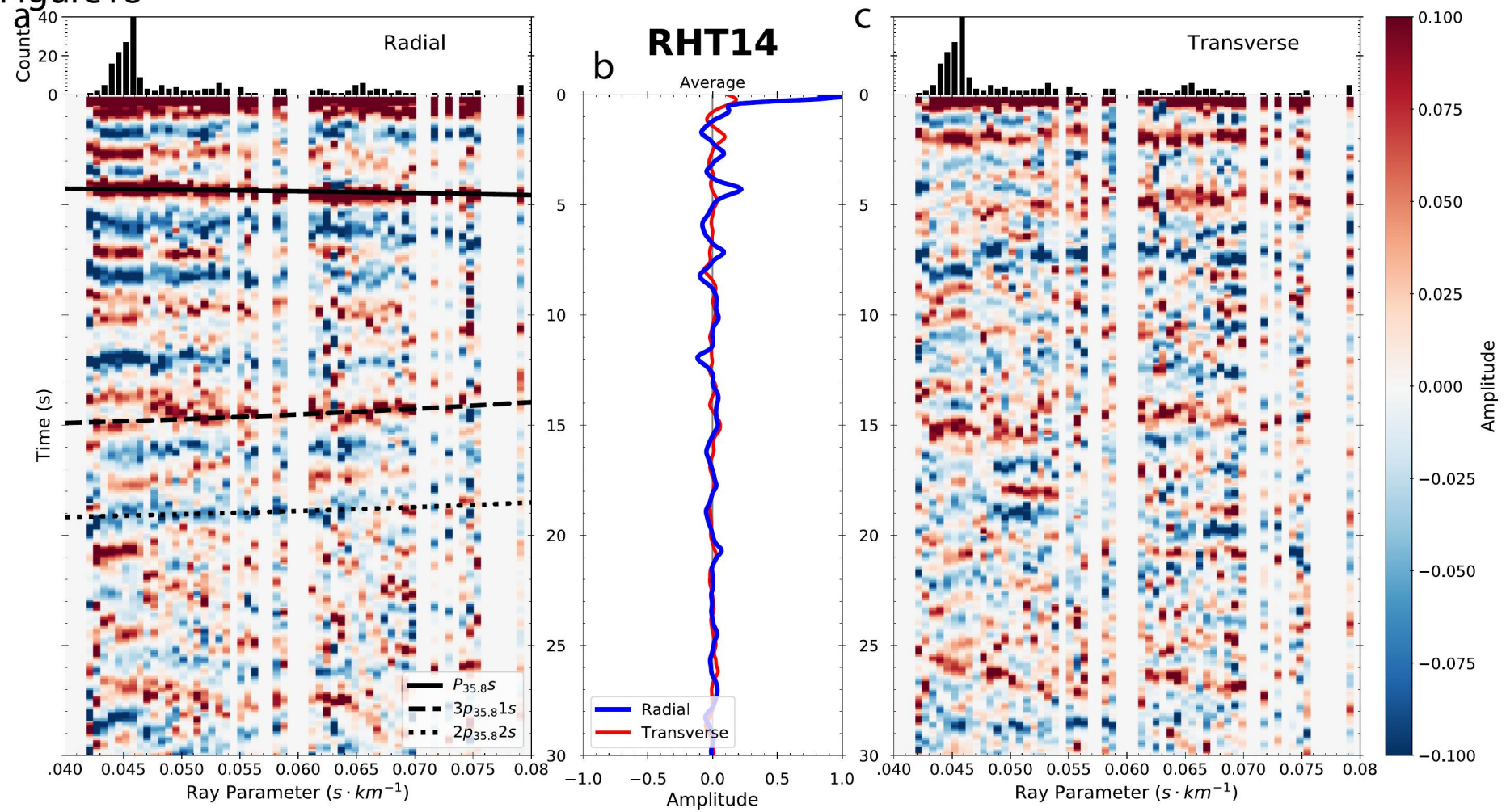

Figure 18. Receiver function gather for station RHT14. Presentation as in Figure 4.

Figure 19
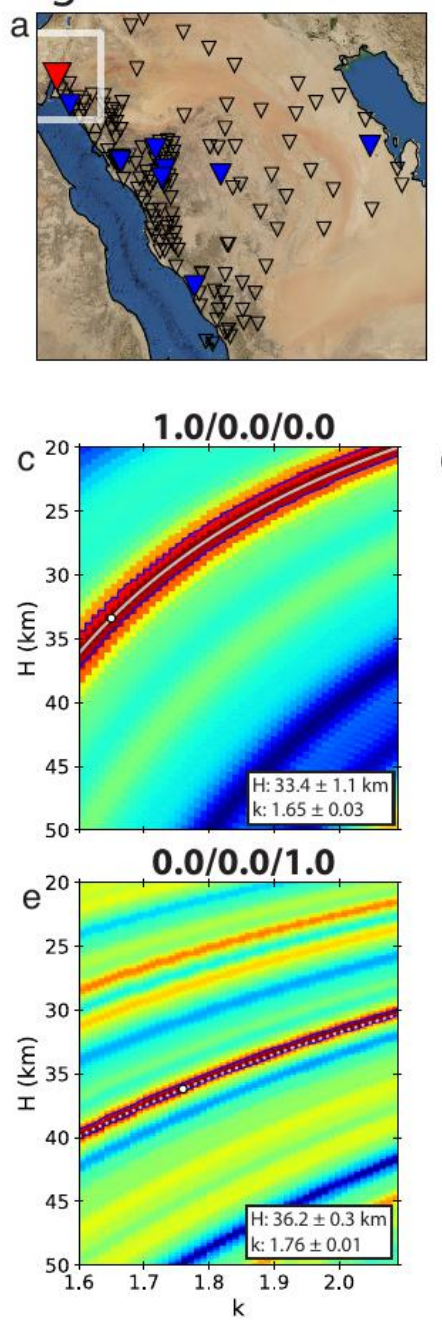

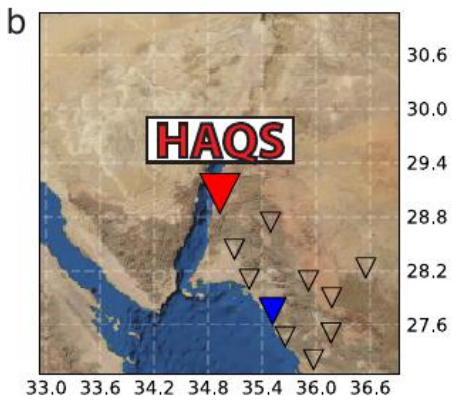

$$
0.0 / 1.0 / 0.0
$$

d
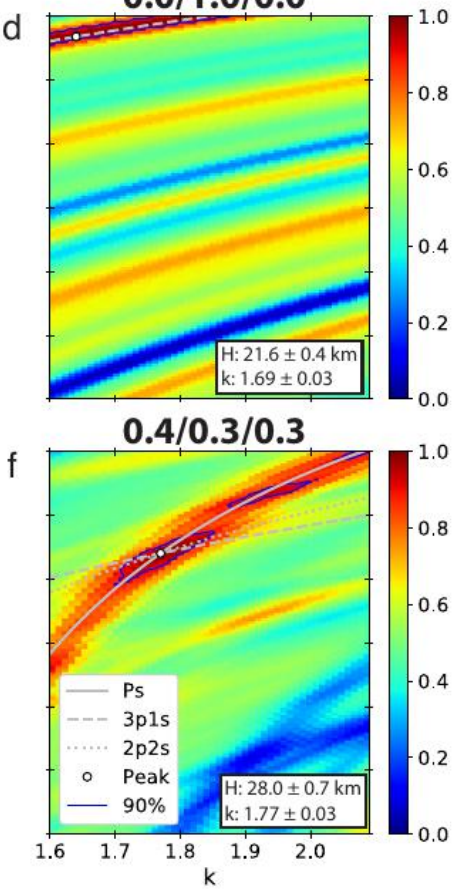

Figure 19. Receiver function analysis of station HAQS. Optimized stack weights are 0.4/0.3/0.3. Presentation as in Figure 3. 


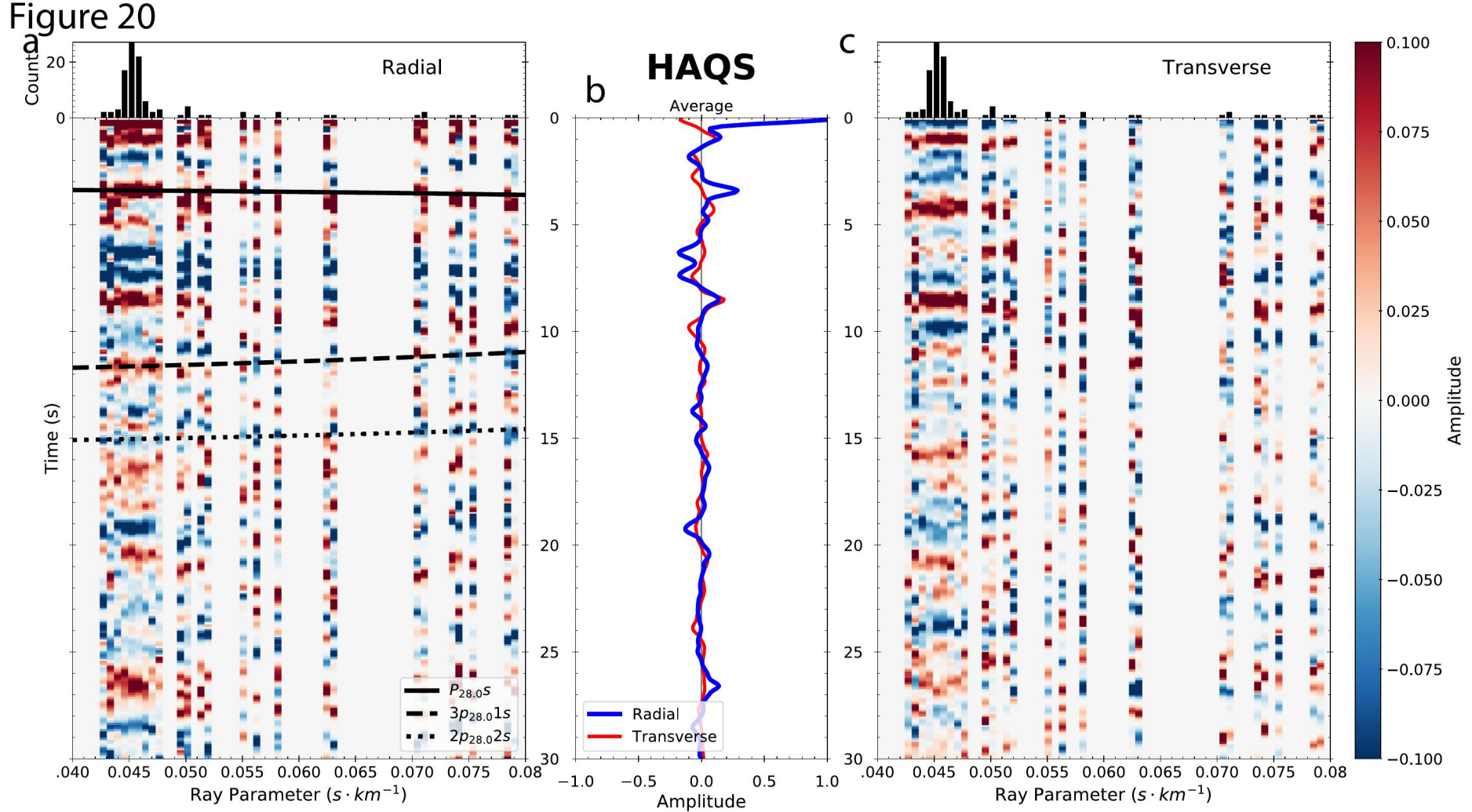

Figure 20. Receiver function gather for station HAQS. Presentation as in Figure 4.

Figure 21

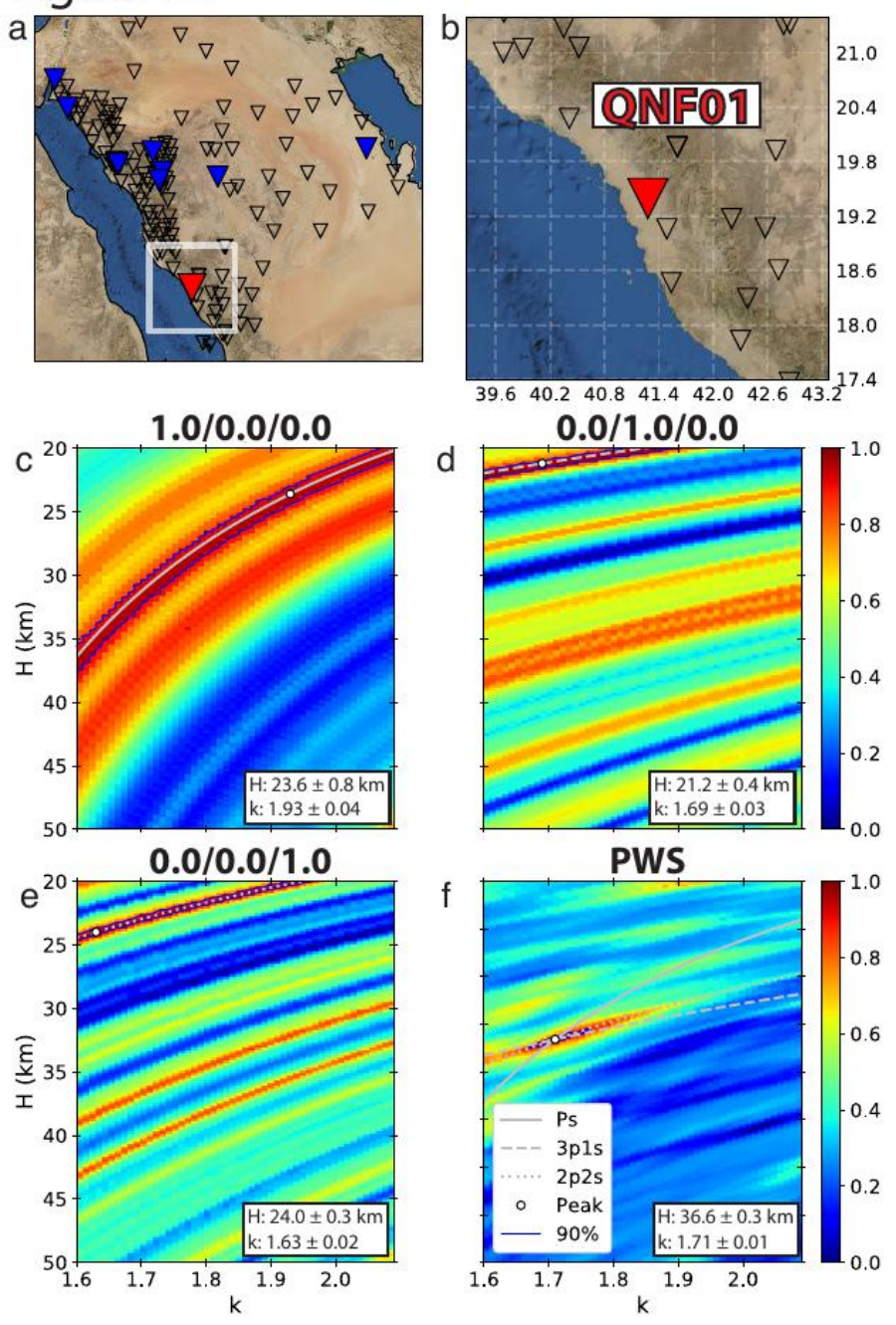

Figure 21. Receiver function analysis of station QNF01. Optimized stack is obtained via unweighted PWS stacking. Presentation as in Figure 3. 
Figure 22
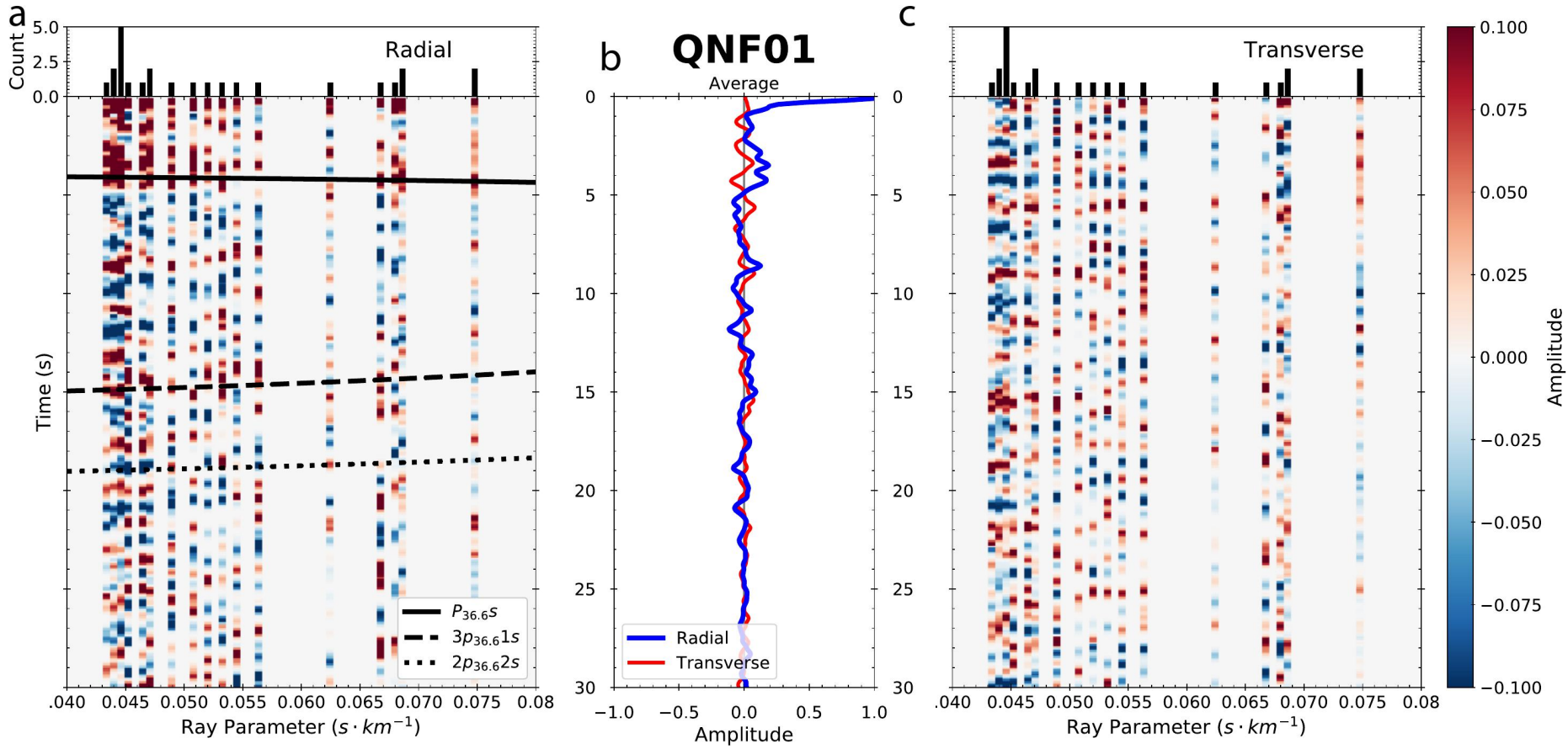

Figure 22. Receiver function gather for station QNF01. Presentation as in Figure 4.

Figure 23
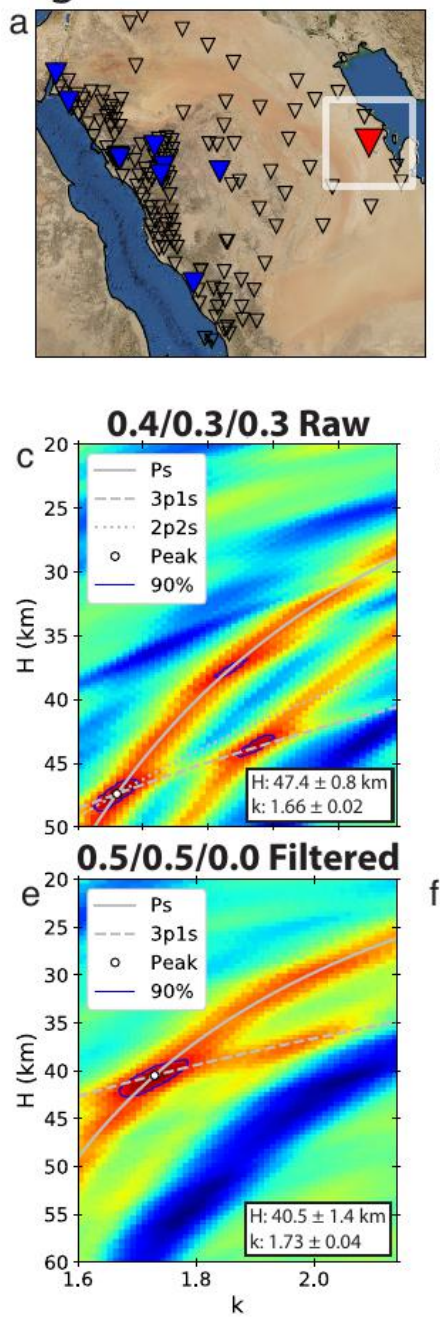
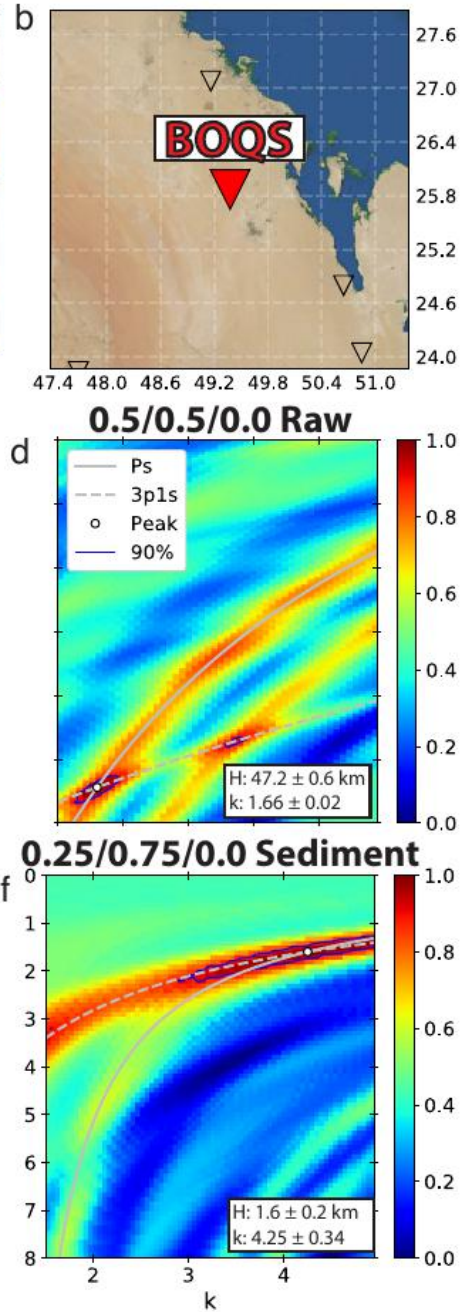

Figure 23. Receiver function analysis of station BOQS. Optimized stacks weights are $0.5 / 0.5 / 0.0$ for the sub-sedimentary crystalline crust $\mathrm{H}-\mathrm{k}$ stack and $0.25 / 0.75 / 0.0$ for the sedimentary H-k stack. Parts a) and b) are as in Figure 3. Parts c) and d) are single layer $\mathrm{H}-\mathrm{k}$ stacks for the raw PRFs (see fig. 24c). e) Sub-sedimentary H-k stack. f) Sedimentary H-k stack. 
Figure 24
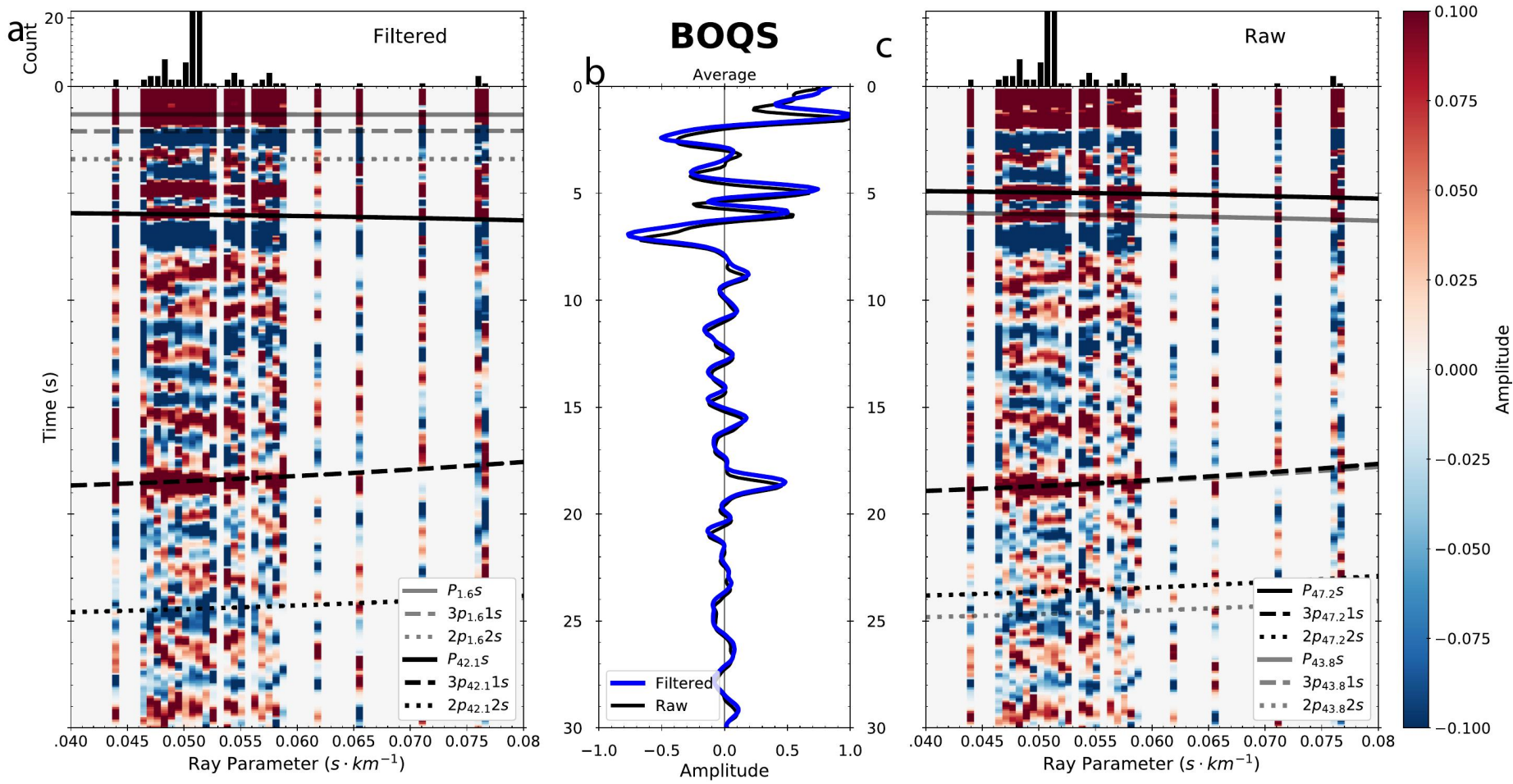

Figure 24. Receiver function gather for station BOQS. a) Radial receiver functions after application of the resonance removal filter and theoretical moveout curves determined from sedimentary and sub-sedimentary crystalline crustal H-k stacking. b) Comparison of average filtered and raw radial receiver functions. c) Radial receiver functions without the application of the resonance removal filter and moveout curve for the earlier candidate Ps arrival chosen from standard H-k stacking. 


\section{Figure 25}
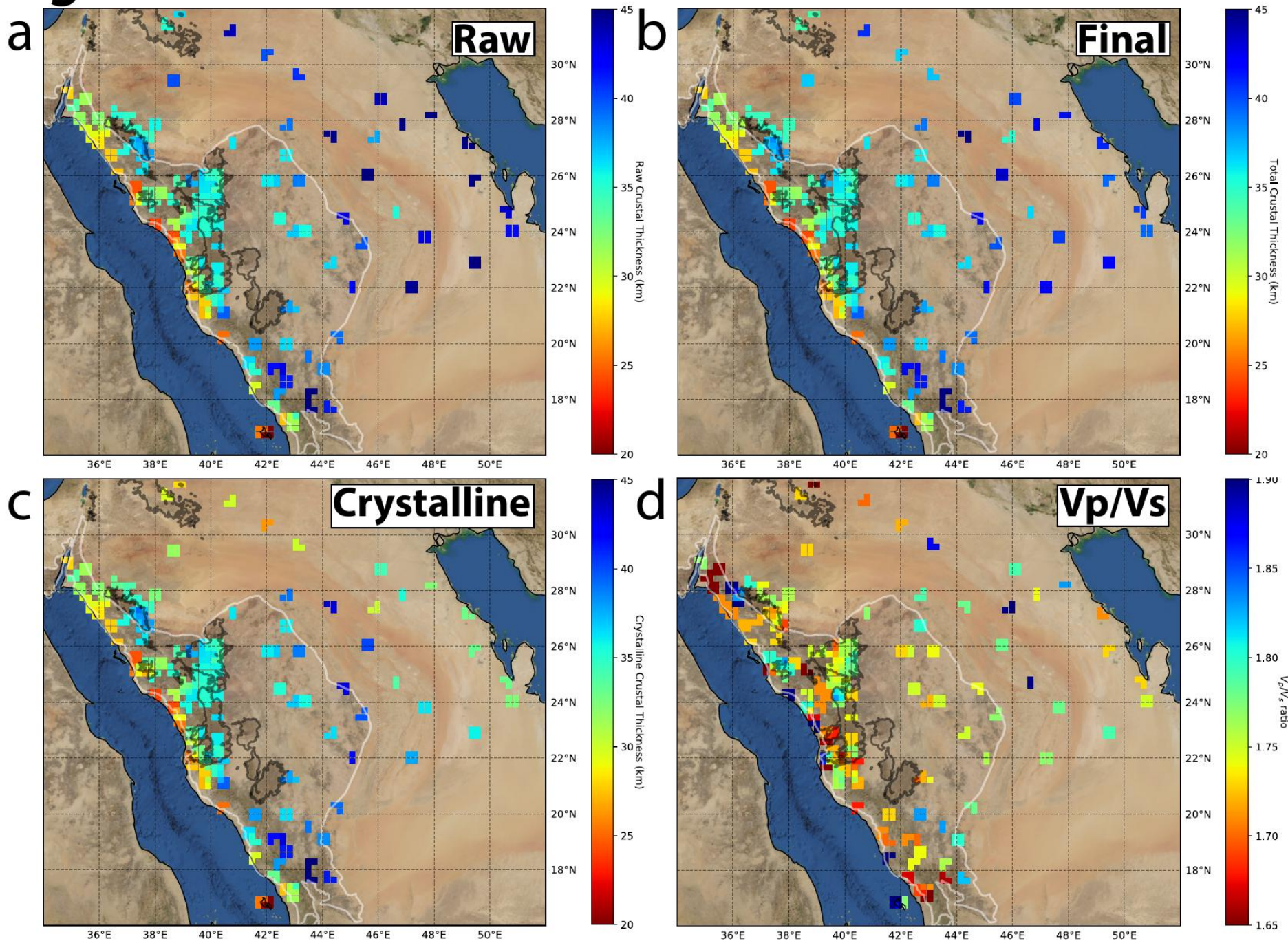

Figure 25. Map view of our H-k stacking results. Values are averaged within bins with radii of 25-km. Thin white line is the shield boundary. a) 'Raw' crustal thickness from H-k stacks before sedimentary correction. b) 'Final' crustal thickness from H-k stacks after sedimentary correction. c) Thickness of the crystalline crust, i.e. final crustal thickness minus sedimentary thickness from Stern and Johnson (2010). d) Crustal $V_{p} / V_{s}$ ratio (no sedimentary correction). Shield boundary from Pollastro (1998b) and harrat boundaries from Pollastro (1998a). 
Table 6. H-k stacking results for the platform

\begin{tabular}{|c|c|c|c|c|c|c|c|c|c|c|}
\hline Station & $\begin{array}{l}\text { Lattude } \\
\left({ }^{\circ} \mathrm{N}\right)\end{array}$ & $\begin{array}{c}\text { Longitude } \\
\left({ }^{\circ} \mathbf{E}\right)\end{array}$ & $\mathbf{w}_{1}$ & $\mathbf{w}_{2}$ & $\mathbf{w}_{3}$ & $\mathbf{H}$ & $2 \sigma_{H}$ & $\mathbf{K}$ & $2 \sigma_{k}$ & $\begin{array}{c}\text { Corrected } \\
\text { Thickness } \\
(\mathrm{km})^{3} \\
\end{array}$ \\
\hline \multirow[t]{2}{*}{ WELA $^{1}$} & 31.78 & 38.91 & 0.4 & 0.3 & 0.3 & 34.3 & 0.4 & 1.60 & 0.03 & 34.1 \\
\hline & & & 0.05 & 0.70 & 0.25 & 2.09 & 0.10 & 3.60 & 0.14 & \\
\hline \multirow[t]{2}{*}{$\mathrm{HANO}^{1}$} & 31.39 & 38.33 & 0.5 & 0.5 & 0 & 32.7 & 0.4 & 1.73 & 0.03 & 33.9 \\
\hline & & & 0.25 & 0.75 & 0.0 & 2.38 & 0.04 & 2.05 & 0.14 & \\
\hline \multirow[t]{2}{*}{ NARAR $^{1}$} & 31.12 & 40.75 & 0.5 & 0.5 & 0 & 38.5 & 1.0 & 1.70 & 0.02 & 40.7 \\
\hline & & & 0.25 & 0.75 & 0.0 & 5.40 & 0.20 & 4.20 & 0.19 & \\
\hline \multirow[t]{2}{*}{ SARAR $^{1}$} & 30.38 & 41.94 & 0.4 & 0.3 & 0.3 & 34.5 & 1.2 & 1.72 & 0.03 & 36.7 \\
\hline & & & 0.05 & 0.70 & 0.25 & 5.30 & 0.40 & 1.65 & 0.17 & \\
\hline \multirow[t]{2}{*}{ WRFHA $^{1}$} & 29.58 & 43.11 & 0.4 & 0.3 & 0.3 & 40.0 & 0.4 & 1.87 & 0.02 & 37.0 \\
\hline & & & 0.05 & 0.70 & 0.25 & 0.72 & 0.20 & 1.50 & 0.59 & \\
\hline JOFS & 29.41 & 38.61 & 0.4 & 0.3 & 0.3 & 40.0 & 0.6 & 1.73 & 0.03 & 36.9 \\
\hline HBTS & 28.73 & 46.05 & 0.5 & 0.5 & 0.0 & 43.6 & 0.4 & 1.79 & 0.02 & 40.1 \\
\hline TBKS & 28.23 & 36.55 & 0.5 & 0.5 & 0.0 & 35.4 & 0.5 & 1.80 & 0.04 & 34.6 \\
\hline KFJS & 28.19 & 47.94 & 0.5 & 0.5 & 0.0 & 47.0 & 0.8 & 1.83 & 0.04 & 41.5 \\
\hline URD10 & 28.17 & 37.10 & 0.4 & 0.3 & 0.3 & 34.8 & 0.7 & 1.74 & 0.02 & 34.5 \\
\hline \multirow{3}{*}{$\begin{array}{l}\text { QLABS } \\
\text { QYSM }^{1}\end{array}$} & 27.86 & 37.93 & 0.4 & 0.3 & 0.3 & 35.8 & 0.8 & 1.76 & 0.03 & 34.5 \\
\hline & 27.85 & 46.88 & 0.4 & 0.3 & 0.3 & 44.3 & 0.3 & 1.74 & 0.02 & 41.9 \\
\hline & & & 0.05 & 0.70 & 0.25 & 0.95 & 0.05 & 1.60 & 0.16 & \\
\hline \multirow{2}{*}{$\begin{array}{l}\text { URD12 } \\
\text { URD13 }\end{array}$} & 27.76 & 37.06 & 0.5 & 0.5 & 0.0 & 34.6 & 0.9 & 1.76 & 0.04 & 34.6 \\
\hline & 27.54 & 37.48 & 0.5 & 0.5 & 0.0 & 35.0 & 0.6 & 1.77 & 0.03 & 35.0 \\
\hline \multirow[t]{2}{*}{ ASYS $^{1}$} & 27.50 & 44.34 & 0.4 & 0.3 & 0.3 & 40.9 & 0.4 & 1.78 & 0.02 & 45.4 \\
\hline & & & 0.05 & 0.70 & 0.25 & 3.80 & 0.1 & 1.60 & 0.11 & \\
\hline \multirow{3}{*}{$\begin{array}{l}\text { URD14 } \\
\text { RQBS }^{1}\end{array}$} & 27.44 & 37.74 & 0.4 & 0.3 & 0.3 & 34.6 & 0.41 & 1.74 & 0.02 & 34.6 \\
\hline & 27.34 & 45.96 & 0.4 & 0.3 & 0.3 & 36.9 & 0.4 & 1.95 & 0.03 & 35.1 \\
\hline & & & 0.05 & 0.70 & 0.25 & 0.72 & 0.10 & 1.60 & 0.34 & \\
\hline URD15 & 27.25 & 37.45 & 0.5 & 0.5 & 0.0 & 38.0 & 0.5 & 1.71 & 0.02 & 38.4 \\
\hline NRYS & 27.08 & 49.16 & 0.5 & 0.5 & 0.0 & 45.8 & 0.8 & 1.71 & 0.02 & 41.0 \\
\hline \multirow{3}{*}{$\begin{array}{l}\text { MJMS } \\
\text { BOQS }^{1}\end{array}$} & 26.05 & 45.66 & 0.5 & 0.5 & 0.0 & 45.2 & 0.5 & 1.78 & 0.02 & 43.3 \\
\hline & 25.87 & 49.38 & 0.5 & 0.5 & 0.0 & 40.5 & 1.4 & 1.73 & 0.04 & 42.4 \\
\hline & & & 0.25 & 0.75 & 0.0 & 1.60 & 0.2 & 4.25 & 0.34 & \\
\hline \multirow[t]{2}{*}{ SLWS $^{1}$} & 24.80 & 50.64 & 0.4 & 0.3 & 0.3 & 40.4 & 0.7 & 1.73 & 0.04 & 40.5 \\
\hline & & & 0.05 & 0.70 & 0.25 & 2.89 & 0.1 & 3.55 & 0.15 & \\
\hline \multirow[t]{2}{*}{ RIYD $^{1}$} & 24.72 & 46.64 & 0.4 & 0.3 & 0.3 & 31.0 & 1.2 & 2.12 & 0.04 & 36.6 \\
\hline & & & 0.05 & 0.70 & 0.25 & 4.50 & 0.50 & 1.50 & 0.57 & \\
\hline \multirow[t]{2}{*}{ BTHS $^{1}$} & 24.05 & 50.85 & 0.4 & 0.3 & 0.3 & 38.7 & 0.7 & 1.75 & 0.03 & 39.3 \\
\hline & & & 0.05 & 0.70 & 0.25 & 2.95 & 0.05 & 1.60 & 0.18 & \\
\hline \multirow[t]{2}{*}{ KHRJ $^{1}$} & 23.84 & 47.68 & 0.4 & 0.3 & 0.3 & 41.8 & 0.4 & 1.78 & 0.02 & 40.4 \\
\hline & & & 0.05 & 0.70 & 0.25 & 0.69 & 0.05 & 1.60 & 0.16 & \\
\hline HRDS & 22.93 & 49.46 & 0.4 & 0.3 & 0.3 & 46.1 & 0.6 & 1.79 & 0.02 & 42.3 \\
\hline \multirow[t]{2}{*}{ LYLS $^{1}$} & 22.039 & 47.24 & 0.5 & 0.5 & 0.0 & 43.8 & 0.5 & 1.77 & 0.03 & 42.1 \\
\hline & & & 0.25 & 0.75 & 0.0 & 0.60 & 0.04 & 4.60 & 0.21 & \\
\hline
\end{tabular}

Stations are listed from north to south. 
${ }^{1}$ Top values are sub-sedimentary crustal $\mathrm{H}-\mathrm{k}$, bottom values are sedimentary H-k.

${ }^{3}$ Corrected thickness $=\mathrm{H}-0.6 \cdot \mathrm{h}_{\mathrm{s}-\mathrm{S} J 2010}$ where $\mathrm{h}_{\mathrm{s}-\mathrm{SJ} 2010}$ is sedimentary thickness from Stern and Johnson (2010) plus elevation a.s.1.; where $h_{s}$ is available from sedimentary H-k stacks, corrected thickness $=\mathrm{H}+\mathrm{h}_{\mathrm{s}}-0.6 \cdot\left(\mathrm{h}_{\mathrm{s}-\mathrm{S} J 2010}-\mathrm{h}_{\mathrm{s}}\right)$.

In map view, the crustal thicknesses show systematic variation (fig. $25 \mathrm{a}, \mathrm{b}, \mathrm{c}$ ) that is not evident for the $\mathrm{V}_{\mathrm{p}} / \mathrm{V}_{\mathrm{s}}$ ratios (fig. 25d). The average $\mathrm{V}_{\mathrm{p}} / \mathrm{V}_{\mathrm{s}}$ for the entire array is $1.76 \pm 0.07$, deviating only slightly from a Poisson solid (1.73). Averages for each tectonic province are given in Table 7. Although crustal thicknesses have distinct means (fig. 26a), all regions of the Arabian plate have statistically equivalent k-values (fig. 26b).

\section{Figure 26}

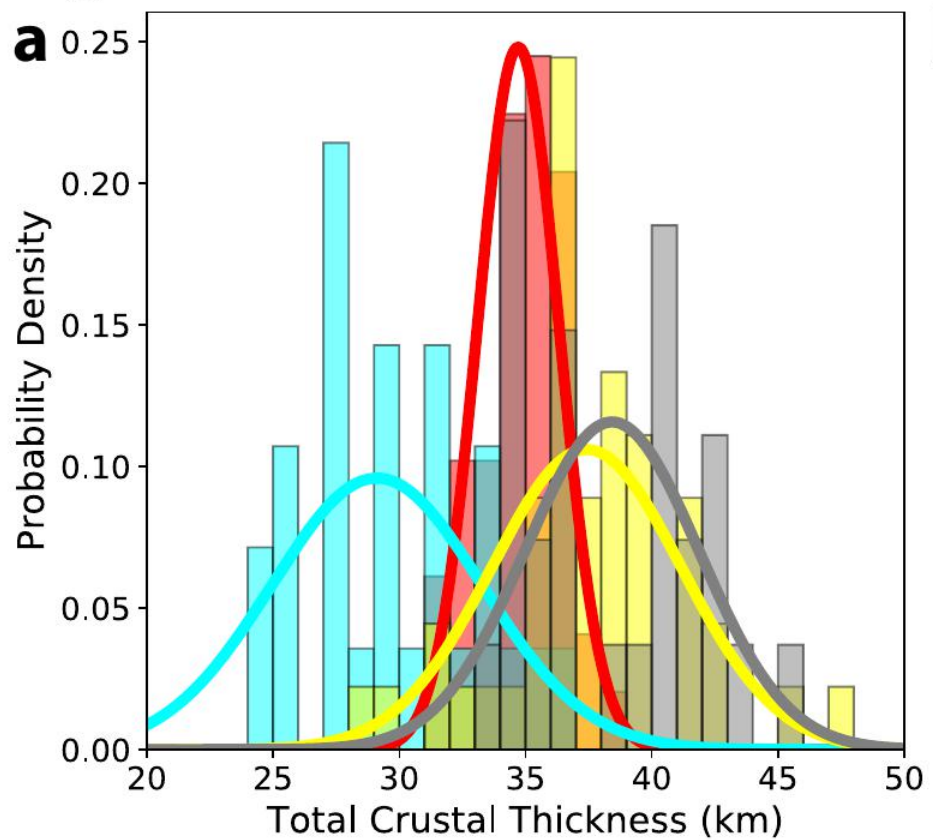

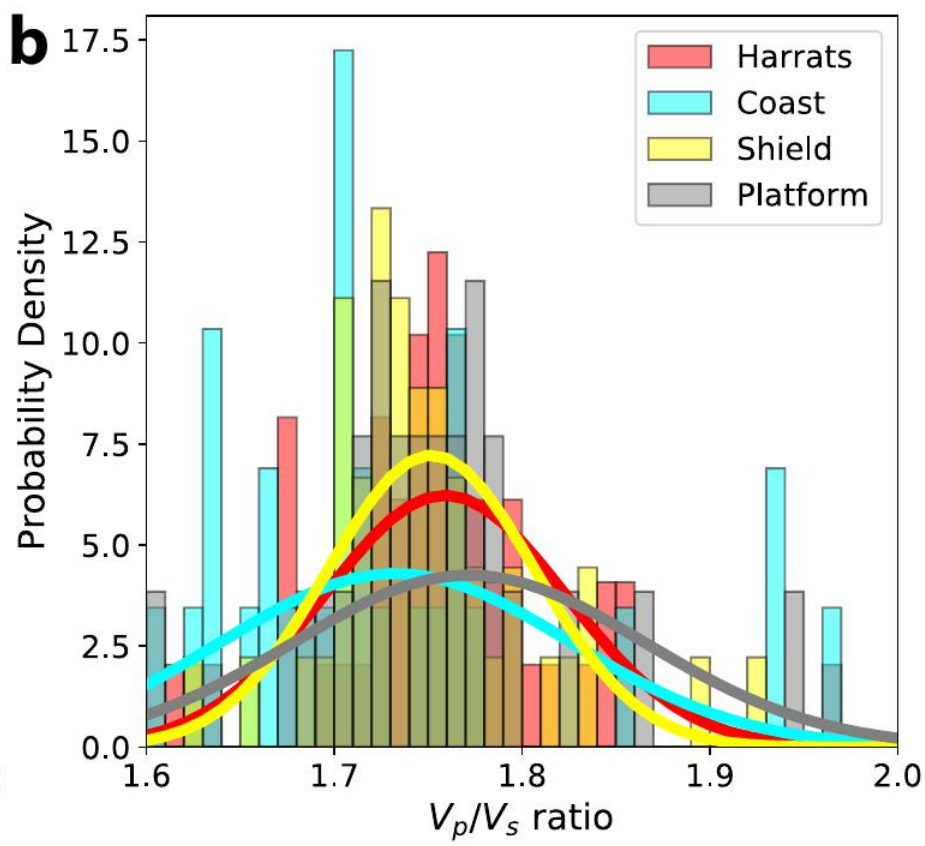

Figure 26. Histograms of (a) corrected crustal thicknesses and (b) k values organized by region. Gaussian curves in the foreground are fits to the data.

Table 7. Regional summary of H-k results. 'same' denotes Total Crustal Thickness equal to Crystalline Crustal Thickness for that geologic province.

\begin{tabular}{lcccc}
\hline \multicolumn{1}{c}{ Region } & $\begin{array}{c}\# \\
\text { Stations }\end{array}$ & $\begin{array}{c}\text { Crystalline } \\
\text { Crustal } \\
\text { Thickness }(\mathbf{k m})\end{array}$ & $\begin{array}{c}\text { Total Crustal } \\
\text { Thickness } \\
(\mathbf{k m})\end{array}$ & $\begin{array}{c}\text { Total Crustal } \mathbf{V}_{\mathbf{p}} / \mathbf{V}_{\mathbf{s}} \\
\text { ratio }\end{array}$ \\
\hline Coast & & & & \\
Coast & 29 & $29.1 \pm 4.2$ & $29.1 \pm 4.1$ & $1.73 \pm 0.09$ \\
(excluding Farasan) & 27 & $29.7 \pm 3.3$ & $29.8 \pm 3.2$ & $1.72 \pm 0.08$ \\
Harrats & 49 & $34.7 \pm 1.6$ & same & $1.76 \pm 0.06$ \\
MMN & 30 & $35.3 \pm 1.2$ & same & $1.75 \pm 0.04$ \\
Harrat Lunayyir & 19 & $33.8 \pm 1.8$ & same & $1.77 \pm 0.09$ \\
Harrat Khaybar & 12 & $35.5 \pm 1.3$ & same & $1.75 \pm 0.03$ \\
Harrat Rahat & 18 & $35.2 \pm 1.1$ & same & $1.75 \pm 0.05$ \\
Shield & 49 & $36.6 \pm 4.8$ & same & $1.76 \pm 0.06$ \\
Platform & 27 & $33.8 \pm 3.6$ & $38.4 \pm 3.4$ & $1.77 \pm 0.09$ \\
\hline
\end{tabular}

\section{Comparison with Previous P-wave Receiver Function Analyses}

The present study greatly improves upon the coverage of seismologically determined crustal thicknesses across the Arabian plate and also includes the distinction between total crustal thickness (Sediment + Crystalline) and crystalline crustal thickness (Table 7). Several previous PRF studies of crustal thickness of the Arabian plate (Table 8) all lacked station coverage compared to our results. These previous authors did not distinguish between total crustal thickness and crystalline crustal thickness, nor did they perform their analysis 
in the same provincial framework as we have done here. We reorganized their results (Table 8) following our classification scheme to enable comparison in sequence: coastal (Red Sea rift flank), harrat, shield, and platform.

Table 8. Regional summary of previous geophysical work.

\begin{tabular}{|c|c|c|c|}
\hline $\begin{array}{c}\text { Region } \\
\text { our mean crustal thickness } / \mathbf{k m} \\
\text { (\# stations) }\end{array}$ & Author & $\begin{array}{c}\# \\
\text { Stations }\end{array}$ & $\begin{array}{c}\text { Average } \\
\text { Thickness/km }\end{array}$ \\
\hline & Al-Damegh and others (2005) & 6 & $25.1 \pm 6.1$ \\
\hline \multirow{2}{*}{$\begin{array}{c}29.1 \pm 4.1 \\
(29)\end{array}$} & Tang and others (2016) & 11 & $27.9 \pm 4.0$ \\
\hline & Tkalčić and others (2006) & 1 & 28.0 \\
\hline $\begin{array}{c}\text { Harrats } \\
34.7 \pm 1.6 \\
(49)\end{array}$ & Tang and others (2016) & 23 & $33.5 \pm 2.7$ \\
\hline $\begin{array}{c}\mathrm{MMN} \\
35.3 \pm 1.2 \\
(30)\end{array}$ & Tang and others (2016) & 12 & $34.2 \pm 2.4$ \\
\hline $\begin{array}{c}\text { Harrat Lunayyir } \\
33.8 \pm 1.8 \\
\text { (19) }\end{array}$ & Tang and others (2016) & 11 & $32.7 \pm 3.0$ \\
\hline \multirow{4}{*}{$\begin{array}{c}\text { Harrat Khaybar } \\
35.5 \pm 1.3 \\
(12) \\
\text { Harrat Rahat } \\
35.2 \pm 1.1 \\
(18) \\
\end{array}$} & Al-Damegh and others (2005) & 1 & 35.2 \\
\hline & Tang and others (2016) & 1 & 35.1 \\
\hline & Tkalčić and others (2006) & 1 & 35.0 \\
\hline & Tang and others (2016) & 11 & $34.1 \pm 2.5$ \\
\hline & Al-Damegh and others (2005) & 12 & $35.6 \pm 6.0$ \\
\hline \multirow{3}{*}{$\begin{array}{c}36.6 \pm 4.8 \\
\quad(49)\end{array}$} & Sandvol and others (1998) & 7 & $39.1 \pm 2.9$ \\
\hline & Tang and others (2016) & 14 & $36.9 \pm 4.7$ \\
\hline & Tkalčić and others (2006) & 5 & $37.6 \pm 2.6$ \\
\hline \multirow{4}{*}{$\begin{array}{l}\text { Platform } \\
38.4 \pm 3.4 \\
\quad(27)\end{array}$} & Al-Damegh and others (2005) & 3 & $37.1 \pm 4.2$ \\
\hline & Sandvol and others (1998) & 1 & 45.0 \\
\hline & Tang and others (2016) & 7 & $42.4 \pm 5.6$ \\
\hline & Tkalčić and others (2006) & 3 & $36.0 \pm 2.6$ \\
\hline
\end{tabular}

For coastal stations, Tang and others (2016) report average total crustal thickness of $27.9 \pm 4.0 \mathrm{~km}$ across 11 stations and Al-Damegh and others (2005) $25.1 \pm 6.1$ (5 stations), consistent with our average of 29.1 $\pm 4.1 \mathrm{~km}$. Tkalčić and others (2006) reported $28.0 \mathrm{~km}$ for a single coastal station (YNBS), for which we obtained $24.0 \pm 0.7 \mathrm{~km}$. This significant discrepancy is due to the greater focus of Tkalčić and others (2006) on fitting the long-period P-wave receiver function, instead of the short-period P-wave receiver function (as can be seen in their Figure 11 part j); for this station Tang and others (2016) reported $25.0 \pm 0.8 \mathrm{~km}$, close to our own result.

All of our average harrat results are consistent with the previous studies, likely because of large station numbers, generally high data quality, and no sedimentary interference. Our shield result (crustal thickness of $36.6 \mathrm{~km}$ ) is lower than most, but within error of all, previous studies, likely due to our inclusion of a greater number of seismic stations in the western shield, closer to the coast. On the Arabian platform our average raw total crustal thicknesses $(40.4 \pm 4.3 \mathrm{~km})$ is within error of previous results. Inclusion of the sedimentary correction (our total crustal thickness, average $38.4 \pm 3.4 \mathrm{~km}$ ) increases our discrepancy from the conventional analysis of Tang and others (2016) (42.4 $\pm 5.6 \mathrm{~km})$, but causes convergence with Tkalčić and others (2006) $(36.0 \pm 2.6 \mathrm{~km})$, suggesting that their inclusion of long-period surface waves in a joint inversion with PRFs, reasonably compensated for the sedimentary cover, without necessitating an additional sedimentary correction. No previous authors published estimates of crystalline crustal thickness (our average is $33.8 \pm 3.6 \mathrm{~km}$ ). 
A long-standing question about the Arabian Plate is whether different crustal terranes have different crustal structures. Stern \& Johnson (2010) claim that the platform is 3-4 km thicker than the shield, and Tang and others (2016) claim they can distinguish between crustal thicknesses of different Proterozoic terranes and that k-values at Harrat Lunayyir are anomalously high. However, these claims were not evaluated statistically. Here, we use different statistical methods to test the equivalence between different geographic regions.

First, we use Welch's t-test method (Welch, 1947), which generalizes the Student's t-test to allow the measurements being compared to contain both different sized populations and different variances. We use a two-tailed test of two scenarios $\left(\mathrm{H}_{0}-\right.$ our null hypothesis, that the population means are equal, or $\mathrm{H}_{1}-$ the population means are different) and calculate the test statistic, $t$, and the degrees of freedom, $v$, associated with the estimated variances. Calculating the Student's distribution with these input values allows us to calculate the probability, $\mathrm{p}$, that the null hypothesis $\left(\mathrm{H}_{0}\right)$ is true. At a $95 \%$ confidence threshold, if $\mathrm{p}<0.05$ we reject the null hypothesis (i.e. the averages are too different to be explained by random chance) and if $p>0.05$ we accept the null hypothesis (i.e. any differences between the averages can be explained by random chance).

As an additional test of equivalence between geographic regions we also use the Mann-Whitney $\mathrm{U}$ (MWU) test (Mann and Whitney, 1947), designed to compare population distributions instead of population means, and to cope with non-normal, e.g. skewed, distributions (Fay and Proschan, 2010). We use the same two-tailed test as for our t-test and calculate $\mathrm{p}$, the probability that the null hypothesis is true. We denote the two different $\mathrm{p}$-values as either $\mathrm{p}_{\mathrm{t}}\left(\mathrm{t}\right.$-test) or $\mathrm{p}_{\mathrm{mwu}}$ (MWU test).

\section{Figure 27}
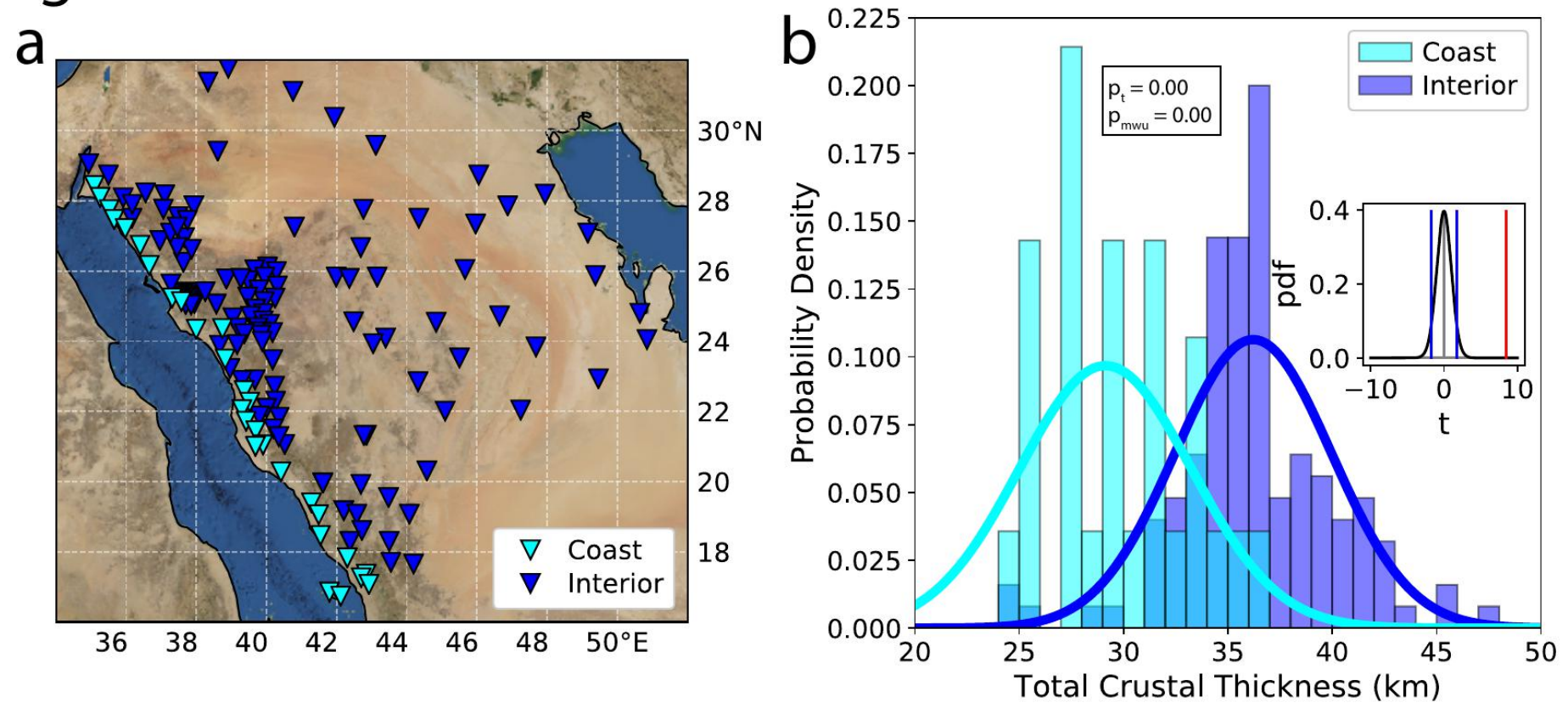

Figure 27. Comparison of 'coastal' (i.e. Red Sea rift margin) stations to 'interior' stations. a) Map of Saudi Arabia with stations marked by category. b) Histogram of depth to Moho below the surface (total crustal thickness) for the two categories. Gaussian curves are fits to the data. Inset in part b) is the t-test, showing the probability density function (pdf) of the Student distribution for the two datasets. Blue vertical bars are $95 \%$ confidence bounds; the red bar is the t-value of this comparison. If the red bar is within the blue bars, then the null hypothesis $\left(\mathrm{H}_{0}\right)$ is accepted, otherwise $\mathrm{H}_{1}$ - that the distributions are different - is accepted. In this case the two population averages and distributions are very different $\left(\mathrm{p}_{\mathrm{t}}<\right.$ $\left.10^{-4}, \mathrm{p}_{\mathrm{mwu}}<10^{-4}\right)$.

The thinnest crust, $16-25 \mathrm{~km}$, is beneath the Farasan Island stations. The two measurements, separated by only $37 \mathrm{~km}$, differ greatly (Table 4), perhaps because of complex overlying sedimentary structure (Almalki and Bantan, 2016), but bracket the previous active-source measurement (17.5 km; Mooney and others, 1985) and represent the transition from thin oceanic to thick continental crust. 
The next thinnest crust is beneath the stations along the Red Sea rift margin. The average thickness of crust beneath the coastal stations is $29.1 \pm 4.1 \mathrm{~km}$, or $29.8 \pm 3.2$ excluding the Farasan Island results. Even excluding the Farasan stations, this value is statistically different from the average thickness of $36.2 \pm 3.8 \mathrm{~km}$ for the rest of the Arabian plate (fig. 27). We note that our definition of "coastal" is necessarily arbitrary, even though geologically informed (within $250 \mathrm{~km}$ of the Red Sea rift axis and at elevations $\leq 400 \mathrm{~m}$ a.s.1.), and other definitions would lead to different numerical values.

\section{Figure 28}
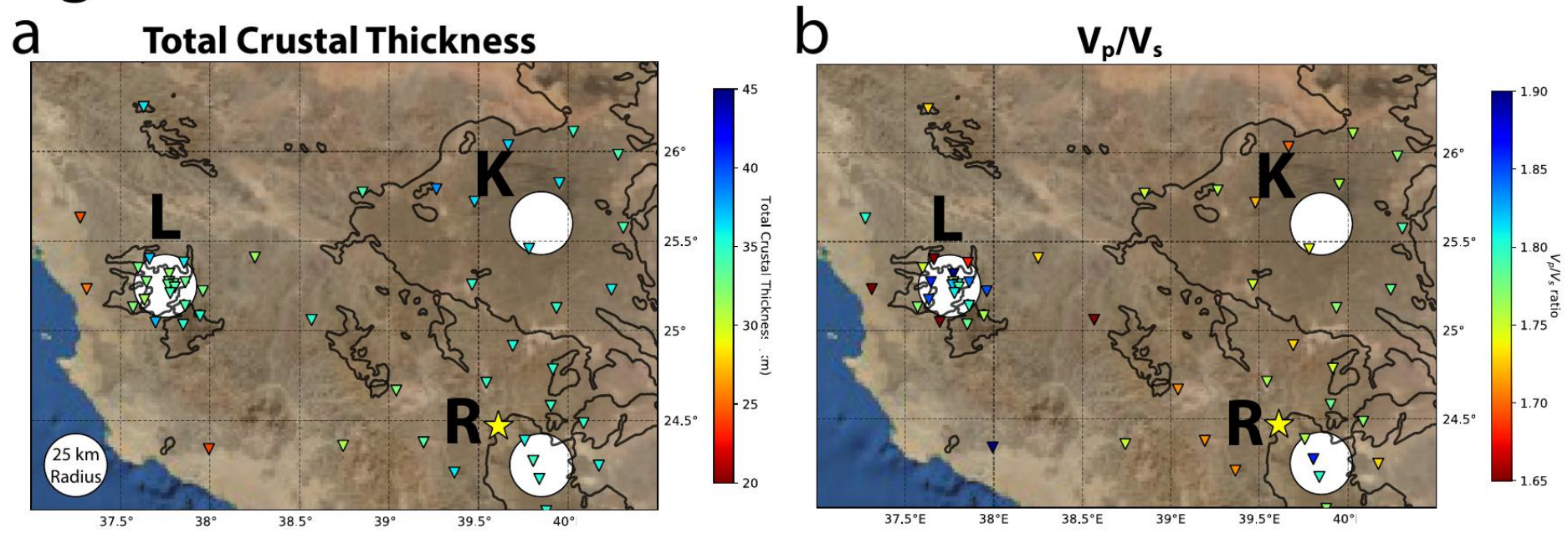

Figure 28. Map view of harrat H-k results. a) Total crustal thickness measurements for each station. b) Crustal $\mathrm{V}_{\mathrm{p}} / \mathrm{V}_{\mathrm{s}}$ ratio for each station. White circles are approximately located at the center of each harrat (Lunayyir, Khaybar, and northern Rahat) and have a radius of $25 \mathrm{~km}$ (the averaging radius for fig. 25, and the distance-scale over which we anticipate commonality between stations due to similar ray path coverage (fig. 2)). Thin black lines: harrat boundaries. Yellow star is Medina.

Moving eastward into the harrats, crustal thickness of Harrat Lunayyir is $33.8 \pm 1.8 \mathrm{~km}$ and the $\mathrm{V}_{\mathrm{p}} / \mathrm{V}_{\mathrm{s}}$ ratio $(\mathrm{k})$ is $1.77 \pm 0.09(1 \sigma)$. The scatter in $\mathrm{k}$ values far exceeds the analytic uncertainty of individual stations; however, this scatter exists between stations that are sufficiently close (fig. 28) that they share many ray-paths contributing to their H-k results (fig. 2), and should have similar results. Hence, we conclude that the low analytic uncertainties fail to represent the oblique eccentricity of resolution in our H-k grid search, which we represent as $90 \%$ amplitude contours. Because crustal $\mathrm{H}$ and $\mathrm{k}$ represent secular evolutionary processes, we might expect correlations within provinces (fig. 29), as well as differences between them (fig. 26b, 29a). Figure 29 demonstrates the lack of correlation between the thickness of the crust and its $\mathrm{V}_{\mathrm{p}} / \mathrm{V}_{\mathrm{s}}$ ratio, except apparently amongst the harrat stations. However, the slope of the apparent trend of $\mathrm{H}$ versus $\mathrm{k}$ is the same as the slope of the H-k confidence ellipses (fig. 29b), suggesting that the trend is due to real uncertainty in the H-k results, not geological differences. Indeed, adding mafic intrusions to increase $\mathrm{k}$ would also increase H. This is important because Tang and others (2016) proposed that the k-values at Harrat Lunayyir are elevated in comparison to the shield due to solidified intrusions. Our statistical testing methodology shows that the claim of Tang and others (2016) is not supported by their data, which consist of 11 Harrat Lunayyir measurements of k with a mean of $1.78 \pm 0.11$ and 36 shield measurements with a mean of $1.74 \pm 0.07$. Our t-test and MWU test applied to their data yields a $\mathrm{p}_{\mathrm{t}}$-value of 0.35 and $\mathrm{p}_{\mathrm{mwu}}=0.27$, both far above the 0.05 threshold, so requiring the null-hypothesis that the $\mathrm{V}_{\mathrm{p}} / \mathrm{V}_{\mathrm{s}}$ ratios of Harrat Lunayyir are statistically the same as for the rest of the shield.

Harrat Khaybar has average crustal thickness of $35.5 \pm 1.3 \mathrm{~km}$ and average $\mathrm{k}$ of $1.75 \pm 0.03$. The consistency of results arises from both the low-noise levels of their receiver functions and the well-resolved phase arrivals. Harrat Rahat has mean $\mathrm{H}$ and $\mathrm{k}$-values of $35.2 \pm 1.1 \mathrm{~km}$ and $1.75 \pm 0.05$, respectively. The highest k-values for Harrat Rahat $(\geq 1.78)$ are at the northern tip, where volcanics erupted $\sim 800$ years ago (Camp and others, 1987), but, as discussed for Harrat Lunayyir, we believe this variability in $\mathrm{V}_{\mathrm{p}} / \mathrm{V}_{\mathrm{s}}$ ratios is likely due to inherent uncertainly. 

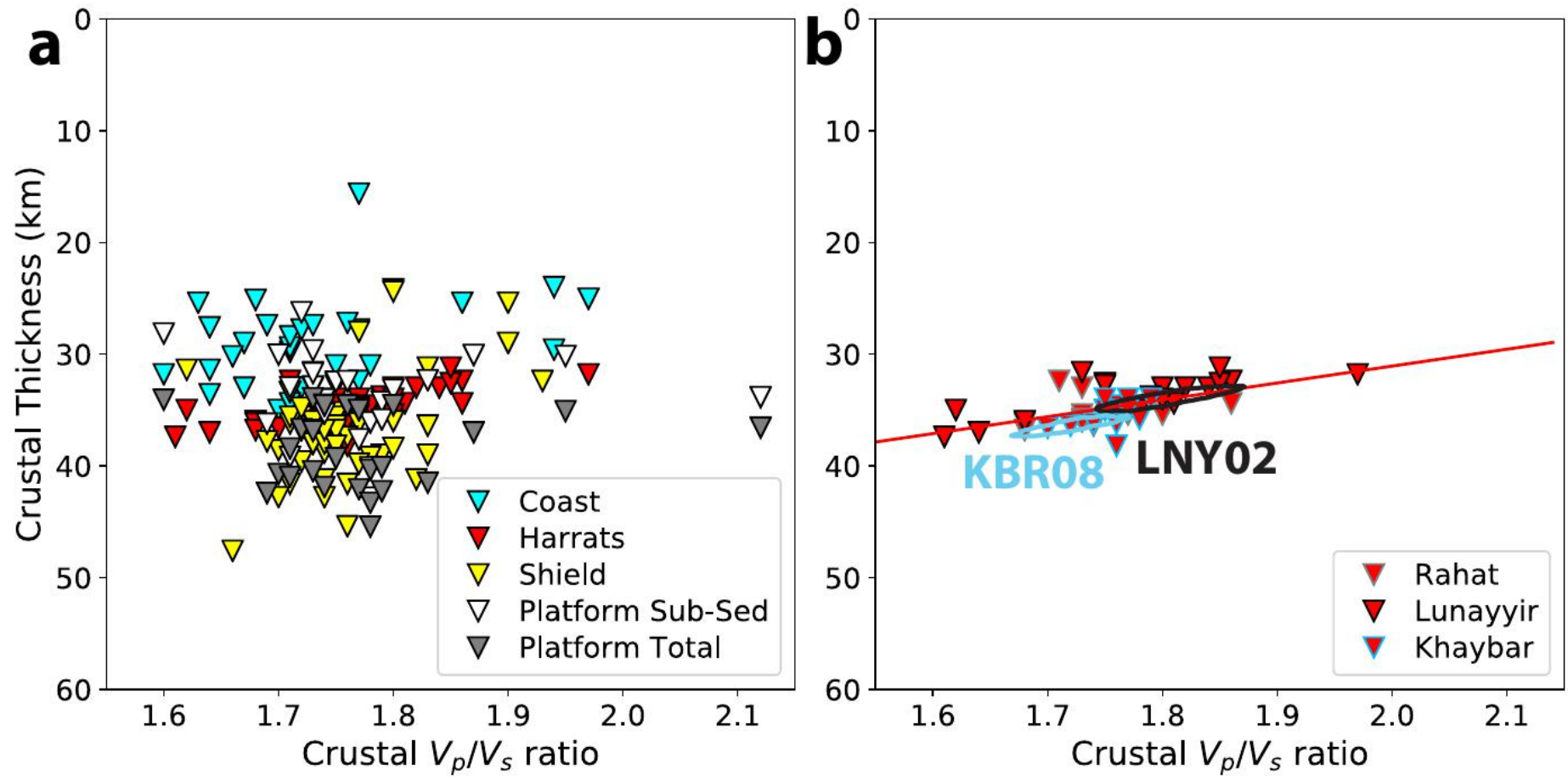

Figure 29. Cross-plot of crustal thickness against $\mathrm{V}_{\mathrm{p}} / \mathrm{V}_{\mathrm{s}}$ ratio. a) For all categories. Platform Total is the total crustal thickness within the platform, while Platform Sub-Sed is the thickness of the subsedimentary crystalline crust. b) For harrats only. Straight-line fit (red line) shows apparent crustal thinning with increasing $\mathrm{V}_{\mathrm{p}} / \mathrm{V}_{\mathrm{s}}$ ratio $90 \% \mathrm{H}-\mathrm{k}$ confidence ellipses are shown for KBR08 (blue) and LNY02 (black).

The three major harrats in this study (Lunayyir, Rahat, and Khaybar) all have overlapping $\mathrm{H}$ and kvalues (fig. 30). The k-values for the three harrats are not statistically distinct (fig. 30c), but Harrat Lunayyir is distinctly thinner than Harrats Khaybar and Rahat, which are essentially identical (fig. 30b). We suspect this thickness difference can be explained by the Harrat Lunayyir stations being closer to the Red Sea rift axis than all Khaybar stations and the majority of Rahat stations. We expand upon this overall west-to-east crustal thickening trend below, but the trend can be seen by comparing harrat versus shield crustal thickness (statistically distinct, fig. 26a), particularly with MMN versus western shield stations (statistically the same, fig. 31b).

Next, we compare the western shield $\left(\mathrm{H}_{\text {total }}=36.0 \pm 5.4 \mathrm{~km}\right)$ to the MMN line (harrats Rahat and Khaybar; $\mathrm{H}_{\text {total }}=35.3 \pm 1.2 \mathrm{~km}$ ) (fig. $31 \mathrm{~b}$ ). The western shield and the MMN line have the same mean thicknesses $\left(p_{t}=0.44\right)$, but significantly different distributions (different variance) $\left(p_{m w u}=0.04\right)$ which we reconcile by looking at the spatial distribution of measurements (fig. 31a). The MMN line samples crust in a small region, so the measurements are tightly grouped around their mean. The western shield spans a much larger spatial region, including north to the DST and south nearly to the Yemen flood basalts, and thus have a more variable range of observations. This is the only example we found where the t-test and MWU test give different results, and is simply due to the different definitions of equivalence (same mean versus same distribution of values). 


\section{Figure 30}

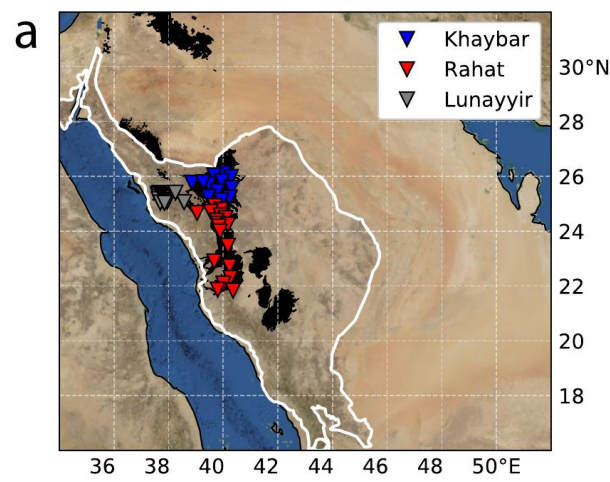

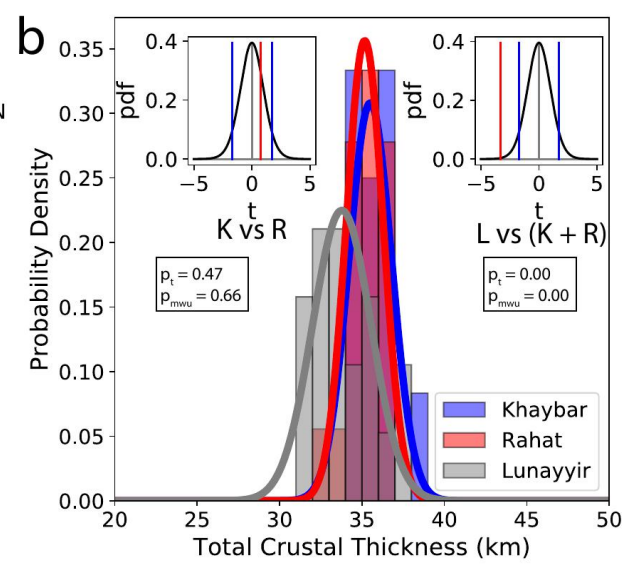

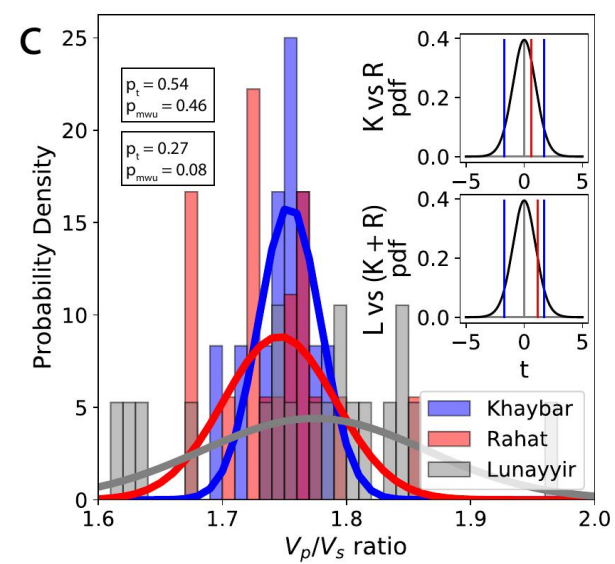

Figure 30. Comparison of Harrats $\operatorname{Khaybar}(\mathrm{K})$ and Rahat (R), and of both with Harrat Lunayyir (L). a) Map of Khaybar (K) and Rahat (R) stations comprising the Makka-Madinah-Nafud (MMN) line, and Lunnayir stations (L) and the Red Sea rift (RSR). b) Histograms of crustal thickness for H, K and R stations. Left inset: Harrat Khaybar tested against Rahat. Right inset: Harrat Lunayyir tested against the MMN stations (Khaybar plus Rahat). c) Histograms of $\mathrm{V}_{\mathrm{p}} / \mathrm{V}_{\mathrm{s}}$ ratio for the different categories. Top inset: Harrat Khaybar tested against Rahat. Bottom inset is Harrat Lunayyir tested against the MMN stations.

Finally, we compare the entire shield $\left(\mathrm{H}_{\text {total }}=36.6 \pm 4.8 \mathrm{~km}\right)$ and the platform $\left(\mathrm{H}_{\text {total }}=38.4 \pm 3.4 \mathrm{~km}\right.$, including sedimentary cover) (fig. 31c). The platform including its sedimentary cover may be thicker, but it is not statistically different $\left(\mathrm{p}_{\mathrm{t}}=0.07, \mathrm{p}_{\mathrm{mwu}}=0.21\right)$. However, when we compare the thickness of the crystalline crust alone (fig. 31d), the platform average is $33.8 \pm 3.6 \mathrm{~km}$, which is $2.8 \mathrm{~km}$ thinner than and distinct ( $\mathrm{p}_{\mathrm{t}}<<$ $0.05, \mathrm{p}_{\mathrm{mwu}}<<0.05$ ) from the shield. Although this result appears conclusive, it is heavily dependent upon how we correct for the sedimentary cover. We tested varying our sedimentary correction factor $\frac{\partial \varepsilon}{\partial h_{s}}$ from -0.3 to -1.0 (corresponding to assumed sedimentary-basin average P wavespeeds of $3.5-4.8 \mathrm{~km} . \mathrm{s}^{-1}$ ) (fig. 7) and found that within this range, the platform crystalline crust is always statistically thinner than the shield $\left(0<\mathrm{p}_{\mathrm{t}}<0.05,0<\right.$ $\mathrm{p}_{\mathrm{mwu}}<0.01$ ) (fig. 31d). In the unlikely case that the sedimentary-basin average $\mathrm{P}$ wavespeed is greater than 4.8 $\mathrm{km} . \mathrm{s}^{-1}$ the platform crystalline crust thickness becomes statistically indistinguishable from the shield.

Another potentially confounding factor is that the relative thicknesses of platform crystalline crust and shield crust may be biased by our station distribution. When we plot crustal thickness against distance from the Red Sea rift axis (RSR) (fig. 32a), we see at the broadest scale that the Arabian Plate thickens from the western rifted margin to the eastern platform. The group of shield stations with $\mathrm{H}>40 \mathrm{~km}$ at distances of $200-400 \mathrm{~km}$ from the RSR does not fit this west-to-east thickening trend, in large part due to a tendency for our measured shield thicknesses to increase to the south (fig. 25a, 32c). Total crustal thicknesses of more than $45 \mathrm{~km}$ close to the Yemen border may reflect the influence of plume magmatism that produced the Yemen flood basalts (Stern and Johnson, 2010). This increase in thickness to the south is also seen in the results of active-source seismic studies (Mooney and others, 1985) (fig. 1a) that show greater shield thicknesses than our averages (fig. 32b). If we limit our comparison to only our southern stations that are within $125 \mathrm{~km}$ of the refraction profile (fig. 32b), this discrepancy largely disappears. A best-fit straight line to the crustal thickness of all stations greater than $250 \mathrm{~km}$ from the RSR (fig. 32c) shows the crust thinning northwards at $0.005 \mathrm{~km} / \mathrm{km}$. If this northward-thinning tendency is representative of the whole Arabian plate, then our bias in station distribution, with the centroid of our shield stations located $\sim 200 \mathrm{~km}$ south of the centroid of our platform measurements, would explain $1 \mathrm{~km}$ of the observed thickness difference between the crystalline crust of the platform and shield. It is possible that when more data become available for the Arabian Platform in southern Saudi Arabia (the Empty Quarter), the Arabian Shield and the Arabian Platform will be found to be statistically indistinguishable. We note that performing the same analysis on areal averages of the data (instead of station averages) does change the amount of weight different stations contribute to the analysis but does not change our final results. 


\section{Figure 31}
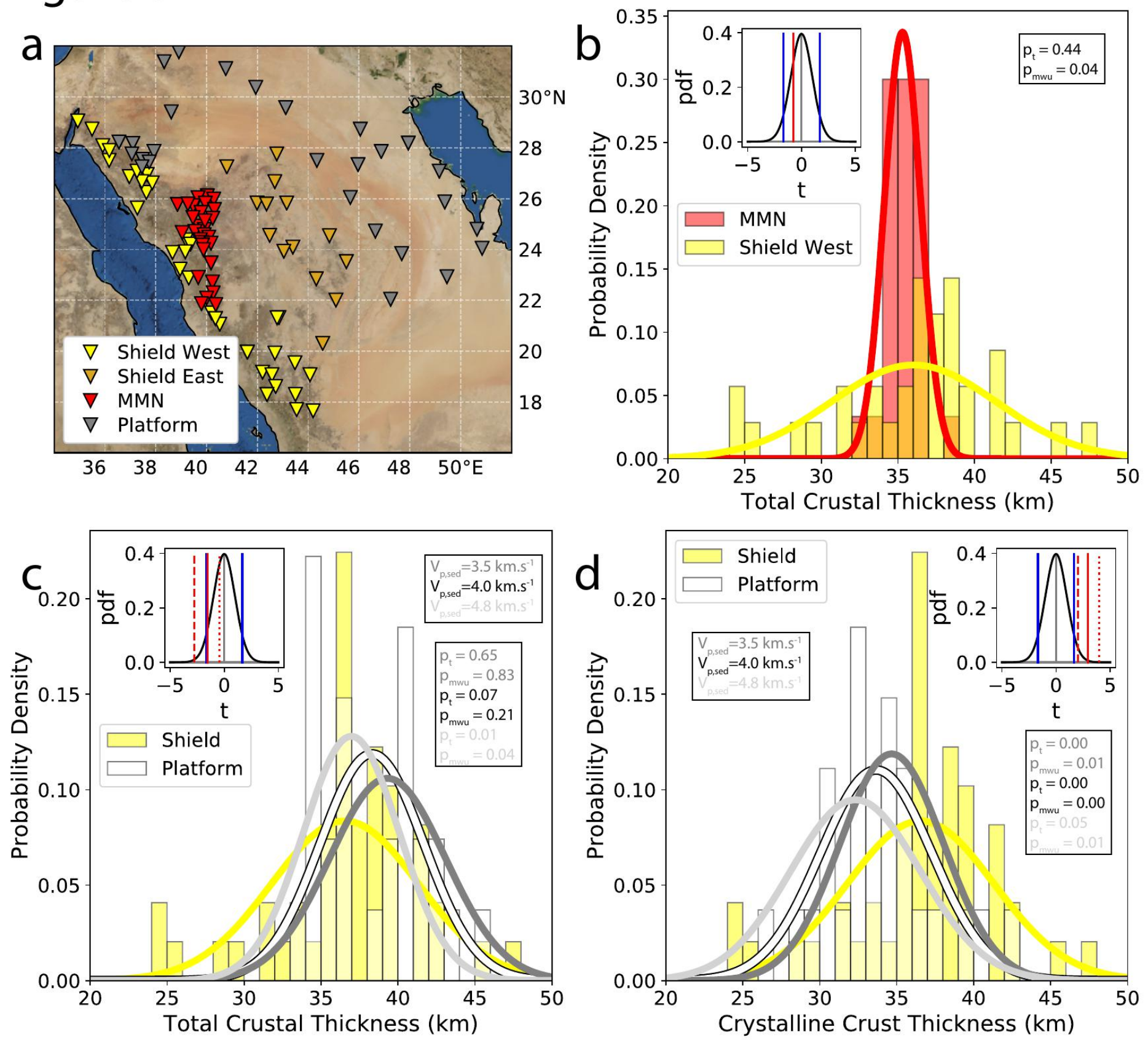

Figure 31. Comparison of harrats (MMN), shield and platform stations. a) Station map with shield stations separated into 'shield west' (for comparison with the MMN line) and 'shield east'. b) MMN versus shield west. c) Shield (west plus east) versus platform, total crustal thickness (Moho depth below surface). Dark gray line is Platform with sedimentary correction factor of -1.0 (average sedimentary $\mathrm{V}_{\mathrm{p}}=$ $\left.3.5 \mathrm{~km} \cdot \mathrm{s}^{-1}\right)$, white line with black outline is our preferred correction factor $-0.6\left(\mathrm{~V}_{\mathrm{p}}=4.0 \mathrm{~km} \cdot \mathrm{s}^{-1}\right)$, light gray is correction factor of $-0.3\left(\mathrm{~V}_{\mathrm{p}}=4.8 \mathrm{~km} . \mathrm{s}^{-1}\right)$. d) Shield (west plus east) versus platform, crystalline crust thickness only. Same color scheme as in part c).

Our observation that crustal thickness increases with distance from the Red Sea Rift (fig. 32a) remains apparent after correcting all data for $0.005 \mathrm{~km} / \mathrm{km}$ northward-thinning (fig. 32d). These data have the visual appearance of and can be fit with, an exponential curve (fig. 32d). An exponential increase in thickness away from the RSR is appropriate for a plate cooling model, but we have no expectation that crustal thickness should be controlled by a rifting process far into the plate interior. We therefore also fit the data with two straight lines: a best-fit line of arbitrary slope $(0.08 \mathrm{~km} / \mathrm{km})$ for all stations less than $250 \mathrm{~km}$ from the RSR; and a best-fit horizontal line (average thickness) for all stations greater than $250 \mathrm{~km}$ from the RSR. That these lines intersect 
at $250 \mathrm{~km}$ from the RSR validates our choice of this distance as the boundary between crust that has been thinned by Red Sea-rifting processes and the plate interior that is unaffected by rifting. The Great Escarpment (fig. 1b) that is the geomorphic expression of the rift boundary is approximately $250 \mathrm{~km}$ from the RSR (fig. 1a), suggesting that Red Sea rifting of the Arabian plate margin occurred via uniform crustal extension that affects a region no broader at depth than at the surface.

Figure 32
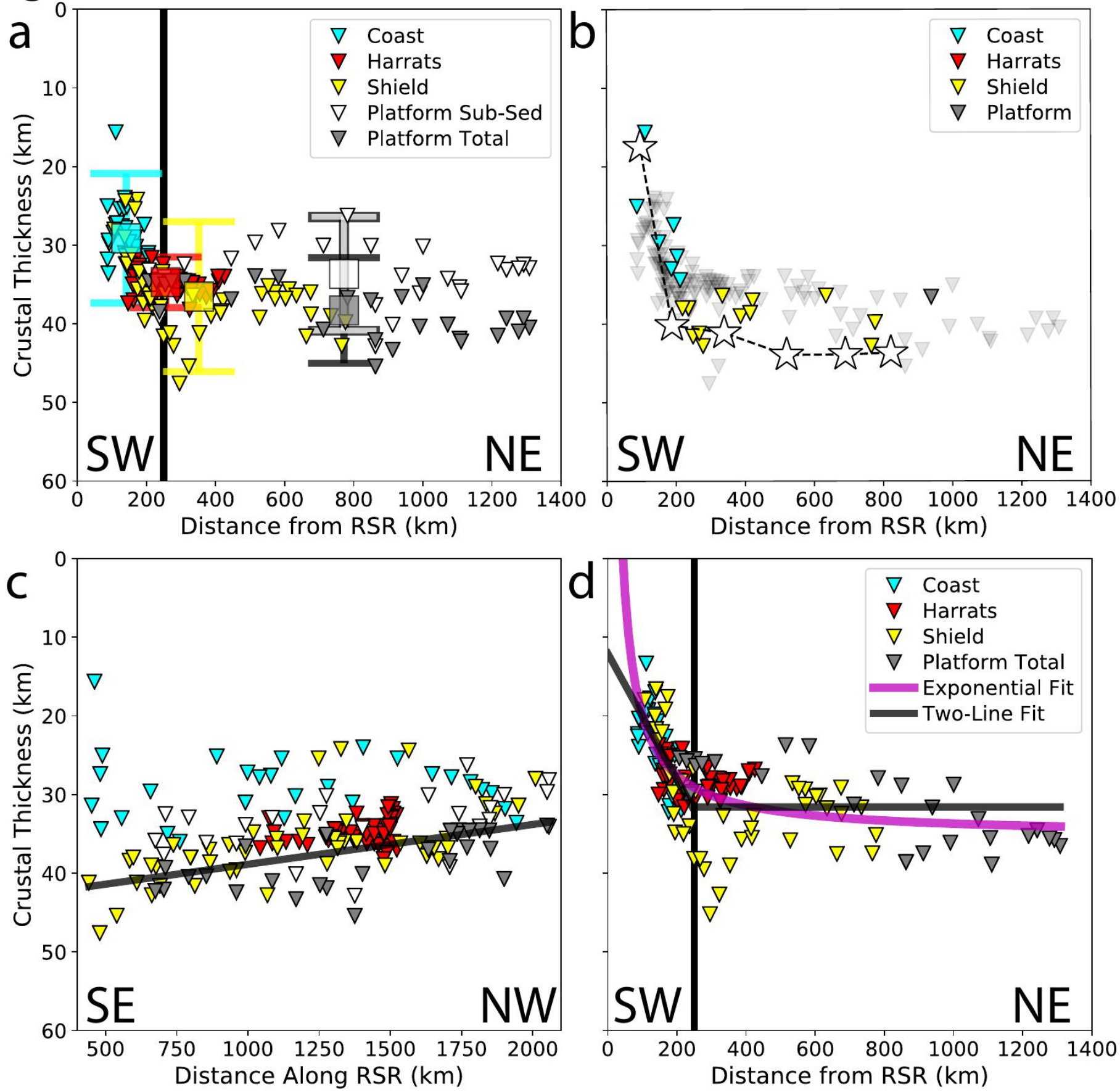

Figure 32. Crustal thickness versus distance from and along the Red Sea rift (RSR) (defined with respect to axes in Figure 1a), displayed with crustal thickness increasing downwards, so plots are comparable with crustal cross-sections (Fig. 33). a) Crustal thickness versus distance from RSR. Triangles are singlestation crustal thickness estimates color-coded by region. For platform stations, we plot both total crustal (gray) and crystalline crustal (white) thicknesses. Squares are regional averages with $2 \sigma$ error bars. b) Same as part a) with crustal thickness values from Mooney and others (1985) (white stars), all stations > $125-\mathrm{km}$ distant from Mooney et al. profile are now gray, and platform crystalline crust thicknesses no longer included. c) Crustal thickness versus distance along RSR, with distance increasing northwards. 
Black line is a straight-line fit to the data $>250 \mathrm{~km}$ from the Red Sea rift, slope is $-0.005 \mathrm{~km} / \mathrm{km}$. d) Same as part a) with the $-0.005 \mathrm{~km} / \mathrm{km}$ SE-NW trend removed from all data. Magenta line is best-fit exponential to all data; horizontal black line is average crustal thickness of all stations $>250 \mathrm{~km}$ from RSR; black line sloping $0.08 \mathrm{~km} / \mathrm{km}$ is best fit to all stations $<250 \mathrm{~km}$ from RSR.

\section{Conclusions}

Previously available measurements of crustal thickness within Saudi Arabia have either been sparse, low-resolution, or highly localized. Our P-wave receiver function analysis fills this data gap by providing new constraints on the thickness and $\mathrm{V}_{\mathrm{p}} / \mathrm{V}_{\mathrm{s}}$ ratio of the crust beneath Saudi Arabia using the SGS seismic array.

Our analysis leads to the following conclusions (with $1 \sigma$ uncertainties reported here, summarized in fig. 33):

1. The thicknesses of the Arabian shield and platform crust are $36.6 \pm 4.8 \mathrm{~km}$ and $38.4 \pm 3.4 \mathrm{~km}$, respectively. The average value of the Arabian shield is on the lower-end of the global average shield value ( $40 \pm 7.0 \mathrm{~km}$; Mooney and others, 1998), due to the effects of Red Sea rifting at its western margin. The thickness of the crust of the Arabian platform matches the global average platform value (39.0 $\pm 7.0 \mathrm{~km}$; Mooney and others, 1998).

2. The sub-sedimentary basement, that is, crystalline crustal thickness, of the Arabian platform has an average thickness of $33.8 \pm 3.6 \mathrm{~km}$. This value has greater uncertainty due to the uncertain nature of the sedimentary corrections, but in contrast to some previous estimates (Stern and Johnson, 2010), our best estimate suggests the sub-sedimentary platform crust is $\sim 10 \%(\sim 3 \mathrm{~km})$ thinner than the shield.

3. The crust of the harrats has an average thickness of $34.7 \pm 1.6 \mathrm{~km}$, which is between that expected for extended crust and shields (Mooney and others, 1998). The harrats have the same thickness as the shield at comparable distances from the Red Sea rift margin, implying negligible crustal growth by magmatism due to harrat volcanism. In contrast, stations closest to Yemen show the largest shield thicknesses, likely representing significant magmatic crustal growth.

4. In contrast to a previous interpretation (Tang and others, 2016), the harrats do not have elevated $\mathrm{V}_{\mathrm{p}} / \mathrm{V}_{\mathrm{s}}$ ratios with respect to the rest of the Arabian shield. Nor is it possible to statistically distinguish the crustal thickness of the different terranes comprising the Arabian shield.

5. Thinning of the Arabian plate extends to (about) the Great Escarpment, diminishing eastward and suggesting uniform extension that is strongly focused beneath the Red Sea Rift axis.

\section{Figure 33}

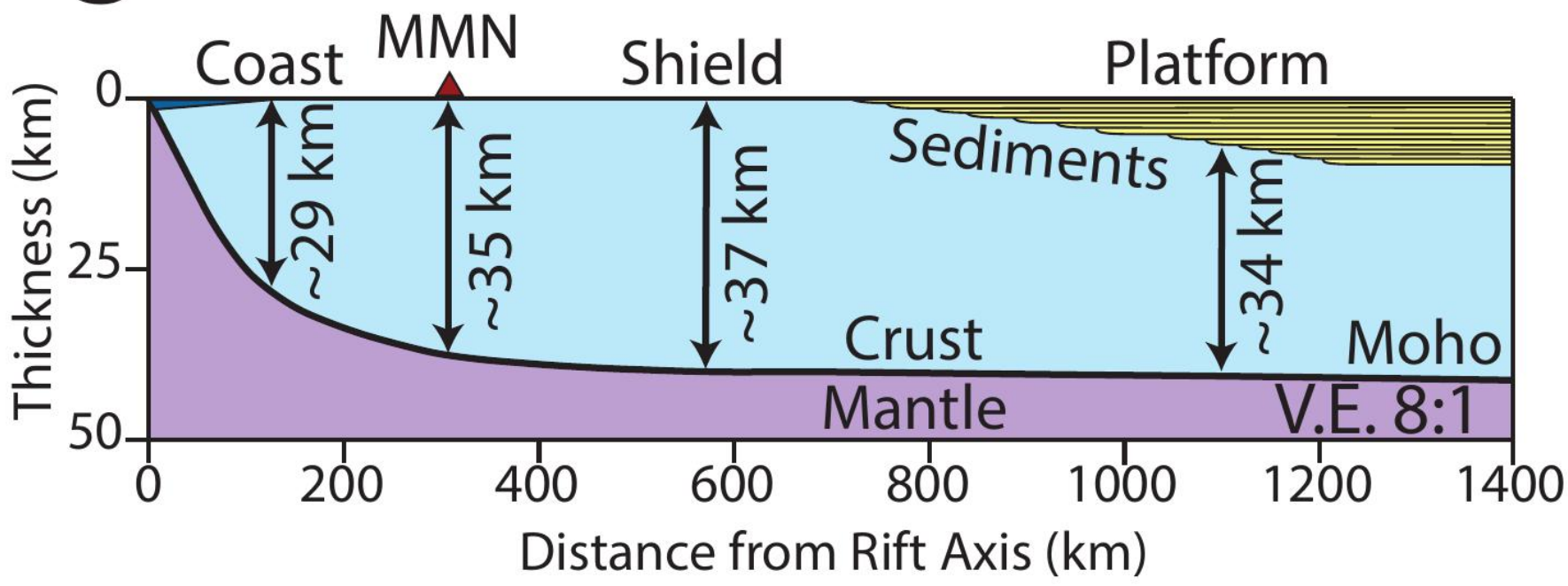

Figure 33. Cartoon cross-section from the Red Sea rift across the Arabian plate. 
Receiver functions contain valuable information on crustal properties, and extracting that information is straightforward beneath stations with low noise on crust that is relatively simple. We have extended this method to stations with higher noise and locations with thick surficial sediments by employing three steps: (1) examine each receiver function for quality and retain only the reliable ones, (2) evaluate the stability of the solution depending on different stacking weights for three well-recorded P-to-S-wave converted phases, and (3) employ more advanced forms of the $\mathrm{H}-\mathrm{k}$ stacking algorithm. These three steps must be done in a self-consistent manner that honors the original waveform data. Finally, it is vital to correct crustal thickness estimates for the effects of lower-wavespeed sedimentary basins.

\section{Acknowledgements}

We thank Rufus Catchings and Gary Chulick for their useful reviews. The authors also thank Tianze Liu, without whose useful conversations this chapter would not be as detailed, thorough, and complete.

\section{References Cited}

Agard, P., Omrani, J., Jolivet, L., Whitechurch, H., Vrielynck, B., Spakman, W., ... \& Wortel, R. (2011). Zagros orogeny: a subduction-dominated process. Geological Magazine, 148(5-6), 692-725.

Al-Damegh, K., Sandvol, E., \& Barazangi, M. (2005). Crustal structure of the Arabian plate: new constraints from the analysis of teleseismic receiver functions. Earth and Planetary Science Letters, 231(3-4), 177196.

Almalki, K. A., \& Bantan, R. A. (2016). Lithologic units and stratigraphy of the Farasan islands, southern Red Sea. Carbonates and Evaporites, 31(2), 115-128.

Artemieva, I. (2011). Lithosphere: an interdisciplinary approach. Cambridge University Press.

Barak, S., Klemperer, S. L., \& Lawrence, J. F. (2015). San Andreas Fault dip, Peninsular Ranges mafic lower crust and partial melt in the Salton Trough, Southern California, from ambient-noise tomography. Geochemistry, Geophysics, Geosystems, 16(11), 3946-3972.

Blanchette, A. R., Klemperer, S. L., Mooney, W. D., \& Zahran, H. M. (2018). Two-stage Red Sea rifting inferred from mantle earthquakes in Neoproterozoic lithosphere. Earth and Planetary Science Letters, 497, 92-101.

Blanchette, A. R., Klemperer, S. L., Mooney, W. D., \& Zahran, H. M. (2021). Crustal thickness measurements and data report from the Saudi Geological Survey National Seismic Network, 2008-2014. U.S. Geological Survey Open File Report, OFR2020-XXX, pp. \#\#\#.

Brew, G. E., Litak, R. K., Seber, D., Barazangi, M., Al-Imam, A., \& Sawaf, T. (1997). Basement depth and sedimentary velocity structure in the northern Arabian platform, eastern Syria. Geophysical Journal International, 128(3), 617-631.

Brocher, T. M. (2005). Empirical relations between elastic wavespeeds and density in the Earth's crust. Bulletin of the Seismological Society of America, 95(6), 2081-2092.

Camp, V. E., Hooper, P. R., Roobol, M. J., \& White, D. L. (1987). The Madinah eruption, Saudi Arabia: magma mixing and simultaneous extrusion of three basaltic chemical types. Bulletin of Volcanology, 49(2), 489-508. 
Camp, V. E., Roobol, M. J., \& Hooper, P. R. (1991). The Arabian continental alkali basalt province: Part II. Evolution of Harrats Khaybar, Ithnayn, and Kura, Kingdom of Saudi Arabia. Geological Society of America Bulletin, 103(3), 363-391.

Camp, V. E., \& Roobol, M. J. (1992). Upwelling asthenosphere beneath western Arabia and its regional implications. Journal of Geophysical Research: Solid Earth, 97(B11), 15255-15271.

Christensen, N. I. (1996). Poisson's ratio and crustal seismology. Journal of Geophysical Research: Solid Earth, 101(B2), 3139-3156.

Cole, G. A., Abu-Ali, M. A., Coiling, E. L., Halpern, H. I., Carrigan, W. J., Savage, G. R., ... \& AI-Sharidi, S. H. (1995). Petroleum geochemistry of the Midyan and Jaizan basins of the Red Sea, Saudi Arabia. Marine and Petroleum Geology, 12(6), 597-614.

Crotwell, H. P. (2007). High data volume seismology: surviving the avalanche. PhD thesis, University of South Carolina, pp. 86.

DESERT Group, Weber, M., Abu-Ayyash, K., Abueladas, A., Agnon, A., Al-Amoush, H., ... \& Bock, G. (2004). The crustal structure of the Dead Sea Transform. Geophysical Journal International, 156(3), 655-681.

Downs, D. T., Stelten, M. E., Champion, D. E., Dietterich, H. R., Nawab, Z., Zahran, H., ... \& Shawali, J. (2018). Volcanic history of the northernmost part of the Harrat Rahat volcanic field, Saudi Arabia. Geosphere, 14(3), 1253-1282.

Earle, P. S., \& Shearer, P. M. (1994). Characterization of global seismograms using an automatic-picking algorithm. Bulletin of the Seismological Society of America, 84(2), 366-376.

El-Isa, Z., Mechie, J., Prodehl, C., Makris, J., \& Rihm, R. (1987). A crustal structure study of Jordan derived from seismic refraction data. Tectonophysics, 138(2-4), 235-253.

Fay, M. P., \& Proschan, M. A. (2010). Wilcoxon-Mann-Whitney or t-test? On assumptions for hypothesis tests and multiple interpretations of decision rules. Statistics surveys, 4,1 .

Hansen, S. E., DeShon, H. R., Moore-Driskell, M. M., \& Al-Amri, A. M. (2013). Investigating the P wave velocity structure beneath Harrat Lunayyir, northwestern Saudi Arabia, using double-difference tomography and earthquakes from the 2009 seismic swarm. Journal of Geophysical Research: Solid Earth, 118(9), 4814-4826.

Hansen, S. E., Rodgers, A. J., Schwartz, S. Y., \& Al-Amri, A. M. (2007). Imaging ruptured lithosphere beneath the Red Sea and Arabian Peninsula. Earth and Planetary Science Letters, 259(3), 256-265.

Hughes, G. W. A. G., \& Johnson, R. S. (2005). Lithostratigraphy of the Red Sea region. GeoArabia, 10(3), 49126.

Julià, J., Ammon, C. J., \& Herrmann, R. B. (2003). Lithospheric structure of the Arabian Shield from the joint inversion of receiver functions and surface-wave group velocities. Tectonophysics, 371(1-4), 1-21.

Karplus, M. S., Klemperer, S. L., Zhao, W., Kind, R., Wu, Z., Mechie, J., ... \& Xue, G. (2019). Receiverfunction imaging of the lithosphere at the Kunlun-Qaidam boundary, Northeast Tibet. Tectonophysics, $759,30-43$. 
Langston, C. A. (1979). Structure under Mount Rainier, Washington, inferred from teleseismic body waves. Journal of Geophysical Research: Solid Earth, 84(B9), 4749-4762.

Langston, C. A. (2011). Wave-field continuation and decomposition for passive seismic imaging under deep unconsolidated sediments. Bulletin of the Seismological Society of America, 101(5), 2176-2190.

Ligorria, J. P., \& Ammon, C. J. (1999). Iterative deconvolution and receiver-function estimation. Bulletin of the seismological Society of America, 89(5), 1395-1400.

Mann, H. B., \& Whitney, D. R. (1947). On a test of whether one of two random variables is stochastically larger than the other. The annals of mathematical statistics, 50-60.

Mechie, J., Abu-Ayyash, K., Ben-Avraham, Z., El-Kelani, R., Qabbani, I., Weber, M., \& DESIRE group. (2009). Crustal structure of the southern Dead Sea basin derived from project DESIRE wide-angle seismic data. Geophysical Journal International, 178(1), 457-478.

Mechie, J., Ben-Avraham, Z., Weber, M. H., Götze, H. J., Koulakov, I., Mohsen, A., \& Stiller, M. (2013). The distribution of Moho depths beneath the Arabian plate and margins. Tectonophysics, 609, 234-249.

Miller, M. S., O’Driscoll, L. J., Porritt, R. W., \& Roeske, S. M. (2018). Multiscale crustal architecture of Alaska inferred from P receiver functions. Lithosphere, 10(2), 267-278.

Mohsen, A., Hofstetter, R., Bock, G., Kind, R., Weber, M., Wylegalla, K., ... \& DESERT Group. (2005). A receiver function study across the Dead Sea Transform. Geophysical Journal International, 160(3), 948960.

Mohsen, A., Asch, G., Mechie, J., Kind, R., Hofstetter, R., Weber, M., ... \& Abu-Ayyash, K. (2011). Crustal structure of the Dead Sea Basin (DSB) from a receiver function analysis. Geophysical Journal International, 184(1), 463-476.

Mooney, W. D. (1984). A traveltime interpretation of the 1978 seismic refraction profile in the Kingdom of Saudi Arabia. US Geol. Surv. Circular, 937, 49-81.

Mooney, W. D., Gettings, M. E., Blank, H. R., \& Healy, J. H. (1985). Saudi Arabian seismic-refraction profile: a traveltime interpretation of crustal and upper mantle structure. Tectonophysics, 111(3-4), 173-246.

Mooney, W. D., Laske, G., \& Masters, T. G. (1998). CRUST 5.1: A global crustal model at 5× 5. Journal of Geophysical Research: Solid Earth, 103(B1), 727-747.

Ogden, C. S., Bastow, I. D., Gilligan, A., \& Rondenay, S. (2019). A reappraisal of the H-א stacking technique: implications for global crustal structure. Geophysical Journal International, 219(3), 1491-1513.

Pallister, J. S., McCausland, W. A., Jónsson, S., Lu, Z., Zahran, H. M., El Hadidy, S., ... \& Moufti, M. R. (2010). Broad accommodation of rift-related extension recorded by dyke intrusion in Saudi Arabia. Nature Geoscience, 3(10), 705.

Pollastro, R. M. (1998a). Bedrock geology of the Arabian Peninsula and selected adjacent areas (geo2bg). https:/catalog.data.gov/dataset/bedrock-geology-of-the-arabian-peninsula-and-selected-adjacent-areasgeo $2 \mathrm{bg}$ 
Pollastro, R. M. (1998b). Geologic Provinces of the Arabian Peninsula and adjacent areas, 2000 (prv2bg). https:/catalog.data.gov/dataset/geologic-provinces-of-the-arabian-peninsula-and-adjacent-areas-2000prv2bg

Sandvol, E., Seber, D., Barazangi, M., Vernon, F., Mellors, R., \& Al-Amri, A. (1998). Lithospheric seismic velocity discontinuities beneath the Arabian Shield. Geophysical Research Letters, 25(15), 2873-2876.

Savage, M. K. (1998). Lower crustal anisotropy or dipping boundaries? Effects on receiver functions and a case study in New Zealand. Journal of Geophysical Research: Solid Earth, 103(B7), 15069-15087.

Seber, D., Barazangi, M., Chaimov, T. A., Al-Saad, D., Sawaf, T., \& Khaddour, M. (1993). Upper crustal velocity structure and basement morphology beneath the intracontinental Palmyride fold-thrust belt and north Arabian platform in Syria. Geophysical Journal International, 113(3), 752-766.

Schulte-Pelkum, V., \& Mahan, K. H. (2014). A method for mapping crustal deformation and anisotropy with receiver functions and first results from USArray. Earth and Planetary Science Letters, 402, 221-233.

Stelten, M. E., Downs, D. T., Dietterich, H. R., Mahood, G. A., Calvert, A. T., Sisson, T. W., ... \& Shawali, J. (2018). Timescales of magmatic differentiation from alkali basalt to trachyte within the Harrat Rahat volcanic field, Kingdom of Saudi Arabia. Contributions to Mineralogy and Petrology, 173(8), 68.

Stern, R. J., \& Johnson, P. (2010). Continental lithosphere of the Arabian Plate: a geologic, petrologic, and geophysical synthesis. Earth-Science Reviews, 101(1), 29-67.

Szymanski, E., Stockli, D. F., Johnson, P. R., \& Hager, C. (2016). Thermochronometric evidence for diffuse extension and two-phase rifting within the Central Arabian Margin of the Red Sea Rift. Tectonics, 35(12), 2863-2895.

Tang, Z., Julià, J., Zahran, H., \& Mai, P. M. (2016). The lithospheric shear-wave velocity structure of Saudi Arabia: Young volcanism in an old shield. Tectonophysics, 680, 8-27.

Tang, Z., Mai, P. M., Julià, J., \& Zahran, H. (2019). Shear velocity structure beneath Saudi Arabia from the joint inversion of $\mathrm{P}$ and $\mathrm{S}$ wave receiver functions, and Rayleigh wave group velocity dispersion data. Journal of Geophysical Research: Solid Earth, 124(5), 4767-4787.

Thurner, S., Margolis, R., Levander, A., \& Niu, F. (2015). PdS receiver function evidence for crustal scale thrusting, relic subduction, and mafic underplating in the Trans-Hudson Orogen and Yavapai province. Earth and Planetary Science Letters, 426, 13-22.

Tkalčić, H., Pasyanos, M. E., Rodgers, A. J., Gök, R., Walter, W. R., \& Al-Amri, A. (2006). A multistep approach for joint modeling of surface wave dispersion and teleseismic receiver functions: Implications for lithospheric structure of the Arabian Peninsula. Journal of Geophysical Research: Solid Earth, 111(B11).

ten Brink, U. S., Al-Zoubi, A. S., Flores, C. H., Rotstein, Y., Qabbani, I., Harder, S. H., \& Keller, G. R. (2006). Seismic imaging of deep low-velocity zone beneath the Dead Sea basin and transform fault: Implications for strain localization and crustal rigidity. Geophysical Research Letters, 33(24).

Vernon, Frank (1995): Broadband Seismic Characterization of the Arabian Shield. International Federation of Digital Seismograph Networks. Dataset/Seismic Network. 10.7914/SN/XI_1995 
Welch, B. L. (1947). The generalization of students' problem when several different population variances are involved. Biometrika, 34(1/2), 28-35.

Yu, Y., Song, J., Liu, K. H., \& Gao, S. S. (2015). Determining crustal structure beneath seismic stations overlying a low-velocity sedimentary layer using receiver functions. Journal of Geophysical Research: Solid Earth, 120(5), 3208-3218.

Zhu, L., \& Kanamori, H. (2000). Moho depth variation in southern California from teleseismic receiver functions. Journal of Geophysical Research: Solid Earth, 105(B2), 2969-2980. 